\title{
Style-Driven Earnings Momentum
}

\author{
Sebastian Müller*
}

This Version: May 2013

First Version: November 2011

Appendix attached

\begin{abstract}
This paper shows that earnings announcements contain information about future returns of "same-style" firms. In the time-series, these information transfers can be used to predict a large number of style-based return spreads (e.g. the profitability of a value minus growth factor). In the cross-section of stocks, a style-based earnings surprise strategy delivers an an equal-weighted (value-weighted) long-short return of 184 (119) basis points per month. The results are neither explained by industry membership, nor by differences in risk, and they are largely unrelated to the performance of a traditional post earnings announcement drift (PEAD) strategy. Further analyses show that investors and analysts underreact to the value-relevant information in earnings announcements of "same-style" firms, suggesting gradual information diffusion as reason for the return predictability.
\end{abstract}

Keywords: Earnings momentum, post earnings announcement drift, style returns, spillovers.

JEL Classification Codes: G11, G12, G14

*Sebastian Müller, Chair of Banking and Finance, University of Mannheim, L 5, 2, 68131 Mannheim, Germany. E-Mail: mueller@bank.bwl.uni-mannheim.de. I thank Alexander Pütz, Sugata Roychowdhury, Michael Weber, participants at the EAA annual meeting in Ljubljana (2012), the VHB annual meeting in Bozen (2012), the AAA annual meeting in Washington (2012), the Colloquium on Financial Markets in Cologne (2013), and seminar participants at the University of Mannheim and at the University of California, Berkeley for valuable comments. Furthermore, I am grateful to Gerard Hoberg and Gordon Phillips for providing industry classification data on their website. Thanks goes also to Shane Corwin for disclosing his algorithm to compute bid-ask spread estimates from daily high and low prices. Parts of this research project have been conducted during a visit at the University of California, Berkeley which was generously supported by a fellowship within the Postdoc-Program of the German Academic Exchange Service (DAAD). 


\section{Introduction}

Being among the most important cornerstones in financial economics, the efficient market hypothesis in its different facets has been contested by a steadily increasing amount of empirical research. One particularly growing arm of this literature focuses on information spillovers across firms. Here, the information released by one firm is of value-relevance for a set of different, but related firms. However, prices appear to react with a delay which gives rise to predictability of returns and is consistent with gradual information diffusion in security markets (see Hong and Stein (1999)).

While the existing evidence on these information transfers improves our understanding about the formation of prices in financial markets, it is largely restricted to the context of industry affiliations. For instance, Ramnath (2002), Thomas and Zhang (2008), and Easton et al. (2010) present evidence of a predictable return drift based on earlier earnings announcements of intra-industry competitors. ${ }^{1}$ Similarly, Hou (2007) finds that slow information diffusion within industries is a leading cause of the lead-lag documented by Lo and MacKinlay (1990). Menzly and Ozbas (2010) document predictability of stock returns based on earlier supplier and customer industry returns, thereby extending the study of Cohen and Frazzini (2008) which focuses on direct customer-supplier relations described in financial statements. More recently, Cohen and Lou (2012) document substantial return predictability using an industry-based information spillover proxy for conglomerates, and Huang (2012) finds similar results when employing a measure that relies on foreign operations of a firm and corresponding industry returns in foreign countries.

Given the obvious economic links between firms within the same industry or along the industry supply chain, the focus of the earlier literature is probably not surprising. However, there may be other, potentially more subtle sources of information transfers that are not captured by industry membership. The goal of this paper is to explore a large set of these additional channels by testing for information spillovers among firms that share similar stock characteristics (such as having a high book-to-market equity ratio) and hence can be classified as "same-style" stocks by investors (such as being a value stock). Particularly, the paper asks to what extent earnings surprises (i.e. abnormal returns over three-day earnings announcement windows) convey valuable information for other same-style stocks which is only gradually incorporated into prices. I call this effect "style-driven earnings momentum".

Earnings surprises proxy for unexpected information disclosures about firm profitability. The value relevance of these information disclosures for related firms might be less obvious at the style level than it is

\footnotetext{
${ }^{1}$ Earlier work in the accounting literature constitutes Foster (1981), Han et al. (1989), Freeman and Tse (1992), and Asthana and Mishra (2001).
} 
the context of industries, but to the extent that same-style stocks exhibit correlations in firm profitability, there is reason to believe that it exists. Indeed, Fama and French (1995) find that a common factor can explain the earnings of firms with a similar size and book-to-market ratio which they consider as evidence that the value and size premiums in stock markets have an underlying economic origin and hence likely reflect rational pricing. In the meanwhile, a number of additional stock characteristics have been found to predict the cross-section of equity returns. To the extent that these characteristics proxy for the sensitivity to risk factors that are not captured by the CAPM or the Fama and French (1993) three-factor model, the return predictability should also trace back to a common future earnings or cash flow risk. Hence, firms with a similar asset growth in the past (Cooper et al. (2008)) or similar level of accruals (Sloan (1996)), to name only two additional predictors, should also have correlated fundamentals. For the accruals anomaly, Hirshleifer et al. (2012) document considerable return comovement associated with this characteristic, citing common sensitivity to economy-wide fluctuations as likely source of this comovement. However, other than Fama and French (1995) I am not aware that the literature has explicitly tested for style-dependent correlations in fundamentals.

To test the "style-driven earnings momentum" hypothesis, this paper uses a total of 15 characteristics to classify stocks into different styles. After outlining the selection of these characteristics in the next section, I start with investigating whether same-style stocks are fundamentally related. There is indeed economically substantial comovement in quarterly earnings for firms that have similar characteristic values. Moreover, the results are neither explained by industry membership nor by a common market, size, or value factor in earnings. This provides evidence that a potential driver for information spillovers exists in the data and motivates the main empirical analysis which focuses on the predictability of stylelevel and stock-level returns based on recent earning surprises.

At the style-level, I construct characteristic-based long-short portfolio returns and perform time-series regressions to test whether realizations of these style factors can be explained by past differences in earnings announcement returns (EAR). For instance, consistent with La Porta et al. (1997), I find that on average, value stocks (stocks with a high book-to-market ratio) have systematically higher EAR than growth stocks, but as shown in figure 1 there is also a substantial variation in earnings surprise differences. Specifically, the difference ranges between up to $+6 \%$ and less than $-4 \%$ for a given month and the timeseries standard deviation is $1.28 \%$. My tests ask whether these variations are related to future long-short style returns. For the value-growth factor the answer is exemplarily illustrated in figure 2 by sorting the sample months into quintiles based on earnings surprise differences between value and growth stocks and relating them to one-month ahead long-short value minus growth returns. For quintile 1, the average 
difference in EAR is $-0.8 \%$ (implying more positive market reactions for growth stocks than value stocks) and the next month return difference between both styles is $-0.6 \%$. For the fifth quintile, the average EAR difference is $2.7 \%$ and the next month value minus growth return is roughly $2 \%$. The $2.6 \%$ difference in returns between quintile 5 and quintile 1 is highly statistically significant (t-statistic: 4.7$)$. EAR differences also predict the value-weighted Fama/French $H M L$ factor; in this case the return difference is reduced to $1.8 \%$ (t-statistic: 3.8 ), implying stronger predictability for smaller firms.

\section{Insert figure 1 here}

\section{Insert figure 2 here}

I find similar evidence of predictability for most other style-based factor returns in univariate and multivariate regressions. Moreover, to test if the predictability is driven by post earnings drifts at the firm-level I also exclude prior announcers from the long-short portfolios before calculating returns. Consistent with an information spillover effect, this procedure leads to similar levels of predictability for the returns of non-announcers. A further specification that uses industry-adjusted stock returns before calculating the return spreads confirms that the findings are not explained by previously documented intra-industry information transfers. I also find that the predictability is related to earnings seasons as it is almost always strongest for the second month of a quarter and largely reduced in the first month when a new earnings season begins. This finding suggests that it is indeed the information content of earnings that matters. A "placebo" test which uses prior returns outside the earnings announcement windows generally shows a substantially weaker relation to future style-based return spreads thereby confirming this conclusion. ${ }^{2}$

At the stock-level, individual returns can be explained by several lagged one-month style-based earnings surprise factors thereby alleviating concerns that that one characteristic alone could drive the previous results. This motivates the examination of a simple trading strategy which assigns a style-based earnings surprise measure ("SESM") to every firm using all earnings surprise signals in combination, and hence exploits the idea that one stock belongs to different styles at the same point in time. An equal-weighted (value-weighted) long-short portfolio based on this measure realizes an abnormal return of 184 bps (119 bps) per month. Adjustments for differences in risk cannot explain the performance of this strategy which

\footnotetext{
${ }^{2}$ Nonetheless, complete one-month returns are highly correlated with earnings announcement returns (which are included in the former), and so a lot of the predictability documented in this paper is also evident when differences in past monthly returns are used as predictors instead of differences in past earnings surprises between high- and low-characteristic portfolios. This lines up with the existing industry-based evidence of information spillovers where papers have focused on both, recent earnings surprises (e.g. Easton et al. (2010)) and recent complete monthly returns (e.g. Cohen and Lou (2012)). Given that the information spillovers likely stem from fundamental connections in earnings, the focus on earnings surprises as advocated in this paper seems to be more intuitive though, and this approach is also justified by the by-quarter and placebo test results.
} 
is somewhat less but still substantially profitable among the largest firms in the sample (market value above the NYSE median) with a value-weighted return spread of 106 bps per month. Furthermore, the returns of the SESM-trading strategy are largely unrelated to the returns of traditional post earnings announcement drift (PEAD) strategies but show a similar evolution over time. Specifically, there is no evidence of a return reversal for up to six months after portfolio formation, but instead a continuing, slowly decaying drift. These findings provide additional support that slow information diffusion of economically relevant information is the driver of the return predictability, and not style-specific overreactions which would be expected to correct in the longer run. I lastly show that SESM positively predicts improvements in firm fundamentals, quarterly analyst forecast errors, forecast revisions, and future returns around earnings announcements which is also consistent with earnings information being not reflected in prices in a timely fashion.

As outlined at the beginning, this paper fits into the literature that examines short term information spillovers between economically related firms (Ramnath (2002), Thomas and Zhang (2008), Easton et al. (2010), Hou (2007), Cohen and Frazzini (2008), Menzly and Ozbas (2010), Cohen and Lou (2012), and Huang (2012)). ${ }^{3}$ Doing so, its key contribution is to go beyond industry affiliations and document the informational content that earnings surprises have for other firms sharing the same style characteristic. While some studies show evidence of price momentum or long-term reversal among style portfolios (see Lewellen (2002), Chen and De Bondt (2004), and Teo and Woo (2004)), they consider longer formation and forecasting periods (as it is common in this literature), do not concentrate on the information coming from earnings releases, and generally focus only on styles based on book-to-market and size. Instead, this paper simultaneously investigates a total of 15 different style factors. It shares this broader scope with the recent studies of Stambaugh et al. (2012) and Greenwood and Hanson (2010). Stambaugh et al. (2012) show that the short legs of a large set of return anomalies are more pronounced in periods of high investor sentiment. Greenwood and Hanson (2010) find that characteristics of stock issuers (where issuance is measured over the most recent year) are useful to forecast characteristic-based factor returns.

The remainder of this paper is organized as follows. Section 2 describes the data and characteristics used to select stocks into styles. It also presents initial evidence on the fundamental connections between samestyle stocks. Section 3 and section 4 contain the results at the style-level and stock-level, respectively. Section 5 presents further evidence of slow information diffusion as the underlying cause of the return predictability. Finally, section 6 provides an additional discussion of the findings and concludes.

\footnotetext{
${ }^{3}$ In a broad sense, this paper is also part of the vast research on the post earnings announcement drift (PEAD). However, unlike most studies on the PEAD (with the market-level study of Kothari et al. (2006) as exception), this paper does not focus on underreaction to firm-specific information but is primarily concerned with information from other firms.
} 


\section{Data, selection of styles, and first evidence on the relevance of style-related spillovers}

Sample data are obtained from three major sources: (1) firms quarterly earnings announcement dates are from quarterly Compustat files (item $r d q$ ), (2) stock return data are from CRSP, and (3) financial statement variables are from annual Compustat files. In addition, data on analyst coverage and earnings estimates from I/B/E/S and on institutional investor holdings from Thomson Reuters 13F filings are used. Consistent with prior research, I focus on common shares (share codes 10 or 11) traded on NYSE, AMEX or NASDAQ (exchange codes 1, 2, or 3). The sample period spans 39 years from 1972 to 2011.4 To be included in the sample, I require companies to have a positive book value of equity in the fiscal year ending in calendar year $t-1$ and to have a CRSP market value of equity at the end of June of year t. This results in a total of 179,933 firm-year observations.

In order to test whether earnings surprises convey valuable information for same-style stocks, I use a set of 15 characteristics and cross-sectionally sort all stocks into five style portfolios based on NYSE quintile breakpoints for each characteristic. Specifically, I select stocks into styles with regard to firm size, firm age, market beta, residual volatility, accruals, sales growth, profitability (return on assets), book-tomarket, dividend yield, stock issuance, asset growth, investments over assets, nominal share price, price momentum, and the financial distress measure of Campbell et al. (2008). ${ }^{5}$ While there are other potential characteristics, the selected ones have often been used in prior work to explain the cross-section of stock returns and appear to be important for investor categorization, which gives a first indication that they might be related to common factors in firm fundamentals such as earnings as well.

Measurement details for each characteristic and an overview of the cross-sectional distribution of all characteristics by firm-year observations can be found in the online appendix to this paper. I apply the convention of Fama and French (1993) and characterize stocks at the end of June in every year and keep this assignment constant for one year. For characteristics that are based on annual financial statement information, I use data from the latest fiscal year ending in the previous calendar year. As exception from

\footnotetext{
${ }^{4}$ Earnings announcement dates not are recorded before the third quarter of 1971. In 1972, CRSP coverage was expanded to include NASDAQ firms. Since I sometimes need a history of past prices (e.g. for price momentum) or accounting variables from the previous fiscal year to construct the characteristics, NASDAQ firms are sometimes excluded from the analysis in the first two years.

${ }^{5}$ For the dividend yield and stock issuance variable I slightly modify the sorting since there are many firms with a zerovalue on these characteristics. For the dividend yield the first portfolio contains all non-paying firms, and the remaining dividend payers are sorted into quartiles. For the stock issuance variable, contracting firms are sorted into the first portfolio, all zero-value firms into the second portfolio, and the remaining firms are then sorted into tertiles. Due to their conceptional similarity with the stock issuance variable, the Daniel and Titman (2006) composite equity issuance measure is not included in the list. The same applies to the Shumway (2001) distress measure which is an alternative to the measure of Campbell et al. (2008). The results for these alternatives are similar though, and available upon request.
} 
annual updating, for price momentum (the stock's last year return excluding the most recent month) and the financial distress measure of Campbell et al. (2008) I follow the convention in the literature and use a monthly rebalancing interval. I verify that none of the construction details are sensitive to my results. ${ }^{6}$

Before focusing on earnings-based spillover effects in returns, I start the empirical analysis by presenting evidence on style-dependent correlations in firm fundamentals. To this end, I compute the average quarterly return on assets (ROA) across all firms belonging to the highest or lowest quintile for a particular characteristic and announcing their earnings in a given month. ROA values are winsorized at the $99.9 \%$ level to limit the impact of potential errors in Compustat. That is, out of 1000 observations, the highest and lowest value are replaced with the second-highest and second-lowest value. The earnings difference between the top and bottom characteristic-based portfolio $\left(\triangle R O A_{X, t}\right)$ is then regressed on its previous one-month value:

$$
\triangle R O A_{X, t}=\alpha+\beta \cdot \triangle R O A_{X, t-1}+\varepsilon .
$$

If firm earnings of same-style firms are connected, they should be predictable from earnings announced earlier by same-style firms, and hence these AR(1) models should display evidence of autocorrelation. As shown in the two leftmost columns of table 1, panel A, this is indeed the case for all characteristics under consideration. The average regression coefficient amounts to 0.48 and the values are significant at $1 \%$ in 14 out of 15 cases. However, to the extent that characteristics are clustered at the industry level, the autocorrelations may pick up fundamental relations within industries. To investigate this question, I subtract average industry ROA from each firm's quarterly ROA and repeat the analysis with these industry-adjusted earnings. The results, reported in the next two columns of panel A, are based on the 48 industry classification system of Fama and French (1997). ${ }^{7}$ Overall, controlling for industry membership has little impact. For some characteristics the coefficients decline whereas they increase for others, but in general the level of statistical significance is unaffected. Next, I run multivariate regressions that include prior realizations of earnings differences between high and low beta stocks, small and large stocks and high and low book-to-market stocks. Whenever these variables are themselves on the left-hand side, only the two remaining variables are additionally added to the regression framework. Characteristics such as

\footnotetext{
${ }^{6}$ First, I redefine stock styles using the 30th and 70th percentile as breakpoints for the top and bottom characteristic portfolio (as opposed to the 20th and 80th percentile), and hence construct only three instead of five style portfolios per characteristic. Second, I use breakpoints on the basis of the complete firm universe, instead of NYSE breakpoints. Third, I also update characteristic-values for market variables (such as firm size) at a monthly frequency. Results are available upon request.

${ }^{7} \mathrm{I}$ require an industry to contain at least five firms which marginally reduces my stock sample in this setting. The conclusions remain valid if different industry definitions are used, and for the return tests later the results of alternative classifications are discussed in greater detail, see section 3.3.
} 
the share price of a firm are highly correlated with firm size which suggests that some of the correlation patterns could be traced back to earnings factors in these variables as documented by Fama and French (1995). Indeed, as displayed in the final two columns in panel A, the autocorrelations tend to shrink in the multivariate regressions, but they remain mostly substantial in both economic and statistic terms.

\section{Insert table 1 here}

Panel B of table 1 provides evidence on the degree of time-series autocorrelation in earnings with regard to the particular month of a given calender quarter. For most firms, the fiscal year end falls upon the end of a calendar quarter (i.e. December, March, June or September). In addition, firms are typically required to file earnings reports within 45 days for fiscal quarters one, two, and three, and within 90 days for fiscal quarter four. This leads to a strong seasonality in earnings announcements whereby the majority of firms report their earnings in the first two months of a calendar quarter such as January or February (see e.g., Hirshleifer et al. (2009)). Therefore, the earnings period for firms announcing in these first two quarter months typically is the same (i.e. refers to the most recent quarter), whereas there often is a mismatch in the earnings periods of firms announcing in the last month of a quarter and firms announcing in the first month of the next quarter. Hence, due to these time differences one would assume that earnings differences can be better predicted for the second quarter-month than for the first quartermonth based on their prior values. To investigate this issue, I separately run the multivariate regressions for quarter-start months such as January, April, July and October, quarter-mid months, and quarter-end months. Consistent with expectations, the findings show that the standardized regression coefficients are on average almost twice as large for second-quarter months compared to first quarter-months. The regression coefficients for third-quarter months range in between, being on average approximately $20 \%$ lower than the second-quarter months coefficients. ${ }^{8}$

At this stage, it is important to discuss what the results of the above regressions imply and what not. First, they are not driven by certain characteristics being per se related to superior or inferior profitability. For instance, firms with low book-to-market ratios tend to be more profitable than firms with high bookto-market ratios. However, the regressions tell that when these differences are particularly pronounced, it can be expected that they remain so for upcoming announcers. Hence, firm characteristics appear to be related to common sensitivity to economy-wide fluctuations in profitability. The effect cannot be explained by autocorrelated earnings at the firm-level (Bernard and Thomas (1990)), since firms that

\footnotetext{
${ }^{8}$ When I repeat the analysis using only firms for which the fiscal quarter end equals the calender quarter end, differences between first- and second-quarter month coefficients tend to increase further, which further suggests that the similarity of earnings periods is indeed a substantial driver of the autocorrelations.
} 
announce in a given month will not announce next-quarter earnings just one month later, except for rare circumstances. Neither stands the aggregate autocorrelation structure of earnings at the market level (Kothari et al. (2006)) ready as an explanation because the regressions are based on differences between top and bottom portfolios, and not on raw levels of earnings. Overall, the implication of these tests is that earnings releases by firms that share the same style are value relevant for later announcers. The value relevance appears to be particularly true for firms announcing in the second- or third-month of a given quarter. If the market is not fully aware about these fundamental relations, it is likely that the prices of later announcers are not completely adjusted immediately but show evidence of a drift, which is the testable empirical prediction the remainder of this paper is concerned with. The fact that analysts as important information providers - generally specialize by industry and not at the style-level (see e.g., Dunn and Nathan (2005), and Menzly and Ozbas (2010)) is an additional ingredient giving content to this prediction beyond the documentation of correlated earnings.

It is also worthwhile mentioning that this "underreaction story" is not conflicting with earlier evidence citing overreaction as the primary cause for abnormal returns associated with some of the long-short characteristic-based portfolio returns such as the asset growth anomaly. This paper is not dealing with general (or unconditional) abnormal returns but focuses on short-term spillover effects. Even if investors generally overestimate the long-term growth prospects of high asset-growth firms and this tendency gives rise to the unconditional underperformance of these firms, there is no plausible reason why investors should not also underestimate the fundamental connections in current earnings associated with asset growth at the same time. In the context of the time-series regression tests carried out next, initial negative earnings surprises of high asset-growth firms (in comparison to low asset-growth firms) might be the result of disappointment with earnings which itself can have its origin in an overestimation of growth prospects. However, to the extent that variations in these earnings surprises predict future short-term realizations of the asset-growth factor, a potential and to be investigated reason is that investors underestimate the implications of current poor earnings of high asset-growth firms for later announcers with similar characteristic values.

\section{Predictability of style returns}

\subsection{Empirical methodology and summary statistics for style portfolios}

Rather than focusing on raw earnings, I am interested in the unexpected component of companies' earnings releases since this is by definition the new information to which investors should react. As 
a measure for earnings surprises, I use the abnormal earnings announcement return (EAR), which is calculated as the cumulative stock return over the three-day window centered around the announcement date minus the cumulative CRSP value-weighted market return over the same period. For each month and every characteristic $X$, I then calculate the average EAR difference between the top and the bottom quintile using all firms having an earnings announcement in that particular month $\left(E A R_{X, t}\right)$. Style-driven earnings momentum effects are tested with time-series regressions of long-short characteristic portfolio returns $\left(\operatorname{Ret}_{X, t}\right)$ on prior one-month differences in earnings surprises: ${ }^{9}$

$$
\operatorname{Ret}_{X, t}=\alpha+\beta \cdot E A R_{X, t-1}+\sum_{k} \beta_{k} \cdot k_{t}+\varepsilon
$$

where $k_{t}$ stands for contemporaneous realizations of several risk factors for which I control in different multivariate regression settings. These include the market excess return, the Fama/French size, value, momentum and short-term reversal factors, and the Pastor and Stambaugh (2003) liquidity factor. The return spread associated with a given characteristic is calculated equal-weighted and value-weighted. The equal-weighted spread is simply given as the average return of quintile 5 firms minus the average return of quintile 1 firms in a given month. The computation of the value-weighted portfolio returns follows a slightly different procedure by adopting the methodology of Fama and French (1993) for the construction of the $H M L$ factor. Specifically, for each characteristic firms are independently sorted into three groups based on the 30th and the 70th NYSE characteristic percentile and into two size buckets based on the NYSE median firm market capitalization. The value-weighted characteristic $X$ return spread is then the average of the value-weighted return difference for small stocks and for large stocks:

$$
\operatorname{Ret}_{X, t}=1 / 2 \cdot\left(\operatorname{Ret}_{h i g h X, s m a l l, t}-\operatorname{Ret}_{l o w X, \text { small }, t}\right)+1 / 2 \cdot\left(\operatorname{Ret}_{\text {highX,big,t }}-\operatorname{Ret}_{\text {low }, \text { big }, t}\right) .
$$

The Fama and French (1993) procedure is chosen because it provides a convenient way for examining any spillovers separately for small and large firms by splitting up the factors into their two components. Note that the control factors in the multivariate regressions are based on the same characteristics as some of the spreads that are to be predicted (in particular the size and value factors). Hence, if for instance $H M L$ is the dependent variable, $H M L$ is not included as a control variable. However, if the equalweighted book-to-market spread is to be predicted, $H M L$ is included as a control in the multivariate

\footnotetext{
${ }^{9} \mathrm{EAR}$ of firms announcing at the last trading day of the month are excluded to avoid a mechanical relation between average month $t-1$ EAR and month $t$ portfolio returns. In unreported robustness tests, I have also delayed all stock returns by one respectively five trading days when calculating monthly characteristic-based style returns and in addition considered weekly forecasting periods. Skipping the first trading day (or the first trading week) impacts the findings only modestly. At the weekly level, the spillover effects are in general more pronounced. Results are available upon request.
} 
regression. This can be regarded as a conservative procedure because equal- and value-weighted spreads are substantially correlated (in the example the correlation is 0.80 ) and hence $H M L$ will be the dominant factor in explaining the contemporaneous equal-weighted return difference thereby also diminishing the potential relation with past earnings surprise spreads.

Given the known PEAD at the individual stock level, one might expect a positive relation between earnings surprises and future style-related return differences even in the absence of information spillovers for same-style stocks. To clarify, suppose that a lot of stocks in the highest (lowest) quintile of characteristic $X$ had a positive (negative) earnings surprise. As a result, the EAR spread for characteristic $X$ will be high in that month. Since stock returns drift after earnings announcements, it might simply be the announcing firms that are responsible for a positive next month characteristic-based return spread. Hence, EAR spreads might forecast future return spreads even though they do not contain any information about other same-style stocks that had no announcement in the last month. To address this concern, I construct portfolio returns $\left(\operatorname{Ret}_{X, t}\right)$ in three different ways using a) all stocks in the long-short portfolios, b) including only stocks with an announcement in the previous month, and c) excluding all stocks with an announcement in the previous month.

Table 2 shows average returns, earnings surprises, and Fama and French (1993) three-factor alphas for each of the 15 characteristic-based strategies. In line with prior research, statistically significant return spreads are associated with firm size, asset growth, accruals, sales growth, book-to-market, investments over assets, stock issuance, price momentum, and financial distress over the sample period. Note however, that the return differences decline if portfolios are value-weighted which indicates that return anomalies are to a substantial extent restricted to small firms (see also Fama and French (2008) for similar results). Another aspect worth highlighting is that style returns and EAR spreads mostly go in the same direction. ${ }^{10}$ Moreover, the values in table 2 suggest that a substantial portion of the return spreads occurs around earnings announcement dates. For instance, the equal-weighted asset growth return spread is $0.88 \%$ per month, which corresponds to a daily return spread of $0.04 \%$. In contrast, the average daily return spread during the earnings announcement period is almost five times as large $(0.57 \% / 3=0.19 \%)$. Hence, earnings announcements appear to play an important role in explaining many return anomalies.

\section{Insert table 2 here}

For descriptive purposes (to which I refer in later parts of this paper), table 2 also summarizes the

\footnotetext{
${ }^{10}$ The exception is the failure measure of Campbell et al. (2008) for which I do not find a large difference in earnings announcement returns between firms in the highest and lowest quintile. However, this finding is consistent with their results.
} 
returns and three-factor alphas of two post earnings announcement drift (PEAD) strategies. Specifically, I report the equal-weighted and value-weighted performance of a strategy based on the firms' most recent earnings announcement return ("PEAD-EAR") and the most recent quarterly standardized unexpected earnings ("PEAD-SUE"). Following Chordia and Shivakumar (2006), SUE are calculated as currentquarter earnings less earnings four quarters ago, divided by the standard deviation of the earnings changes in the prior eight quarters. As can be seen, both PEAD-strategies deliver substantial positive returns which are however again lower using a value-weighting portfolio approach. Specifically, the equal-weighted (value-weighted) return of the EAR-based strategy is 139 bps (69 bps) per month, and for the SUE-based strategy the corresponding numbers are 96 bps (45 bps) per month. ${ }^{11}$

\subsection{Baseline results: equal-weighted style returns}

Table 3 documents the results of the baseline analysis (see equation 2). The table shows regression coefficients and t-statistics associated with the EAR spreads (the independent variables). Panel A reports univariate regression results and panel $\mathrm{B}$ the results of multivariate regressions where the excess market return, $H M L$, and $S M B$ are added as control variables. Empirically, it would be consistent with the predictions of the style-driven earnings momentum hypothesis that the EAR spreads also contain some level of time-series autocorrelation, as one would expect investors who underestimate the implications of current earnings for later announcers to be continuously surprised. This point will be explicitly covered in section 5. In terms of the currently discussed regression model however, the time-series autocorrelation may downward bias traditional OLS-standard errors. Therefore, I calculate t-statistics based on the approach of West and Newey (1987) with a lag of four months to take heteroskedasticity and autocorrelation into account. ${ }^{12}$ Also, to facilitate comparison across the different characteristics whose long-short factors display different standard deviations, table 3 reports standardized beta coefficients. As outlined in section 3.1, characteristic-based long-short portfolio returns (the dependent variables) are constructed in three different ways. The first two columns pertain to using all stocks ("All"), the third and fourth column to including only stocks with an announcement in the previous month ("Announcers"),

\footnotetext{
${ }^{11}$ For further evidence on the relation between these two PEAD-strategies see Brandt et al. (2008). I note also that the SUE-based strategy portfolio is conceptionally the same as the "PMN"-portfolio of Chordia and Shivakumar (2006). Albeit it is slightly differently computed (Chordia and Shivakumar (2006) use deciles to construct equal-weighted longshort portfolios), it has a high correlation with the "PMN"-portfolio and the same properties with regard to explaining the momentum factor.

${ }^{12}$ The results are not sensitive to the exact number of lags. Also, if t-statistics are based on the heteroskedasticityconsistent standard errors of White (1980), similar levels of statistical significance emerge. In a recent study Novy-Marx (2012) discusses the problem of overstated statistical significances in predictive regressions with highly persistent regressors such as the Baker and Wurgler (2006) sentiment index which has a monthly persistence of more than 0.985 in an AR(1) process. This is unlikely to be a problem here, because the average monthly persistence of the EAR spreads amounts to relatively low 0.079 in comparison.
} 
and the last two columns to including only stocks without an announcement in the most recent month ("Non-Announcers"). At this stage all portfolio components are equal-weighted.

\section{Insert Table 3 here}

The univariate results support the style-driven earnings momentum hypothesis in many cases and often with a high degree of statistical significance. In fact, considering columns one and two (the "All" portfolio return calculation scheme), ten out of 15 coefficients are significant at the $1 \%$ level. In economic terms, the standardized beta coefficients suggest that the largest influence can be observed for residual volatility where a one standard deviation increase in the prior one-month EAR spread is associated with a 0.28 standard deviation increase in the long-short portfolio return, and for book-to-market for which the coefficient estimate is 0.23 . The average coefficient amounts to 0.17 . When return spreads are calculated using only announcers or only non-announcers very similar coefficients and levels of statistical significance are obtained. The results suggest that past EAR spreads forecast future characteristic-based returns for both announcers and non-announcers, and provide first evidence that style-driven earnings momentum does not simply emerge as a consequence of the post earnings announcement drift at the individual stock level.

In comparison to panel A, most regression coefficients have a similar statistical significance in panel B, indicating that conventional adjustments for systematic risk make little difference. Exceptions are beta and book-to-market which is not surprising since these spreads are tightly linked to the added valueweighted control factors. However, for the size-based EAR spread the reduction in the coefficient is less substantial when $S M B$ is added (for instance, in column one the coefficient is now 0.13 compared to 0.18 in panel A). This result can be explained by the differences in construction of the size factor used as dependent variable in table 3 and the size factor of Fama and French. While I use only the top 20\% and bottom $20 \%$ of the stock universe, they consider each stock as either large or small by taking the median market capitalization of NYSE stocks as breakpoint. In contrast, when constructing the value factor, Fama and French use the 30th and the 70th percentile as breakpoints, which is closer to my definition.

While table 3 displays only the results for a three-factor model, I have also tested a four-, five-, and six-factor risk model including momentum, short-term reversal, and the Pastor and Stambaugh (2003) liquidity factor as controls. The results for these models are very similar to the ones shown in panel B and can be found in the online appendix. 


\subsection{Predictability of industry-adjusted style returns}

In this section, I examine the robustness of the earnings surprise effect after controlling for industry membership. To the extent that characteristics are clustered at the industry level, the above presented results could pick up the known effect of within-industry information transfers. To investigate this question, stock returns are adjusted by industry (based on the 48 classification system of Fama and French (1997)) before calculating the return spreads. As with the autocorrelation in earnings tests before, industry-adjustment means that the average industry return is subtracted from the stock return with the aim to control for general industry movements. Table 4 shows the regression results for industry-adjusted return spreads.

\section{Insert Table 4 here}

The evidence presented in table 4 suggests that industry-information transfers cannot explain the predictive abilities of earnings surprises at the style level. The univariate regression results in panel A display a similar level of statistical significance for most characteristics; the same applies to the multivariate results in panel B. Also, the standardized regression coefficients are generally very similar to ones obtained without industry adjustment which indicates that the economic significance of the results is also unaffected.

To see if the results are sensitive to the exact procedure of industry-adjustment, I also calculate and control for value-weighted industry returns and use different industry definitions. Particularly, I classify stocks according to their first digit, first two digits, and first three digits SIC-code. This approach allows me to check whether changes in how narrow an industry definition is defined affect the conclusions. In addition, the text-based analysis of product descriptions from firm 10-K statements (see Hoberg and Phillips (2010a) and Hoberg and Phillips (2010b)) is used to generate a new set of industries which do not rely on SIC-codes. The results of these robustness tests are reported in the online appendix and confirm that style-driven earnings momentum is distinct from previously documented within-industry information transfers.

\subsection{Predictability of style returns by quarter month}

Given the seasonality in earnings announcements discussed in section 2, one might also expect that styledriven earnings momentum effects to differ with respect to the month within a quarter. Specifically, announcements made in the first month of a calendar quarter should be most informative to investors as they are the first to provide earnings data about the most recent quarter and their earnings numbers 
usually refer to the same time period as the releases made by firms in the second month of a quarter. In contrast, announcements in the third month of a quarter should have the lowest informational value for next month announcements (i.e. in the first month of the next quarter), which typically are on a different earnings period. Hence, if it is indeed the information content of earnings which matters, predictability of style returns should mirror the autocorrelation structure in firm fundamentals as highlighted in section 2 , and hence the strongest effects should be observed in the second month of a quarter (using first month earnings releases as predictors) and the weakest effect in the first month.

To test this conjecture, I repeat the baseline analysis separately for the first, second, and third month of a given quarter. Results are reported in table 5. To save space, the characteristic-based return spreads are calculated only for the "All" firms sample. (Like in the previous analyses the regression coefficients are very similar when I split the sample for the return calculation between prior one-month announcers and non-announcers.)

\section{Insert Table 5 here}

Table 5 strongly supports the idea that seasonality in earnings announcements leads to time-series variation in the level of predictability. In panel A which shows the univariate regression results, the coefficients for quarter mid observations are all significant at $5 \%$ or higher (t-statistics range from 2.2 to 4.5 ). Past earnings surprises are in general also successful in forecasting style-based return spreads in the last month of a quarter, although the point estimates and levels of statistical significance are somewhat lower. In contrast, for the first months of a quarter, only a minority of five coefficients is significant at $5 \%$ or $10 \%$, and none at 1\%. Overall, the same tendency is apparent in panel B which displays the three-factor regression results.

The results of table 5 suggest that the ability to predict future style-returns indeed stems from an underreaction to the information imbedded in earnings releases. To provide an additional test for this conclusion, I run a "placebo" predictability test where I try to forecast future style-returns with artificially constructed EAR spreads. These artificial EAR spreads are calculated using randomly selected three-day

period returns in excess of the market return from the previous month that are outside the earnings announcement windows. To the extent that it is the information from earnings announcements which matters, the placebo regressions should provide substantially less evidence of predictability. The results of the exercise which are shown in table 5 of the online appendix confirm this prediction. For the "All" firms sample I find five artificial EAR spreads that are significant positive predictors at $5 \%$ or $10 \%$ (out of a total of 15 univariate and 15 three-factor regression coefficients). No coefficient is significant at $1 \%$. In 
contrast, the results from the baseline analysis in table 3 show that 24 out of the 30 regression coefficients are statistically significantly positive. Again, differentiating between announcing and non-announcing firms does not lead to different conclusions.

\subsection{Predictability of style returns by firm size}

Prior research finds that the traditional PEAD is is less pronounced for large firms (see e.g., Bernard and Thomas (1989) and Peress (2008)). This evidence is confirmed by the summary statistics in table 2 which in addition show that characteristic-based trading strategies also tend to produce lower return spreads among large firms. Hence, it seems obvious that the above documented predictability of style returns should be decreasing in firm size as well. To investigate this issue, I test whether EAR spreads (which are constructed in the same manner as before) also forecast value-weighted style-returns. As outlined in section 3.1, for the calculation of the value-weighted long-short returns, I apply the same methodology that Fama and French (1993) use for construction of the $H M L$ factor (except for firm size for which the value-weighted return is simply the $S M B$ factor). This allows me to investigate the predictability of value-weighted return spreads separately for small firms and large firms based on the NYSE median firm market capitalization (except for firm size). The findings - restricted to the the "All" firms sample to conserve space - are displayed in 6.

\section{Insert Table 6 here}

The first two columns in table 6 refer to the results for forecasting the baseline value-weighted return spread as average of the spread for the small and the large firm sample. Inspection of these columns reveals clear evidence that earnings surprises are less successful predictors for value-weighted returns. This is particularly true for the three-factor regression results. For instance, nine coefficients remain statistically significant positive in the univariate models, but only five are so in the multivariate regressions. In line with expectations, I also find more evidence in favor of predictability when I try to forecast the valueweighted spread of small stocks. For the big stock sample, there is only one statistically significant positive coefficient in the multivariate results (which is for book-to-market). In contrast, seven coefficients are still statistically positive for small firms in the three-factor models. Since returns are value-weighted for small firms also, these findings imply that style-based earnings momentum is not only a micro-cap effect. ${ }^{13}$

\footnotetext{
${ }^{13}$ As an alternative way to control for firm size, I follow Fama and French (2008) and sort stocks into a tiny, small, and large group based on the 20th and 50th percentile of end-of-June market capitalization for NYSE stocks. For each size bucket, I then calculate equal-weighted characteristic-based long-short returns and regress them on past earnings surprises. This robustness test which is also reported in the online appendix confirms the above documented results: There is substantial
} 
Nonetheless, the evidence is consistent with earlier work documenting generally less underreaction effects for larger firms. Note however, that most coefficients are still positive even for the large firm sample, although they generally fail to achieve statistical significance. Since firms can belong to different style groups at the same point, the results therefore do not say that there is no underreaction at all among large firms once one gives up the isolated view on single styles. The remaining parts of the paper will investigate this issue in greater detail.

\section{Switching to the stock level: Predictability using style-based earnings surprises}

\subsection{Time-series panel regressions}

In this section, I move from the style- to the stock level perspective. A stock belongs to different styles at the same time. Hence, one might be interested whether combining the information from all style-based earnings surprises improves the predictability of future stock returns beyond what has been documented before at the style-level. On the other hand, many characteristic-based trading strategies also tend to be correlated: The average correlation between the EAR spreads (the predictor variables) is 0.16 and the highest absolute correlation is $0.76 .{ }^{14}$ Since a high absolute correlation between two signals reduces the additional informational value when using both signals in combination, it is a priori unclear how strong the gain in predictability for stock returns would be. Moreover, while the multivariate regressions control partially for some of the correlation structure by including beta, size, and value factors, they fail to completely isolate the importance of a single characteristic after simultaneously controlling for other style effects.

To start the analysis at the stock level, I run pooled panel regressions of individual stock returns on style-based earnings surprises, the main variables of interest, as well as a number of controls. Style-based earnings surprises are calculated as the average prior one-month EAR of same-style stocks, i.e. stocks that are in the same characteristic-quintile. For example, style-based EAR for small (large) stocks are the average earnings surprise of all stocks being in the lowest (highest) size quintile. I note that this approach is conceptionally different from the previous long-short procedure used in the time-series regressions since earnings surprises are now also calculated for quintiles two to four and used as predictors. Doing so allows me to classify stocks with medium-level characteristic values into a style group as well (such as "mid-cap"

evidence of predictability for the tiny- and small-cap firm sample, but - analogous to table 6 - weaker evidence if big stocks are investigated.

${ }^{14}$ Correlations are reported in table 2 of the internet appendix. 
stocks), and is on technical grounds necessary to avoid losing these observations in the regressions.

Control variables include firm size, book-to-market, prior one-month and prior one year returns (prior one year returns exclude the most recent month). Furthermore, I add the most recent earnings announcement returns (EAR) and standardized unexpected quarterly earnings (SUE) for each stock. This provides a more complete control for stock-specific post earnings drifts than the style level regressions where the distinction between non-announcers and announcers is based on a single month only, since even firms that have not announced in a given month may be announcers one or two months before. I also include industry-wide earnings surprises as predictors to capture any intra-industry information transfers. These are calculated as the average EAR of same-industry stocks (again based on the 48 industries from Fama and French (1997)) that have announced in the most recent month. (Going back further than one month does not alter the results in a meaningful way.) The regression results are displayed in table 7. As suggested by Petersen (2009) all specifications include month dummies and standard errors are clustered by month to control for unobserved time effects.

\section{Insert Table 7 here}

For comparison, panel A of Table 7 displays a baseline specification that does not include style-based EAR spreads. The results are consistent with book-to-market, momentum, and short-term reversal effects in the sample. The post earnings announcement drift at the individual stock level is also confirmed (for both EAR and SUE), as well as the fact that recent industry-wide earnings surprises positively impact on stock returns.

Panel B reports the regression coefficients and t-statistics for the style-based earnings surprises. In this panel, style-based earnings surprises are selectively added as explanatory variables. All specifications include the same list of controls as shown in panel A but since the regressions coefficients are very similar in size and statistical significance they are suppressed for brevity. Panel B documents statistically significant effects for all styles with the exception of beta and momentum. For eleven out of 15 styles, the coefficients are significant at the $1 \%$ level. Moreover, the effects compare quite well with the time-series findings documented in the baseline analysis in table 3 which is to some extent remarkable, given the differences in the regression design. Next, I investigate whether controlling for past style returns subsumes the positive relation between stock returns and past style-based earnings surprises. The underlying motivation is similar to the one for running the "placebo" predictability test before: To what extent is it important to focus specifically on the market reaction around earnings announcements? Past style returns are calculated as the average return over all stocks pertaining to a particular quintile minus the market return in that 
month. Hence, the calculation is the same as for earnings surprises with the exception of using a longer time period. Panel $\mathrm{C}$ shows the regression results for both past style-based earnings surprises and past style returns. The regressions are again conducted separately for each style and include the same list of controls as before. The results show that with the exception of investment over assets, style-based EAR remain significant predictors of future stock returns even after controlling for past style returns.

What happens if all style-related EAR are collectively included in one regression? The answer is given in panel D of table 7 . Interestingly, ten out of the 15 coefficients are still statistically significant, and the remaining coefficients are positive. Hence, the evidence does not support the idea that style-driven earnings momentum can be traced back to only one or two characteristics.

\subsection{Trading strategy results for a style-based earnings surprise measure}

Since the panel regressions suggest that there are multiple sources of predictability, I move on to test whether one could use the earnings information of all styles in combination to make predictions about cross-sectional differences in future stock returns for the complete firm universe. To operationalize this, I construct a Style-based Earnings Surprise Measure ("SESM") for each stock as an equal-weighted average of the style-based EAR over all 15 styles. SESM is arguably the simplest possible measure in this context, since it is not optimized by over- or underweighting certain styles for which earnings surprises have proven to be more or less successful return predictors. It has a mean value of $0.33 \%$ and a cross-sectional standard deviation of $0.78 \%$. The positive mean is consistent with an average earnings announcement premium as documented by Frazzini and Lamont (2006). ${ }^{15}$ The complete (and relatively normal) distribution is shown in the online appendix.

\subsubsection{Portfolio tests}

To investigate the potential profitability of a trading strategy based on SESM, I form equal- and valueweighted long-short portfolios as before. Specifically, the equal-weighted portfolios are long in the $20 \%$ of stocks with the highest SESM and short in the 20\% with the lowest SESM. Value-weighted returns are constructed as the average of a value-weighted long-short portfolio for small stocks (below the median NYSE market value) and large stocks. Raw return differences as well as intercepts from multi-factor regressions are reported in table 8 .

\footnotetext{
${ }^{15}$ Note however, that SESM varies over time and across stocks and hence is conceptionally different from the earnings announcement premium which varies over time only.
} 


\section{Insert Table 8 here}

As can be seen, the equal-weighted return from the long-short portfolio is 184 bps per month (t-value: 7.5), or over $22 \%$ per year. The value-weighted return difference is 119 bps (t-value: 6.0 ), which roughly corresponds to $14 \%$ per year. While value-weighting reduces the return spread, there are only minor differences between the long-short portfolio for small and large firms: In the small firm sample the spread is 132 bps (t-value: 6.6), and for large firms it is 106 bps (t-value: 4.7). This suggests that in contrast to the style-level findings (see subsection 3.5), style-based earnings surprises are still very useful at the individual stock level when conditioning on larger firms. In fact, the value-weighted monthly return difference is considerably larger than that of the traditional PEAD with 69 bps for an EAR-strategy and 45 bps for an SUE-strategy (see table 2).

The intercepts of multifactor models which control for other return factors are not very different from the raw return spreads. The CAPM one-factor alpha is $1.91 \%$ per month (equal-weighted returns) and $1.24 \%$ per month (value-weighted returns), respectively. A six-factor model which includes the market excess return, the Fama/French size, value, momentum and short-term reversal factors, and the Pastor and Stambaugh (2003) liquidity factor in the regressions delivers a monthly alpha of $2.17 \%$ for the equalweighted portfolio, and $1.55 \%$ for the value-weighted portfolio. The six factor alphas are larger than the one-, three- or four-factor alphas because the short-term reversal factor is substantially negatively related to the SESM returns. The next two columns examine to what extent the profits of the SESMstrategy are related to the PEAD-strategy (either based on EAR or SUE). In both models, the alphas are fairly comparable to the six-factor estimates, further confirming that style-based earnings momentum is relatively unrelated to the traditional PEAD.

Finally, in the last column of table 8 the value-weighted long-short returns of all 15 characteristic-based strategies are added as controls. (This increases the number of independent variables by twelve, since the value, size, and momentum factor are already included.) One might argue that part of the profitability of the SESM-strategy emerges from a general tendency to load on characteristic-based strategies that have been successful over the past. For instance, since low asset growth firms tend to have more positive EAR, these firms should in general have a higher probability of entering the long SESM-portfolio. As can be seen, the results of the enlarged regression model do not provide strong support for this line of reasoning. Neither the alphas nor their levels of statistical significance are materially affected. ${ }^{16}$ Overall,

\footnotetext{
${ }^{16}$ An examination of the variance inflation factors suggests that the enlarged regression model suffers from multicollinearity problems. This is however not a serious concern here, since my focus is on the constant of the model, and not on the slopes of the independent variables.
} 
the profitability of the SESM-strategy seems to be rather explained by exploiting time-series variations in characteristic-based return spreads.

\subsubsection{Fama/MacBeth regressions}

The fact that earnings surprises of same-style stocks are less informative for the returns of large stocks is consistent with a limited attention explanation as well as an explanation based on market frictions. To examine this issue in more detail, I run a set of Fama/MacBeth regressions, which allow me to analyze the influence of certain firm characteristics on the profitability of SESM. In particular, I use analyst coverage and institutional investor ownership as proxies for investor attention, and the monthly bid-ask-spread estimator of Corwin and Schultz (2011) and the Amihud (2002) illiquidity ratio as measures for market frictions. Corwin and Schultz (2011) show that their estimator works well compared to other estimators, especially for small stocks. In addition, it can be easily applied to the whole sample period. Since all four measures are also strongly correlated with firm size, I orthogonalize them with respect to the natural log of market capitalization and dummies for NYSE market value deciles. ${ }^{17}$ Results can be found in table 9 .

\section{Insert Table 9 here}

The first column shows the raw impact of SESM on future stock returns, controlling for the same set of additional predictors as in table 7. The impact of SESM is statistically strong (t-statistic: 8.15). In economic terms the estimated coefficient indicates that a one standard deviation increase in SESM increases the future stock return by $1.5 \%$ (1.89 times 0.78\%). Hence, the Fama/MacBeth results confirm the portfolio tests. The second column adds an interaction term between firm size and SESM. To ease interpretation, size is measured as an indicator variable being 0 (1) for firms below (above) the NYSE median market value. The statistically significant interaction term is -0.4 , which suggests a rather modest decline of the forecasting abilities for the largest firms. Going further, I separately add interaction terms between SESM and analyst coverage (column 3), institutional ownership (column 4), the estimated bidask-spread (column 5), and the illiquidity ratio (column 6). These interaction terms are insignificant in all columns, providing no further evidence that limited attention or market frictions play a role in explaining the return predictability. If all interaction terms are added simultaneously in the regression (column 7), the coefficient for residual illiquidity is now marginally significant with a t-value of -1.75 . To summarize,

\footnotetext{
${ }^{17}$ The methodology follows Hong et al. (2000) by running monthly cross-sectional regressions and storing the residuals for each month. Dummies for NYSE market value deciles are included in the regressions to control for non-linear relations between firm size and the four measures. Using the residuals from a regression without these dummy variables leads to qualitatively similar findings.
} 
there is little evidence beyond the influence of firm size that a limited attention or market based frictions story can explain the results of the SESM-strategy.

I note that this finding is not consistent with the results in prior literature about industry-based spillover effects which generally finds weaker predictability particularly for firms with high analyst coverage or high institutional ownership. I cannot provide a definite reason for the discrepancy, but some explanations seem plausible. First, while analysts and institutional investors might be well informed about fundamental connections within industries, they could be as unaware about style-based connections as the general market audience. Supportive evidence is provided later where I show that SESM is related to quarterly analyst forecast errors, as opposed to recent industry-based earnings surprises. Second, the chosen regression design generally appears stricter in documenting the incremental effect of analyst coverage and other variables after controlling for firm size. For instance, Menzly and Ozbas (2010) document that return predictability based on recent industry supplier and customer returns is decreasing in analyst coverage and institutional ownership but they do not control for firm size in their analysis which makes it difficult to directly compare their results (see table 3 in their paper).

Lastly, the monthly coefficient estimates of the Fama/MacBeth regressions are also informative about the time-series evolution of the profitability of the SESM-strategy. To see this, I plot rolling three-year beta averages from the first regression model in figure 3. The figure suggests that the strategy was particularly successful during the mid-80's and the early 2000's. However, a clear trend (and specifically one that would point towards decreasing returns over time) is not evident. ${ }^{18}$

\section{Insert figure 3 here}

\subsection{Relation to the traditional post earnings announcement drift}

This section examines the relation between the SESM-based strategy and traditional post earnings drift strategies which seems interesting from two angles. First, as previous sections suggest that the profitability of SESM cannot be explained by the traditional PEAD anomaly, combining both strategies has the potential to increase trading profits. Second, for the PEAD anomaly investor underreaction has emerged as the prevalent explanation. For instance, Bernard and Thomas (1989, 1990) argue that investors fail to fully recognize the implications of current earnings for future earnings which leads to a delayed price response. Additionally, two recent studies (DellaVigna and Pollet (2009) and Hirshleifer et al. (2009))

\footnotetext{
${ }^{18}$ Consistent with the by-quarter results in section 3.4 betas estimated for the second and third quarter months are substantially larger than the estimates for the first quarter months (2.35 and 2.43 vs. 0.86).
} 
show that price drifts are stronger when the earnings announcement is released on a Friday or when there is a greater number of same-day earnings announcements by other firms which is also consistent with the investor underreaction hypothesis. Hence, to the extent that underreaction also explains the abnormal returns associated with the SESM strategy, one would expect a similar return evolution over time (i.e. after the first month). To examine this question, I first create five equal-sized stock portfolios either based on their most recent EAR or their most recent SUE. Within each of these quintiles, I create five further bins using the stocks' SESM. Three-factor alphas for the resulting portfolios are reported in table 10. I consider a monthly rebalancing interval, and to investigate longer term return effects also a six-month rebalancing strategy. The returns from the six-month rebalancing strategy are based on overlapping portfolios as in Jegadeesh and Titman (1993).

\section{Insert Table 10 here}

Panel A and B report the performance of portfolios based on an "EAR-SESM"-strategy. Inspection shows an increase in the three-factor alphas along both dimensions for the monthly as well as the six-month rebalancing frequency. Under monthly rebalancing, the (low EAR/low SESM)-portfolio has a monthly alpha of $-1.37 \%$, whereas the abnormal performance of the (high EAR/high SESM)-portfolio amounts to $1.34 \%$. The alpha of the corresponding long-short portfolio is $2.71 \%$ per month (equalling $33 \%$ per year) with a t-value of 9.3 , which roughly doubles the alpha of $1.39 \%$ that is obtained when using earnings announcement returns in isolation (see table 2). The monthly alpha of the long-short portfolio under a six-month rebalancing regime is lower at $1.22 \%$ (t-value: 6.9 ), which leads to the conclusion that profits are to a substantial extent realized in the short-term. Comparing the numbers however, it is also obvious that the abnormal performance is not restricted to the first month after the portfolio formation: The total six-month alpha of the longer holding period strategy (obtained by multiplying by six) is $7.32 \%$, which is approximately 2.7 times the alpha for the one month holding period. Further inspection of the final rows and final columns in panel $\mathrm{A}$ and $\mathrm{B}$, which report the return differences holding either the EAR or the SESM stock portfolio constant, shows that both measures contribute to the continued abnormal performance after the first month. Hence, both strategies are associated with a continuing, slowly decaying drift and there is no evidence of a return reversal. This finding is consistent with the conclusion that similar to the origin of the profitability of traditional post earnings drifts, slow information diffusion of economically relevant information appears to be the driver of the return predictability associated with the SESM strategy. 
In panel C and D, I report the abnormal performance for an "SUE-SESM"-strategy. Overall, the results are comparable to those shown in panel A and B. It is noteworthy also that a combination of all three measures leads to the same conclusions and achieves a further increase in profitability. ${ }^{19}$

\section{Further evidence on underreaction as the source of profitabil- ity}

In order to further understand the mechanisms which lead to the predictable price drift, this section examines how SESM is related to improvements in firm profitability, subsequent earnings announcement returns, quarterly analyst forecast errors, and changes in consensus forecasts for the next annual earnings. To the extent that recent earnings announcements of same-style firms provide value-relevant information about firm fundamentals to which market participants underreact, I would expect that SESM is positively related to standardized unexpected earnings (SUE) and also announcement returns (EAR) for upcoming announcing firms. Analysts may contribute to the process if they are not fully aware about the fundamental connections apparent at the style level, potentially because they form peer groups at the industry level. If so, analysts should also be surprised, and the empirical prediction would be a positive association between SESM and analyst forecast errors with regard to quarterly earnings. Also, a delayed reaction to value-relevant information would suggest that SESM positively predicts subsequent revisions in consensus analyst estimates of next year annual earnings.

To test these empirical predictions, I use the Fama/MacBeth regression design of section 4.2.2 to forecast SUE, EAR, analyst forecast errors and revisions. The regressions include the same set of controls as before to capture the residual effect of SESM. Quarterly analyst forecast errors and revisions in annual consensus forecasts are based on I/B/E/S data and calculated using the same methodology as for the calculation of SUE. Specifically, quarterly forecast error is the difference between realized quarterly earnings as published in $\mathrm{I} / \mathrm{B} / \mathrm{E} / \mathrm{S}$ and the consensus forecast, divided by the standard deviation of these differences over the last eight quarters. The consensus is based on the median of all analyst forecasts that have been issued over the last 90 days before the quarterly earnings announcement date. ${ }^{20}$ Annual forecast revision is the monthly change in the median consensus estimate for the upcoming fiscal year, scaled by the standard deviation of

\footnotetext{
${ }^{19}$ For direct evidence, see table 9 in the online appendix.

${ }^{20}$ I rely on the I/B/E/S Detail Unadjusted File to compute the quarterly forecast error because the Detail Unadjusted File contains information on announcement dates for analyst estimates and hence allows an exact identification of all analyst forecasts that were made right up to the company announcement of actual earnings. Earnings per share estimates are appropriately adjusted for stock splits between the actual earnings announcement date and the analyst forecast date using the cumulative share adjustment factor from CRSP. I find similar results with regard to SESM as predictor variable if the consensus is based on the mean forecast over the last 90 days or only the latest available forecast (instead of the median).
} 
the last eight observations. Consensus estimates are taken from the I/B/E/S Summary Unadjusted File. As I/B/E/S usually publishes consensus estimates the third Thursday each month, forecast revisions are lagged by one month. This ensures a non-overlap between revisions and the independent variables, and hence grants analysts some time to revise their forecasts. Results are displayed in table 11. Coefficients are standardized to compare the economic significance of the independent variables. Finally, note that since not all firms announce in a particular month, and not all firms are covered by analysts, the Fama/MacBeth regressions are based on a fewer number of observations for each month.

\section{Insert table 11 here}

As observable from inspection of column 1, SESM is a positive predictor of future earnings announcement returns with a statistical significance at the $1 \%$ level. Hence, in line with the style-driven earnings momentum hypothesis, investor surprises can be partially inferred from recent announcement returns of same-style firms. Column 2 shows that firms with a higher SESM also enjoy improvements in operating performance as proxied by standardized unexpected earnings; the coefficient estimate is again highly statistically significant (t-value: 2.9). In economic terms, the influence of SESM is stronger on EAR than on SUE, for which most recent SUE display the by far strongest economic significance.

Turning to columns 3 and 4, SESM is also positively related to quarterly analyst forecast errors (statistical significance at 5\%) and forecast revisions in annual earnings estimates (statistical significance at 1\%), even after controlling for past returns, most recent earnings surprises, and other variables. These results suggest that analysts do not timely adjust their estimates to fundamental information embedded in SESM which leads to predictable forecast errors for quarterly earnings and predictable future revisions. To the extent that investors overweight analyst forecasts, these results reveal a channel for the price drift related to SESM. It is also noteworthy that the economic influence of SESM is always higher in these regressions than the influence of recent industry-based earnings surprises, despite the literature focus on industry spillovers so far. The same holds true in three out of four regressions in terms of statistical significance. Taken together the findings provide further evidence that investor underreaction is the main driver of style driven earnings momentum.

\section{Conclusion}

Earnings announcements provide investors with a variety of information about future stock returns. In addition to being informative about the the stock's own price development (the traditional post earnings 
drift), earnings announcements are important for other firms that operate in the same industry, and - as this paper shows - also for stocks that share the same style (or characteristic) like being a value stock. The connections at the style-level can be exploited to predict future characteristic-based long-short portfolio returns as well as future stock return differences. The style-based earnings surprise measure (SESM) constructed in this paper proves to be a strong return predictor both in calendar-time portfolio tests as well as cross-sectional Fama/MacBeth regressions. With a value-weighted return spread of 106 bps per month the measure is particularly useful for larger firms. The predictability is not explained by other known return determinants and provides further evidence that value-relevant information is only gradually incorporated into prices. In the context of this paper, I present evidence that the value-relevance stems from comovement in firm fundamentals and that investors and analysts are not fully aware about the fact that earnings are informative about the future earnings of other same-style stocks.

Among other things, this paper also shows that "enhanced" earnings momentum strategy that uses several signals in combination yields substantially larger trading profits. While recent work (see e.g., Richardson et al. (2010), Chordia et al. (2007), Ng et al. (2008)) apparently comes to the conclusion that transaction costs can explain the existence of the PEAD based on standardized unexpected earnings, these studies do not investigate whether transaction costs can also account for the profitability of "enhanced" strategies. Another venue for future research is a closer examination of the underlying (likely macroeconomic) factors that cause same-style stocks to have correlated earnings. As pointed out by Richardson et al. (2010) in their recent survey, our knowledge in this area is still limited. 


\section{References}

Amihud, Y., 2002, "Illiquidity and stock returns: Cross-section and time-series effects," Journal of Financial Markets, 5, 31-56.

Asthana, S. C., and B. K. Mishra, 2001, "The differential information hypothesis, firm size, and earnings information transfer: An empirical investigation," Journal of Business Research, 53, 37-47.

Baker, M., and J. Wurgler, 2006, "Investor sentiment and the cross-section of stock returns," Journal of Finance, 61, 1645-1680.

Bernard, V. L., and J. K. Thomas, 1989, "Post-earnings-announcement drift: Delayed price response or risk premium?," Journal of Accounting Research, 27, 1-36.

— 1990, "Evidence that stock prices do not fully reflect the implications of current earnings for future earnings," Journal of Accounting and Economics, 13, 305-340.

Brandt, M. W., R. Kishore, P. Santa-Clara, and M. Venkatachalam, 2008, "Earnings announcements are full of surprises," Working Paper.

Campbell, J. Y., J. Hilscher, and J. Szilagyi, 2008, "In search of distress risk," Journal of Finance, 63, 2899-2939.

Chen, H.-L., and W. De Bondt, 2004, "Style momentum within the S\&P 500 index," Journal of Empirical Finance, 11, 483-507.

Chordia, T., A. Goyal, G. Sadka, R. Sadka, and L. Shivakumar, 2007, "Liquidity and the post-earningsannouncement drift," Financial Analysts Journal, 65, 18-32.

Chordia, T., and L. Shivakumar, 2006, "Earnings and price momentum," Journal of Financial Economics, $80,627-656$.

Cohen, L., and A. Frazzini, 2008, "Economic links and predictable returns," Journal of Finance, 63, 1977-2011.

Cohen, L., and D. Lou, 2012, "Complicated Firms," Journal of Financial Economics, 104, 383-400.

Cooper, M. J., H. Gulen, and M. J. Schill, 2008, "Asset growth and the cross-section of stock returns," Journal of Finance, 63, 1609-1651.

Corwin, S., and P. Schultz, 2011, "A simple way to estimate bid-ask spreads from daily high and low prices," Working Paper, forthcoming Journal of Finance. 
Daniel, K., and S. Titman, 2006, "Market reaction to tangible and intangible information," Journal of Finance, 61, 1605-1643.

DellaVigna, S., and J. M. Pollet, 2009, "Investor inattention and friday earnings announcements," Journal of Finance, 64, 709-749.

Dunn, K., and S. Nathan, 2005, "Analyst industry diversification and earnings forecast accuracy," Journal of Investing, 14, 7-14.

Easton, P., G. Gao, and P. Gao, 2010, "Pre-Earnings announcement drift," Working Paper.

Fama, E. F., and K. R. French, 1993, "Common risk factors in the returns on stocks and bonds," Journal of Financial Economics, 33, 3-56.

, 1995, "Size and book-to-market factors in earnings and returns," Journal of Finance, 50, 131-155.

— , 1997, "Industry costs of equity," Journal of Financial Economics, 43, 153-193.

— , 2008, "Dissecting anomalies," Journal of Finance, 63, 1653-1678.

Fama, E. F., and J. D. MacBeth, 1973, "Risk, return, and equilibrium: Empirical tests," Journal of Political Economy, 81, 607-636.

Foster, G., 1981, "Intra-industry information transfers associated with earnings releases," Journal of Accounting and Economics, 3, 201-232.

Frazzini, A., and O. Lamont, 2006, "The earnings announcement premium and trading volume," Working Paper.

Freeman, R., and S. Tse, 1992, "An earnings prediction approach to examining intercompany information transfers," Journal of Accounting and Economics, 15, 509-523.

Greenwood, R., and S. Hanson, 2010, "Share issuance and factor timing," Working Paper, forthcoming Journal of Finance.

Han, J. C. Y., J. J. Wild, and K. Ramesh, 1989, "Managers' earnings forecasts and intra-industry information transfers," Journal of Accounting and Economics, 11, 3-33.

Hirshleifer, D., K. Hou, and S. H. Teoh, 2012, "The accrual anomaly: Risk or mispricing?," Management Science, 58, 320335 .

Hirshleifer, D., S. Seongyeon, and S. H. Teoh, 2009, "Driven to distraction: Extraneous events and underreaction to earnings news," Journal of Finance, 64, 2289-2325. 
Hoberg, G., and G. Phillips, 2010a, "Product market synergies and competition in mergers and acquisitions: A text-based analysis.," Review of Financial Studies, 23, 3773-3811.

— , 2010b, "Text-based network industries and endogenous product differentiation," Working Paper.

Hong, H. G., T. Lim, and J. C. Stein, 2000, "Bad news travels slowly: Size, analyst coverage, and the profitability of momentum strategies," Journal of Finance, 55, 265-295.

Hong, H. G., and J. C. Stein, 1999, "A unified theory of underreaction, momentum trading, and overreaction in asset markets," Journal of Finance, 54, 2143-2184.

Hou, K., 2007, "Industry information diffusion and the lead-lag effect in stock returns," Review of Financial Studies, 20, 1113-1138.

Huang, X., 2012, "Thinking outside the borders: Investors inattention to foreign operations," Working Paper.

Jegadeesh, N., and S. Titman, 1993, "Returns to buying winners and selling losers: implications for stock market efficiency," Journal of Finance, 48, 65-91.

Kothari, S., J. Lewellen, and J. B. Warner, 2006, "Stock returns, aggregate earnings surprises, and behavioral finance," Journal of Financial Economics, 79, 537-568.

La Porta, R., J. Lakonishok, A. Shleifer, and R. Vishny, 1997, "Good news for value stocks: Further evidence on market efficiency," Journal of Finance, 52, 859-874.

Lewellen, J., 2002, "Momentum and autocorrelation in stock returns," Review of Financial Studies, 15, 533-563.

Lo, A. W., and A. C. MacKinlay, 1990, "When are contrarian profits due to stock market overreaction?," Review of Financial Studies, 3, 175-205.

Menzly, L., and O. Ozbas, 2010, "Market segmentation and cross-predictability of returns," Journal of Finance, 65, 1555-1580.

Ng, J., T. O. Rusticus, and R. S. Verdi, 2008, "Implications of transaction costs for the post-earnings announcement drift," Journal of Accounting Research, 46, 661-696.

Novy-Marx, R., 2012, "Pseudo-predictability in conditional asset pricing tests: Explaining anomaly performance with politics, the weather, global warming, sunspots, and the stars," Working Paper.

Pastor, L., and R. F. Stambaugh, 2003, "Liquidity risk and expected stock returns," Journal of Political Economy, 111, 642-685. 
Peress, J., 2008, "Media coverage and investors' attention to earnings announcements," Working Paper.

Petersen, M. A., 2009, "Estimating standard errors in finance panel data sets: Comparing approaches," Review of Financial Studies, 22, 435-480.

Ramnath, S., 2002, "Investor and analyst reactions to earnings announcements of related firms: An empirical analysis," Journal of Accounting Research, 40, 1351-1376.

Richardson, S., I. Tuna, and P. Wysocki, 2010, "Accounting anomalies and fundamental analysis: A review of recent research advances," Journal of Accounting and Economics, 50, 410-454.

Shumway, T., 2001, "Forecasting bankruptcy more accurately: A simple hazard model," Journal of Business, $74,101-124$.

Sloan, R., 1996, "Do stock prices fully reflect information in accruals and cash flows about future earnings?," Accounting Review, 71, 289-315.

Stambaugh, R. F., J. Yu, and Y. Yu, 2012, "The short of it: Investor sentiment and anomalies," Journal of Financial Economics, 104, 288-302.

Teo, M., and S.-J. Woo, 2004, "Style effects in the cross-section of stock returns," Journal of Financial Economics, 74, 367-398.

Thomas, J., and F. Zhang, 2008, "Overreaction to intra-industry information transfers?," Journal of Accounting Research, 46, 909-940.

West, K. D., and W. K. Newey, 1987, "A simple, positive semi-definite, heteroskedasticity and autocorrelation consistent covariance matrix," Econometrica, 55, 703-708.

White, H., 1980, "A heteroskedasticity-consistent covariance matrix estimator and a direct test for heteroskedasticity," 48, 817-838. 
Figure 1: Average monthly earnings surprise in \%: Difference between value and growth stocks This figure shows the monthly difference in average earnings surprises between value and growth stocks over the sample period from 1972 to 2011. For each announcer, the earnings surprise is calculated as the cumulative stock return over the three-day window centered around the quarterly earnings announcement date minus the cumulative market return over the same period. The value (growth) portfolio contains all stocks belonging to the highest (lowest) book-to-market equity quintile.

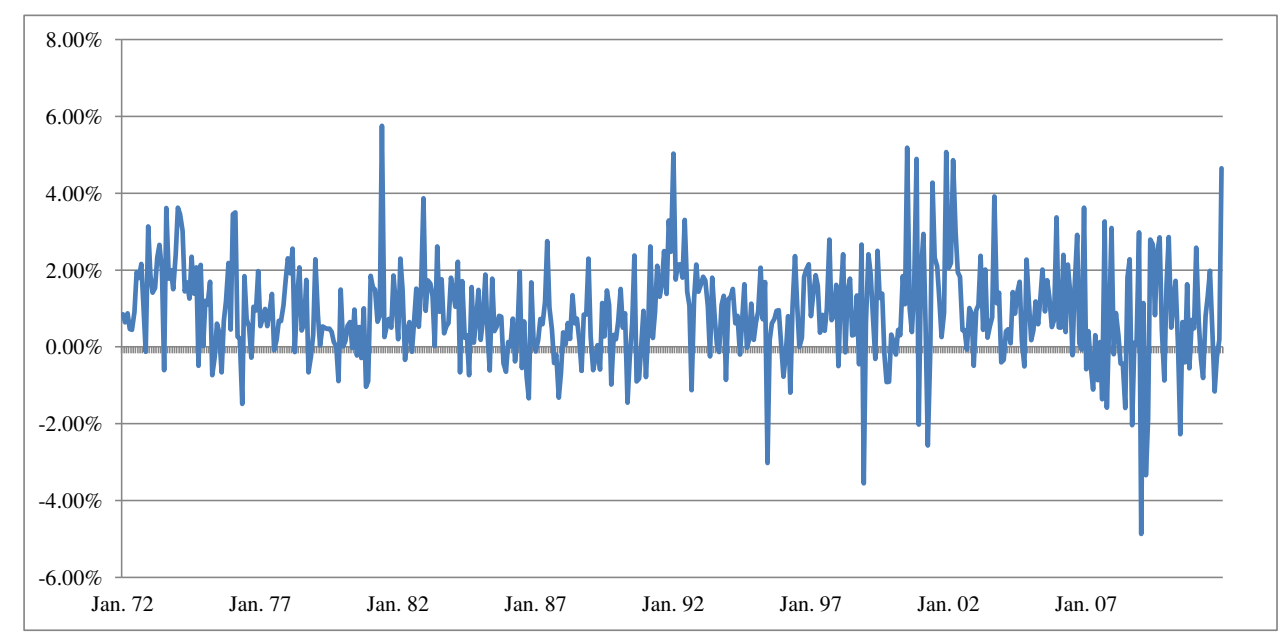


Figure 2: One-month ahead value-growth long-short returns by quintiles earnings surprise differences

This figure sorts the sample months into quintiles based on earnings surprise differences between value and growth stocks and shows corresponding average one-month ahead value minus growth return spreads. The return spreads are calculated using equal-weighting and value-weighting of stocks. The construction of valueweighted returns follows the methodology of Fama and French (1993), i.e. the value-weighted return is the $H M L$ factor.

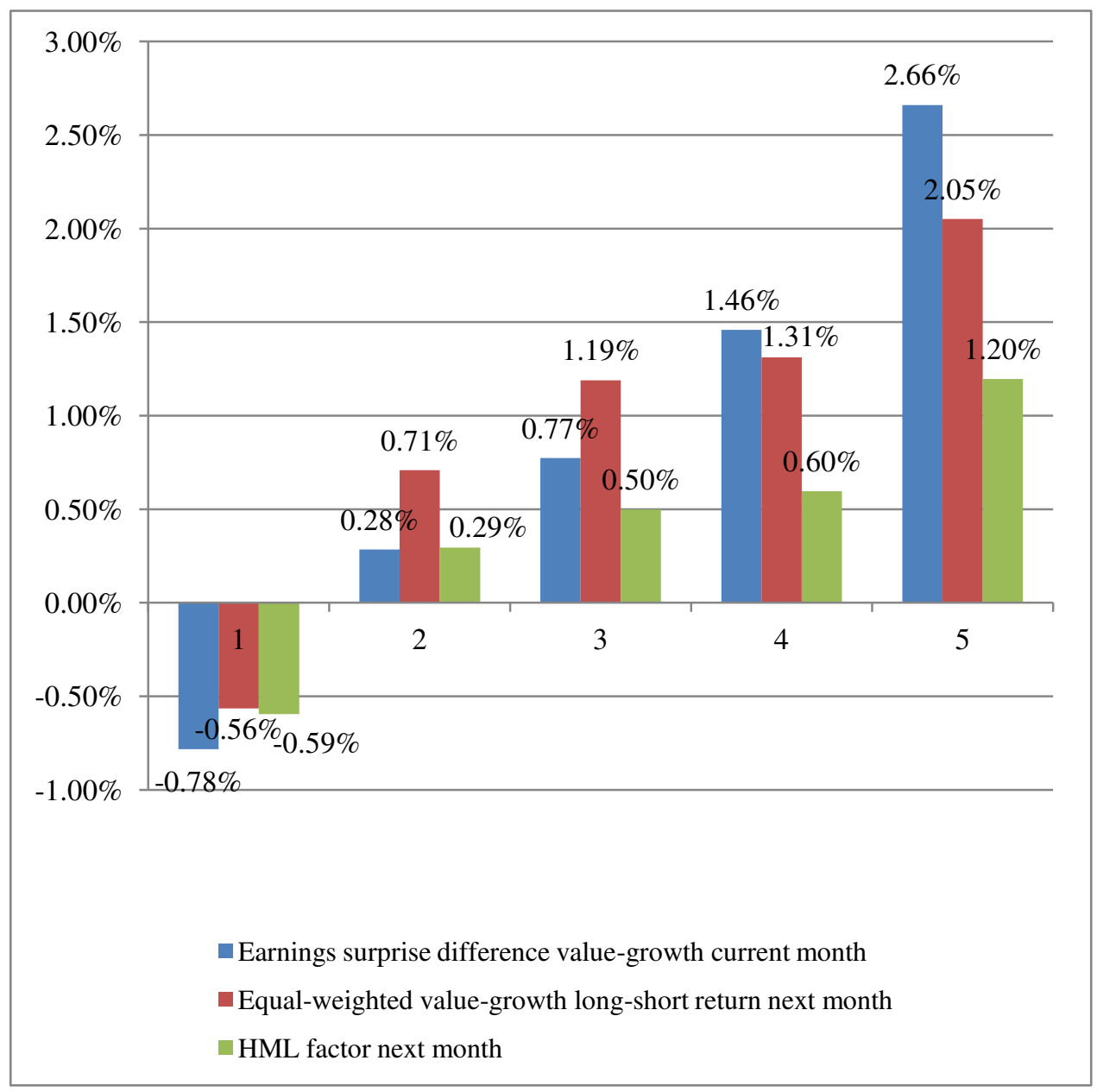


Figure 3: Three-year rolling slope estimates for SESM, 1975-2011

The figure plots three-year rolling averages of Fama/MacBeth slopes for the style-based earnings surprise measure (SESM). The estimates come from the first regression model in table 9.

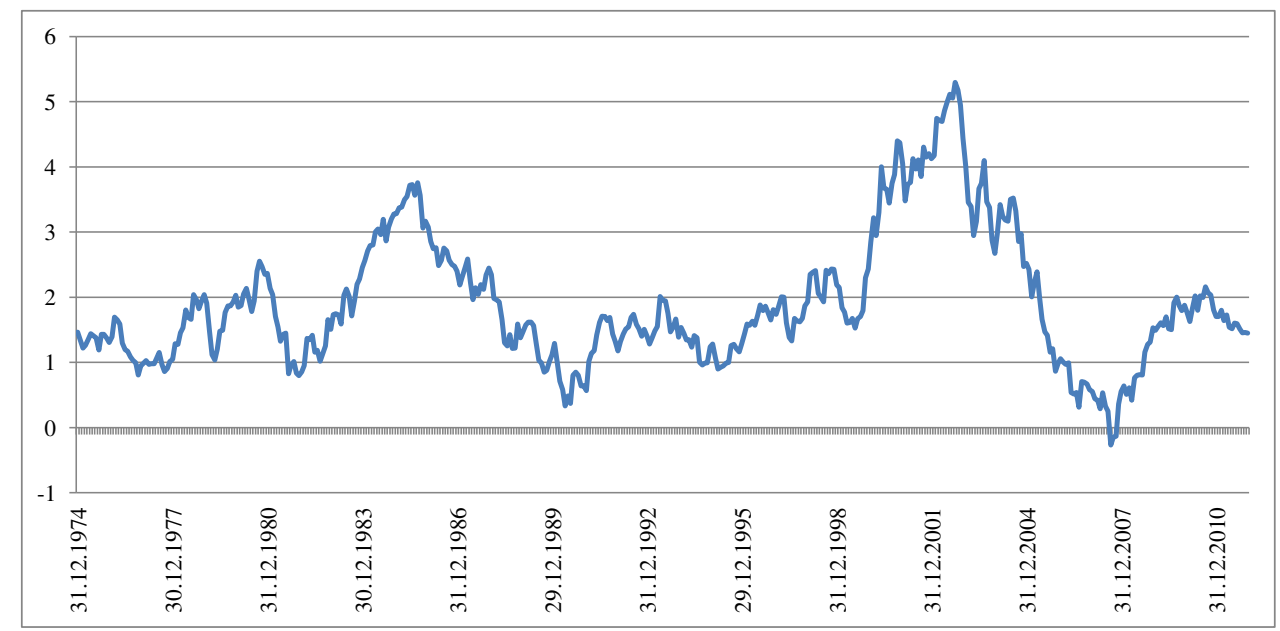


Table 1: AR(1) models of style-based spreads in quarterly return on assets

This table presents standardized coefficients and t-statistics of $\operatorname{AR}(1)$ models to predict equal-weighted characteristic-based differences in quarterly return on assets (ROA) and industry-adjusted quarterly return on assets (IROA). For a given firm, ROA is calculated as Compustat item $i b q$ divided by item $a t q$. The spreads are calculated at monthly level based on all firms announcing their quarterly earnings in that particular month. To compute the IROA for a given firm, the average ROA of all firms being in the same Fama/French 48 industry and announcing in the same month is subtracted from ROA. The two rightmost columns of panel A present the results when prior one-month ROA-spreads between high and low beta firms, small and big firms, and value and growth firms are added as additional predictors. If any of these three characteristics-based spreads is to be predicted, only the two remaining spreads are additionally added. The additional coefficients are suppressed for brevity. In panel B the multivariate regressions are carried out separately to predict spreads for "quarter start" months (January, April, July, and October), "quarter mid" months (February, May, August, and November), and "quarter end" months (March, June, September, and December observations). For the computations ROA are winsorized at the 99.9\%-level. The sample period is from Q1:1972-Q4:2011. * indicates significance at the $10 \%$ level, ${ }^{* *}$ indicates significance at the $5 \%$ level and ${ }^{* * *}$ indicates significance at the $1 \%$ level. See appendix for details about characteristics.

\begin{tabular}{|c|c|c|c|c|c|c|}
\hline \multirow[t]{3}{*}{ Style } & \multicolumn{6}{|c|}{ Panel A: All months } \\
\hline & \multicolumn{2}{|c|}{ ROA Univariate } & \multicolumn{2}{|c|}{ IROA Univariate } & \multicolumn{2}{|c|}{ IROA Multivariate } \\
\hline & $\mathrm{b}$ & t-stat & $\mathrm{b}$ & t-stat & $\mathrm{b}$ & t-stat \\
\hline Firm Size & $0.5387^{* * *}$ & 12.491 & $0.6387^{* * *}$ & 16.706 & $0.4595^{* * *}$ & 7.992 \\
\hline Age & $0.6650^{* * *}$ & 11.966 & $0.5864^{* * *}$ & 9.581 & $0.3467^{* * *}$ & 4.436 \\
\hline Beta & $0.5281^{* * *}$ & 9.107 & $0.3709^{* * *}$ & 5.465 & $0.3200^{* * *}$ & 4.284 \\
\hline Residual Vol & $0.5804^{* * *}$ & 13.404 & $0.4951^{* * *}$ & 6.645 & $0.3891^{* * *}$ & 5.063 \\
\hline Asset Growth & $0.4107^{* * *}$ & 7.696 & $0.4428^{* * *}$ & 8.407 & $0.4011^{* * *}$ & 6.799 \\
\hline Accruals & $0.1421^{* *}$ & 2.401 & $0.1526^{* *}$ & 2.054 & 0.0803 & 1.216 \\
\hline Sales Growth & $0.2398^{* * *}$ & 4.625 & $0.3232^{* * *}$ & 5.799 & $0.3255^{* * *}$ & 5.711 \\
\hline Return on Assets & $0.6123^{* * *}$ & 14.125 & $0.7120^{* * *}$ & 19.497 & $0.7275^{* * *}$ & 12.715 \\
\hline Book-to-Market & $0.3148^{* * *}$ & 6.851 & $0.2103^{* * *}$ & 4.320 & $0.2108^{* * *}$ & 3.631 \\
\hline Dividend Yield & $0.4880^{* * *}$ & 11.484 & $0.2355^{* * *}$ & 5.618 & -0.0730 & -1.552 \\
\hline Investments/Assets & $0.2064^{* * *}$ & 3.654 & $0.1514^{* * *}$ & 3.258 & $0.1541^{* * *}$ & 3.313 \\
\hline Net Stock Issuance & $0.5683^{* * *}$ & 14.141 & $0.5254^{* * *}$ & 13.439 & $0.3176^{* * *}$ & 4.948 \\
\hline Price & $0.6501^{* * *}$ & 14.496 & $0.6884^{* * *}$ & 14.056 & $0.5839^{* * *}$ & 7.963 \\
\hline Momentum & $0.7218^{* * *}$ & 12.908 & $0.6932^{* * *}$ & 12.283 & $0.6290^{* * *}$ & 9.221 \\
\hline Distress & $0.5611^{* * *}$ & 8.014 & $0.6146^{* * *}$ & 8.888 & $0.5261^{* * *}$ & 4.809 \\
\hline \multirow[t]{3}{*}{ Style } & \multicolumn{6}{|c|}{ Panel B: Multivariate results separated by quarter-month } \\
\hline & \multicolumn{2}{|c|}{ Quarter start } & \multicolumn{2}{|c|}{ Quarter mid } & \multicolumn{2}{|c|}{ Quarter end } \\
\hline & $\mathrm{b}$ & t-stat & $\mathrm{b}$ & t-stat & $\mathrm{b}$ & t-stat \\
\hline Firm Size & $0.4451^{* * *}$ & 6.377 & $0.7012^{* * *}$ & 7.457 & $0.5299^{* * *}$ & 4.955 \\
\hline Age & $0.3536^{* * *}$ & 3.390 & $0.6437^{* * *}$ & 12.204 & $0.4143^{* * *}$ & 3.093 \\
\hline Beta & $0.2375^{* * *}$ & 4.302 & $0.4975^{* *}$ & 2.039 & $0.5965^{* * *}$ & 5.470 \\
\hline Residual Vol & $0.5477^{* * *}$ & 4.730 & $0.6306^{* * *}$ & 10.180 & $0.6655^{* * *}$ & 5.704 \\
\hline Asset Growth & $0.3204^{* * *}$ & 3.520 & $0.5964^{* * *}$ & 7.147 & $0.4220^{* * *}$ & 3.969 \\
\hline Accruals & -0.0336 & -0.332 & 0.0081 & 0.059 & $0.2341^{*}$ & 1.794 \\
\hline Sales Growth & $0.2398^{* *}$ & 2.471 & $0.6302^{* * *}$ & 7.939 & $0.3265^{* * *}$ & 3.969 \\
\hline Return on Assets & $0.5567^{* * *}$ & 7.167 & $0.8046^{* * *}$ & 9.406 & $1.0108^{* * *}$ & 14.089 \\
\hline Book-to-Market & $0.5262^{* * *}$ & 6.100 & $0.5394^{* * *}$ & 5.384 & $0.2662^{* * *}$ & 2.784 \\
\hline Dividend Yield & $0.2176^{* * *}$ & 3.314 & $0.1585^{* *}$ & 2.414 & $0.2546^{*}$ & 1.789 \\
\hline Investments/Assets & 0.0558 & 0.688 & $0.3706^{* * *}$ & 4.723 & $0.2104^{* *}$ & 2.261 \\
\hline Net Stock Issuance & $0.4003^{* * *}$ & 4.379 & $0.5849^{* * *}$ & 7.402 & $0.3903^{* *}$ & 2.200 \\
\hline Price & $0.4606^{* * *}$ & 5.096 & $0.7559^{* * *}$ & 15.341 & $0.6448^{* * *}$ & 3.817 \\
\hline Momentum & $0.6858^{* * *}$ & 9.304 & $0.8358^{* * *}$ & 9.790 & $0.6538^{* * *}$ & 7.427 \\
\hline Distress & $0.4686^{* * *}$ & 5.100 & $4^{0.6325^{* * *}}$ & 5.362 & $1.0073^{* * *}$ & 9.610 \\
\hline
\end{tabular}


Table 2: Time-series summary statistics: Style returns and earnings surprises

This table reports average style returns (equal-weighted and value-weighted), earnings surprises (EAR) and three-factor alphas. For descriptive purposes, the table also shows corresponding numbers for two post earnings announcement drift strategies (PEAD): "PEAD-EAR" is a long-short portfolio based on the firms' most recent earnings announcement return; "PEAD-SUE" is a long-short portfolio on the basis of the most recent quarterly standardized unexpected earnings (SUE). Following Chordia and Shivakumar (2006), SUE are calculated as current-quarter earnings less earnings four quarters ago, divided by the standard deviation of the earnings changes in the prior eight quarters (Compustat item $i b q$ ). The sample period is from Q1:1972 to Q4:2011 and all numbers are expressed in \% per month. For equal-weighted ("ew") style returns and earnings surprises, the portfolios are based on characteristic quintiles (top quintile minus bottom quintile). The computation of value-weighted ("vw") returns follows the procedure that Fama and French (1993) use for the construction of the $H M L$ factor (except for firm size for which the value-weighted return is simply the $S M B$ factor). The value-weighted returns are also shown separately for small and big stocks using the NYSE median firm market capitalization as breakpoint. Values that are significant at $10 \%$ or higher using a two-sided t-test are in bold. Construction details for each characteristic are in the appendix.

\begin{tabular}{lccccccc}
\hline \hline Style Variable & $\begin{array}{c}\text { EW } \\
\text { return }\end{array}$ & EAR & $\begin{array}{c}\text { VW } \\
\text { return }\end{array}$ & $\begin{array}{c}\text { VW } \\
\text { return } \\
\text { small }\end{array}$ & $\begin{array}{c}\text { VW } \\
\text { return } \\
\text { big }\end{array}$ & $\begin{array}{c}\text { 3f alpha } \\
\text { EW }\end{array}$ & $\begin{array}{c}\text { 3f alpha } \\
\text { VW }\end{array}$ \\
\hline Firm Size & $\mathbf{- 0 . 3 8}$ & $\mathbf{- 0 . 3 2}$ & -0.19 & N.A. & N.A. & -0.11 & N.A. \\
Age & 0.02 & -0.09 & 0.06 & 0.15 & -0.04 & 0.03 & 0.00 \\
Beta & -0.01 & $\mathbf{- 0 . 3 0}$ & -0.08 & -0.05 & -0.11 & $\mathbf{- 0 . 3 5}$ & $\mathbf{- 0 . 2 5}$ \\
Residual Vol & 0.23 & $\mathbf{0 . 1 7}$ & -0.01 & -0.11 & 0.09 & -0.08 & -0.12 \\
Asset Growth & $\mathbf{- 0 . 8 8}$ & $\mathbf{- 0 . 5 7}$ & $\mathbf{- 0 . 3 1}$ & $\mathbf{- 0 . 3 6}$ & $\mathbf{- 0 . 2 5}$ & $\mathbf{- 0 . 7 8}$ & $\mathbf{- 0 . 1 8}$ \\
Accruals & $\mathbf{- 0 . 3 3}$ & $\mathbf{- 0 . 2 4}$ & $\mathbf{- 0 . 2 7}$ & $\mathbf{- 0 . 2 9}$ & $\mathbf{- 0 . 2 4}$ & $\mathbf{- 0 . 2 8}$ & $\mathbf{- 0 . 2 6}$ \\
Sales Growth & $\mathbf{- 0 . 5 2}$ & $\mathbf{- 0 . 4 5}$ & -0.10 & $\mathbf{- 0 . 1 4}$ & -0.06 & $\mathbf{- 0 . 4 0}$ & 0.04 \\
Return on Assets & -0.20 & $\mathbf{- 0 . 3 9}$ & 0.06 & 0.08 & 0.04 & 0.00 & $\mathbf{0 . 3 1}$ \\
Book-to-Market & $\mathbf{0 . 9 5}$ & $\mathbf{0 . 8 8}$ & $\mathbf{0 . 3 7}$ & $\mathbf{0 . 5 1}$ & 0.24 & $\mathbf{0 . 6 3}$ & N.A. \\
Dividend Yield & -0.01 & -0.09 & 0.11 & 0.18 & 0.04 & 0.07 & 0.05 \\
Investments/Assets & $\mathbf{- 0 . 7 5}$ & $\mathbf{- 0 . 4 7}$ & $\mathbf{- 0 . 2 2}$ & $\mathbf{- 0 . 3 1}$ & -0.13 & $\mathbf{- 0 . 7 0}$ & $\mathbf{- 0 . 1 2}$ \\
Net Stock Issuance & $\mathbf{- 0 . 6 4}$ & $\mathbf{- 0 . 4 7}$ & $\mathbf{- 0 . 2 5}$ & $\mathbf{- 0 . 2 8}$ & $\mathbf{- 0 . 2 3}$ & $\mathbf{- 0 . 6 2}$ & $\mathbf{- 0 . 2 3}$ \\
Price & $\mathbf{- 0 . 2 8}$ & $\mathbf{- 0 . 1 8}$ & 0.03 & 0.10 & -0.03 & 0.07 & $\mathbf{0 . 4 1}$ \\
Momentum & $\mathbf{0 . 7 7}$ & $\mathbf{0 . 5 1}$ & $\mathbf{0 . 6 5}$ & $\mathbf{0 . 8 7}$ & $\mathbf{0 . 4 4}$ & $\mathbf{0 . 9 9}$ & $\mathbf{0 . 8 9}$ \\
Distress & $\mathbf{0 . 6 2}$ & -0.07 & $\mathbf{- 0 . 4 0}$ & $\mathbf{- 0 . 6 5}$ & -0.15 & $\mathbf{- 1 . 0 3}$ & $\mathbf{- 0 . 8 0}$ \\
\hline PEAD-EAR & $\mathbf{1 . 3 9}$ & N.A. & $\mathbf{0 . 6 9}$ & $\mathbf{1 . 0 1}$ & $\mathbf{0 . 3 7}$ & $\mathbf{1 . 5 6}$ & $\mathbf{0 . 7 5}$ \\
PEAD-SUE & $\mathbf{0 . 9 6}$ & N.A. & $\mathbf{0 . 4 5}$ & $\mathbf{0 . 6 7}$ & $\mathbf{0 . 2 2}$ & $\mathbf{1 . 0 2}$ & $\mathbf{0 . 5 4}$ \\
\hline \hline
\end{tabular}


Table 3: Forecasting style-based return spreads

This table presents the results of regressing equal-weighted characteristic-based long-short portfolio returns on prior one-month characteristic-based long-short earnings announcement returns (EAR). Panel A (B) shows results from univariate (multivariate) regressions; in the multivariate design the market excess return, and the Fama/French factors $H M L$ and $S M B$ are added as controls. Columns with heading "All" show results when portfolio returns are computed using all stocks in the extreme quintiles. Columns with heading "Announcers" ("Non-Announcers") show results when portfolio returns are computed using only the subset of stocks with (without) an earnings announcement in the previous month. The sample period is from Q1:1972-Q4:2011. * indicates significance at the $10 \%$ level, ${ }^{* *}$ indicates significance at the $5 \%$ level and ${ }^{* * *}$ indicates significance at the $1 \%$ level. Regression coefficients are standardized. All t-statistics are based on West and Newey (1987) standard errors with a lag of four months. See appendix for details about characteristics.

\begin{tabular}{|c|c|c|c|c|c|c|}
\hline \multirow[t]{3}{*}{ Style } & \multicolumn{6}{|c|}{ Panel A: Univariate Regression Results } \\
\hline & \multicolumn{2}{|c|}{ All } & \multicolumn{2}{|c|}{ Announcers } & \multicolumn{2}{|c|}{ Non-Announcers } \\
\hline & $\mathrm{b}$ & t-stat & $\mathrm{b}$ & t-stat & $\mathrm{b}$ & t-stat \\
\hline Firm Size & $0.1766^{* * *}$ & 3.998 & $0.1578^{* * *}$ & 3.357 & $0.1645^{* * *}$ & 3.753 \\
\hline Age & $0.1949^{* * *}$ & 4.138 & $0.1427^{* * *}$ & 2.670 & $0.1866^{* * *}$ & 3.925 \\
\hline Beta & $0.1552^{* * *}$ & 2.614 & $0.1793^{* * *}$ & 3.055 & $0.1447^{* *}$ & 2.529 \\
\hline Residual Vol & $0.2804^{* * *}$ & 4.721 & $0.2638^{* * *}$ & 4.361 & $0.2774^{* * *}$ & 4.723 \\
\hline Asset Growth & $0.1787^{* *}$ & 2.544 & $0.1975^{* * *}$ & 3.155 & $0.1599^{* *}$ & 2.284 \\
\hline Accruals & $0.0799^{*}$ & 1.665 & $0.1231^{* *}$ & 2.351 & 0.0422 & 0.920 \\
\hline Sales Growth & $0.1438^{* *}$ & 2.582 & $0.1066^{*}$ & 1.941 & $0.1277^{* *}$ & 2.335 \\
\hline Return on Assets & $0.1850^{* * *}$ & 4.237 & $0.1542^{* * *}$ & 3.109 & $0.1718^{* * *}$ & 4.060 \\
\hline Book-to-Market & $0.2314^{* * *}$ & 3.525 & $0.2115^{* * *}$ & 3.742 & $0.2279 * * *$ & 3.435 \\
\hline Dividend Yield & $0.1678^{* * *}$ & 3.127 & $0.1798^{* * *}$ & 3.569 & $0.1571 * * *$ & 2.946 \\
\hline Investments/Assets & 0.0715 & 1.204 & 0.0851 & 1.351 & 0.0382 & 0.671 \\
\hline Net Stock Issuance & $0.1333^{* * *}$ & 2.591 & 0.0833 & 1.452 & $0.1339 * * *$ & 2.708 \\
\hline Price & $0.1952^{* * *}$ & 3.349 & $0.1584^{* *}$ & 2.401 & $0.1851^{* * *}$ & 3.302 \\
\hline Momentum & 0.0610 & 0.760 & 0.0387 & 0.511 & 0.0529 & 0.672 \\
\hline Distress & $0.1488^{* * *}$ & 3.040 & $0.1547^{* * *}$ & 3.011 & $0.1342^{* * *}$ & 2.838 \\
\hline \multirow[t]{3}{*}{ Style } & \multicolumn{6}{|c|}{ Panel B: Multivariate Regression Results } \\
\hline & \multicolumn{2}{|c|}{ All } & \multicolumn{2}{|c|}{ Announcers } & \multicolumn{2}{|c|}{ Non-Announcers } \\
\hline & $\mathrm{b}$ & t-stat & $\mathrm{b}$ & t-stat & $\mathrm{b}$ & t-stat \\
\hline Firm Size & $0.1268^{* * *}$ & 4.284 & $0.1045^{* * *}$ & 3.031 & $0.1157^{* * *}$ & 4.021 \\
\hline Age & $0.1201^{* * *}$ & 3.624 & $0.0721^{*}$ & 1.728 & $0.1159^{* * *}$ & 3.337 \\
\hline Beta & 0.0348 & 0.972 & $0.0671^{*}$ & 1.681 & 0.0256 & 0.761 \\
\hline Residual Vol & $0.1438^{* * *}$ & 3.873 & $0.1234^{* * *}$ & 3.183 & $0.1418^{* * *}$ & 3.889 \\
\hline Asset Growth & $0.1554^{* *}$ & 2.351 & $0.1737^{* * *}$ & 2.922 & $0.1391^{* *}$ & 2.097 \\
\hline Accruals & 0.0678 & 1.364 & $0.1165^{* *}$ & 2.142 & 0.0323 & 0.688 \\
\hline Sales Growth & $0.1052^{* *}$ & 2.361 & 0.0787 & 1.562 & $0.0916^{* *}$ & 2.140 \\
\hline Return on Assets & $0.1548^{* * *}$ & 3.084 & $0.1272^{* *}$ & 2.418 & $0.1421^{* * *}$ & 2.957 \\
\hline Book-to-Market & $0.0745^{* *}$ & 2.045 & $0.0710^{*}$ & 1.795 & $0.0748^{*}$ & 1.928 \\
\hline Dividend Yield & $0.1059^{* * *}$ & 3.332 & $0.1223^{* * *}$ & 3.476 & $0.0956^{* * *}$ & 3.046 \\
\hline Investments/Assets & 0.0646 & 1.074 & 0.0843 & 1.293 & 0.0332 & 0.577 \\
\hline Net Stock Issuance & $0.1125^{* * *}$ & 2.907 & 0.0644 & 1.373 & $0.1142^{* * *}$ & 2.952 \\
\hline Price & $0.1402^{* * *}$ & 3.265 & $0.1056^{* *}$ & 2.020 & $0.1307^{* * *}$ & 3.217 \\
\hline Momentum & 0.0370 & 0.516 & 0.0131 & 0.195 & 0.0287 & 0.410 \\
\hline Distress & $0.1340 * *$ & 2.534 & $0.1430 * * *$ & 2.687 & $0.1184^{* *}$ & 2.189 \\
\hline
\end{tabular}


Table 4: Forecasting industry-adjusted return spreads

This table presents the results of regressing characteristic-based long-short portfolio returns on prior onemonth characteristic-based long-short earnings announcement returns (EAR). Portfolio returns are based on industry-adjusted stock returns; the Fama/French 48 industry classification system is used and SIC codes are from CRSP. Panel A (B) shows results from univariate (multivariate) regressions; in the multivariate design the market excess return, $H M L$, and $S M B$ are added as controls. Columns with heading "All" show results when portfolio returns are computed using all stocks in the extreme quintiles. Columns with heading "Announcers" ("Non-Announcers") show results when portfolio returns are computed using only the subset of stocks with (without) an earnings announcement in the previous month. The sample period is from Q1:1972-Q4:2011. * indicates significance at the $10 \%$ level, $* *$ indicates significance at the $5 \%$ level and ${ }^{* * *}$ indicates significance at the $1 \%$ level. Regression coefficients are standardized. All t-statistics are based on West and Newey (1987) standard errors with a lag of four months. See appendix for details about characteristics.

\begin{tabular}{|c|c|c|c|c|c|c|}
\hline \multirow[t]{3}{*}{ Style } & \multicolumn{6}{|c|}{ Panel A: Univariate Regression Results } \\
\hline & \multicolumn{2}{|c|}{ All } & \multicolumn{2}{|c|}{ Announcers } & \multicolumn{2}{|c|}{ Non-Announcers } \\
\hline & $\mathrm{b}$ & t-stat & $\mathrm{b}$ & t-stat & $\mathrm{b}$ & t-stat \\
\hline Firm Size & $0.1497^{* * *}$ & 3.341 & $0.1422^{* * *}$ & 2.973 & $0.1346^{* * *}$ & 3.054 \\
\hline Age & $0.1781^{* * *}$ & 3.824 & $0.1171^{* *}$ & 2.086 & $0.1692^{* * *}$ & 3.577 \\
\hline Beta & $0.1493^{* *}$ & 2.300 & $0.1530^{* *}$ & 2.212 & $0.1396^{* *}$ & 2.341 \\
\hline Residual Vol & $0.2803^{* * *}$ & 4.637 & $0.2252^{* * *}$ & 3.481 & $0.2762^{* * *}$ & 4.699 \\
\hline Asset Growth & $0.1768^{* *}$ & 2.574 & $0.2016^{* * *}$ & 3.257 & $0.1561^{* *}$ & 2.283 \\
\hline Accruals & 0.0320 & 0.640 & $0.0989^{*}$ & 1.781 & -0.0080 & -0.168 \\
\hline Sales Growth & $0.1780^{* * *}$ & 3.269 & $0.1233^{* *}$ & 2.427 & $0.1602^{* * *}$ & 2.955 \\
\hline Return on Assets & $0.1794^{* * *}$ & 3.935 & $0.1446^{* * *}$ & 2.768 & $0.1719^{* * *}$ & 3.915 \\
\hline Book-to-Market & $0.1939^{* * *}$ & 3.271 & $0.1681^{* * *}$ & 3.279 & $0.1833^{* * *}$ & 2.911 \\
\hline Dividend Yield & $0.1709^{* * *}$ & 3.340 & $0.1460^{* * *}$ & 2.893 & $0.1520^{* * *}$ & 3.059 \\
\hline Investments/Assets & 0.0815 & 1.381 & $0.1079 *$ & 1.675 & 0.0465 & 0.836 \\
\hline Net Stock Issuance & $0.1324^{* * *}$ & 2.723 & 0.0730 & 1.395 & $0.1284^{* * *}$ & 2.820 \\
\hline Price & $0.1877^{* * *}$ & 3.179 & $0.1544^{* *}$ & 2.297 & $0.1766^{* * *}$ & 3.146 \\
\hline Momentum & 0.0674 & 0.757 & 0.0337 & 0.402 & 0.0595 & 0.694 \\
\hline Distress & $0.1664 * * *$ & 3.046 & $0.1645^{* * *}$ & 3.075 & $0.1559^{* * *}$ & 2.871 \\
\hline \multirow[t]{3}{*}{ Style } & \multicolumn{6}{|c|}{ Panel B: Multivariate Regression Results } \\
\hline & \multicolumn{2}{|c|}{ All } & \multicolumn{2}{|c|}{ Announcers } & \multicolumn{2}{|c|}{ Non-Announcers } \\
\hline & $\mathrm{b}$ & t-stat & $\mathrm{b}$ & t-stat & $\mathrm{b}$ & t-stat \\
\hline Firm Size & $0.1016^{* * *}$ & 3.216 & $0.0911^{* *}$ & 2.382 & $0.0876^{* * *}$ & 2.881 \\
\hline Age & $0.0987^{* * *}$ & 2.885 & 0.0454 & 0.975 & $0.0959^{* * *}$ & 2.640 \\
\hline Beta & 0.0226 & 0.580 & 0.0454 & 0.908 & 0.0159 & 0.466 \\
\hline Residual Vol & $0.1274^{* * *}$ & 3.306 & 0.0740 & 1.544 & $0.1273^{* * *}$ & 3.510 \\
\hline Asset Growth & $0.1535^{* *}$ & 2.426 & $0.1795^{* * *}$ & 3.050 & $0.1354^{* *}$ & 2.136 \\
\hline Accruals & 0.0230 & 0.472 & 0.0938 & 1.643 & -0.0144 & -0.311 \\
\hline Sales Growth & $0.1438^{* * *}$ & 3.172 & $0.1008^{* *}$ & 2.054 & $0.1284^{* * *}$ & 2.927 \\
\hline Return on Assets & $0.1555^{* * *}$ & 3.022 & $0.1234^{* *}$ & 2.236 & $0.1469^{* * *}$ & 2.975 \\
\hline Book-to-Market & 0.0672 & 1.501 & 0.0652 & 1.394 & 0.0603 & 1.202 \\
\hline Dividend Yield & $0.1176^{* * *}$ & 2.749 & $0.1046^{* *}$ & 2.117 & $0.0998^{* *}$ & 2.397 \\
\hline Investments/Assets & 0.0708 & 1.191 & 0.1040 & 1.550 & 0.0388 & 0.696 \\
\hline Net Stock Issuance & $0.1055^{* * *}$ & 3.347 & 0.0529 & 1.196 & $0.1035^{* * *}$ & 3.251 \\
\hline Price & $0.1334^{* * *}$ & 2.977 & $0.1028^{*}$ & 1.870 & $0.1229^{* * *}$ & 2.957 \\
\hline Momentum & 0.0380 & 0.487 & 0.0039 & 0.052 & 0.0302 & 0.406 \\
\hline Distress & $0.1514^{* * *}$ & 2.602 & $0.1516^{* * *}$ & 2.817 & $0.1403^{* *}$ & 2.334 \\
\hline
\end{tabular}


Table 5: Forecasting style-based return spreads: Results by quarter-month

This table presents the results of regressing equal-weighted characteristic-based long-short portfolio returns on prior one-month characteristic-based long-short earnings announcement returns (EAR). Panel A (B) shows results from univariate (multivariate) regressions; in the multivariate design the market excess return, and the Fama/French factors $H M L$ and $S M B$ are added as controls. Columns 1 and 2 ("Quarter start") refer to forecasts for style-based return spreads in January, April, July, and October; Columns 3 and 4 ("Quarter mid") to forecasts for spreads in February, May, August, and November; and Columns 5 and 6 ("Quarter end") to forecasts for March, June, September, and December observations. The sample period is from Q1:1972-Q4:2011. * indicates significance at the $10 \%$ level, ${ }^{* *}$ indicates significance at the $5 \%$ level and $* * *$ indicates significance at the $1 \%$ level. Regression coefficients are standardized. All t-statistics are based on West and Newey (1987) standard errors with a lag of one quarter. See appendix for details about characteristics.

\begin{tabular}{|c|c|c|c|c|c|c|}
\hline \multirow[t]{3}{*}{ Style } & \multicolumn{6}{|c|}{ Panel A: Univariate regression results } \\
\hline & \multicolumn{2}{|c|}{ Quarter Start } & \multicolumn{2}{|c|}{ Quarter Mid } & \multicolumn{2}{|c|}{ Quarter End } \\
\hline & $\mathrm{b}$ & t-stat & $\mathrm{b}$ & t-stat & $\mathrm{b}$ & t-stat \\
\hline Firm Size & $0.1478^{*}$ & 1.959 & $0.2490^{* * *}$ & 2.686 & 0.1439 & 1.049 \\
\hline Age & $0.1491^{*}$ & 1.774 & $0.2879^{* * *}$ & 4.454 & $0.2476^{* *}$ & 2.316 \\
\hline Beta & 0.0425 & 0.442 & $0.2388^{* * *}$ & 2.633 & $0.2669^{* *}$ & 2.445 \\
\hline Residual Vol & $0.1969 * *$ & 2.149 & $0.3123^{* * *}$ & 3.431 & $0.4003^{* * *}$ & 4.788 \\
\hline Asset Growth & 0.1413 & 1.268 & $0.3284^{* * *}$ & 3.042 & 0.0963 & 1.216 \\
\hline Accruals & 0.0209 & 0.281 & $0.2923^{* * *}$ & 3.953 & -0.0014 & -0.017 \\
\hline Sales Growth & 0.1452 & 1.508 & $0.1891^{* *}$ & 2.577 & $0.1434^{*}$ & 1.871 \\
\hline Return on Assets & $0.1387^{*}$ & 1.918 & $0.2153^{* * *}$ & 2.763 & $0.2594^{* * *}$ & 2.783 \\
\hline Book-to-Market & $0.1751^{*}$ & 1.732 & $0.3261^{* * *}$ & 3.406 & $0.1894^{* *}$ & 1.991 \\
\hline Dividend Yield & 0.0095 & 0.104 & $0.2964^{* * *}$ & 4.244 & $0.3264^{* * *}$ & 3.444 \\
\hline Investments/Assets & 0.0148 & 0.145 & $0.1841^{* *}$ & 2.227 & 0.0854 & 1.115 \\
\hline Net Stock Issuance & 0.0878 & 1.084 & $0.2138^{* * *}$ & 2.976 & $0.1457^{*}$ & 1.666 \\
\hline Price & 0.0818 & 0.896 & $0.3324^{* * *}$ & 4.063 & $0.2941^{* * *}$ & 2.810 \\
\hline Momentum & -0.0563 & -0.427 & $0.2523^{* *}$ & 2.209 & $0.1686^{*}$ & 1.752 \\
\hline Distress & -0.0064 & -0.083 & $0.3637^{* * *}$ & 3.688 & $0.2980^{* * *}$ & 3.376 \\
\hline \multirow[t]{3}{*}{ Style } & \multicolumn{6}{|c|}{ Panel B: Multivariate regression results } \\
\hline & \multicolumn{2}{|c|}{ Quarter Start } & \multicolumn{2}{|c|}{ Quarter Mid } & \multicolumn{2}{|c|}{ Quarter End } \\
\hline & $\mathrm{b}$ & t-stat & $\mathrm{b}$ & t-stat & $\mathrm{b}$ & t-stat \\
\hline Firm Size & 0.0046 & 0.095 & $0.1571^{* * *}$ & 3.508 & $0.2465^{* * *}$ & 5.333 \\
\hline Age & 0.0459 & 0.780 & $0.1557^{* * *}$ & 3.167 & $0.2243^{* * *}$ & 2.813 \\
\hline Beta & -0.0575 & -1.467 & $0.1169^{*}$ & 1.806 & $0.1149^{* *}$ & 2.301 \\
\hline Residual Vol & 0.0362 & 0.682 & $0.1678^{* * *}$ & 3.450 & $0.2635^{* * *}$ & 4.490 \\
\hline Asset Growth & 0.1052 & 1.119 & $0.2399 * * *$ & 2.829 & $0.1491^{* *}$ & 2.148 \\
\hline Accruals & 0.0063 & 0.088 & $0.2638^{* * *}$ & 3.541 & -0.0024 & -0.028 \\
\hline Sales Growth & 0.0966 & 1.316 & $0.1431^{* *}$ & 2.081 & $0.1442^{* *}$ & 2.252 \\
\hline Return on Assets & 0.0956 & 1.502 & $0.1443^{*}$ & 1.701 & $0.2767^{* * *}$ & 3.026 \\
\hline Book-to-Market & 0.0801 & 1.219 & 0.0783 & 1.425 & 0.0362 & 0.719 \\
\hline Dividend Yield & -0.0045 & -0.094 & $0.1689^{* * *}$ & 3.801 & $0.2449 * * *$ & 4.258 \\
\hline Investments/Assets & 0.0140 & 0.144 & 0.1182 & 1.574 & 0.1141 & 1.509 \\
\hline Net Stock Issuance & $0.1317^{* *}$ & 1.993 & 0.0862 & 1.384 & $0.1196^{*}$ & 1.805 \\
\hline Price & -0.0164 & -0.323 & $0.1939^{* * *}$ & 3.721 & $0.3265^{* * *}$ & 4.080 \\
\hline Momentum & -0.0845 & -0.715 & $0.1938^{* *}$ & 2.019 & $0.1924^{* *}$ & 2.105 \\
\hline Distress & 0.0257 & 0.305 & $0.2455^{* * *}$ & 2.746 & $0.2831^{* * *}$ & 3.102 \\
\hline
\end{tabular}


Table 6: Forecasting value-weighted style-based return spreads

This table presents the results of regressing value-weighted characteristic-based long-short portfolio returns on prior one-month characteristic-based long-short earnings announcement returns (EAR). The computation of value-weighted returns follows the procedure that Fama and French (1993) use for the construction of the $H M L$ factor (except for firm size for which the value-weighted return is simply the $S M B$ factor). The baseline value-weighted characteristic return spread is the average of the value-weighted return difference for small stocks and for large stocks (below and above the NYSE median market value). Results for this average are reported in columns 1 and 2 (heading "Average"). The next columns display the coefficients and t-statistics for predicting the small and large stock value-weighted spread separately. Panel A (B) shows results from univariate (multivariate) regressions; in the multivariate design the market excess return, and the Fama/French factors $H M L$ and $S M B$ are added as controls. $S M B(H M L)$ is excluded as explanatory variable when $S M B(H M L)$ is the to-be-predicted variable. The sample period is from Q1:1972-Q4:2011. Regression coefficients are standardized. * indicates significance at the $10 \%$ level, ${ }^{* *}$ indicates significance at the $5 \%$ level and $* * *$ indicates significance at the $1 \%$ level. All t-statistics are based on West and Newey (1987) standard errors with a lag of four months. See appendix for details about characteristics.

\begin{tabular}{|c|c|c|c|c|c|c|}
\hline \multirow[t]{3}{*}{ Style } & \multicolumn{6}{|c|}{ Panel A: Univariate Regression Results } \\
\hline & \multicolumn{2}{|c|}{ All } & \multicolumn{2}{|c|}{ Small } & \multicolumn{2}{|c|}{ Large } \\
\hline & $\mathrm{b}$ & t-stat & $\mathrm{b}$ & t-stat & $\mathrm{b}$ & t-stat \\
\hline Firm Size & 0.0428 & 0.991 & N.A. & N.A. & N.A. & N.A. \\
\hline Age & 0.0684 & 1.633 & $0.0667^{*}$ & 1.727 & 0.0598 & 1.297 \\
\hline Beta & $0.1574^{* * *}$ & 2.943 & $0.1594^{* * *}$ & 3.043 & $0.1426^{* * *}$ & 2.670 \\
\hline Residual Vol & $0.1892^{* * *}$ & 3.478 & $0.2223^{* * *}$ & 3.951 & $0.1430^{* * *}$ & 2.723 \\
\hline Asset Growth & $0.0873^{* *}$ & 1.972 & $0.1579^{* * *}$ & 2.986 & 0.0113 & 0.275 \\
\hline Accruals & $0.0871^{*}$ & 1.951 & $0.0867^{*}$ & 1.915 & 0.0648 & 1.317 \\
\hline Sales Growth & 0.0349 & 0.648 & $0.1082^{*}$ & 1.904 & -0.0165 & -0.324 \\
\hline Return on Assets & $0.1141^{* *}$ & 2.233 & $0.1082^{* *}$ & 2.366 & 0.0833 & 1.539 \\
\hline Book-to-Market & $0.1799 * * *$ & 3.726 & $0.2228^{* * *}$ & 4.504 & $0.0963^{*}$ & 1.809 \\
\hline Dividend Yield & $0.1077^{* *}$ & 2.044 & $0.1267 * *$ & 2.259 & $0.0815^{*}$ & 1.682 \\
\hline Investments/Assets & 0.0723 & 1.479 & 0.0750 & 1.538 & 0.0484 & 0.927 \\
\hline Net Stock Issuance & $0.0888^{*}$ & 1.708 & 0.0833 & 1.626 & 0.0701 & 1.391 \\
\hline Price & $0.1296^{* *}$ & 2.260 & $0.1780^{* * *}$ & 3.035 & 0.0738 & 1.356 \\
\hline Momentum & 0.0686 & 0.886 & 0.0651 & 0.787 & 0.0653 & 0.935 \\
\hline Distress & 0.0515 & 0.969 & $0.1188^{* *}$ & 2.094 & -0.0055 & -0.107 \\
\hline \multirow[t]{3}{*}{ Style } & \multicolumn{6}{|c|}{ Panel B: Multivariate Regression Results } \\
\hline & \multicolumn{2}{|c|}{ All } & \multicolumn{2}{|c|}{ Small } & \multicolumn{2}{|c|}{ Large } \\
\hline & $\mathrm{b}$ & t-stat & $\mathrm{b}$ & t-stat & $\mathrm{b}$ & t-stat \\
\hline Firm Size & 0.0461 & 1.115 & N.A. & N.A. & N.A. & N.A. \\
\hline Age & 0.0104 & 0.386 & 0.0151 & 0.511 & 0.0048 & 0.143 \\
\hline Beta & 0.0460 & 1.422 & 0.0455 & 1.453 & 0.0428 & 1.182 \\
\hline Residual Vol & $0.0734^{* * *}$ & 2.637 & $0.0929^{* * *}$ & 3.360 & 0.0492 & 1.497 \\
\hline Asset Growth & 0.0253 & 0.731 & $0.1268^{* * *}$ & 2.644 & -0.0529 & -1.511 \\
\hline Accruals & 0.0735 & 1.644 & 0.0713 & 1.559 & 0.0557 & 1.151 \\
\hline Sales Growth & -0.0231 & -0.543 & 0.0569 & 1.308 & -0.0684 & -1.494 \\
\hline Return on Assets & 0.0406 & 1.037 & $0.0786^{*}$ & 1.688 & -0.0016 & -0.044 \\
\hline Book-to-Market & $0.1662^{* * *}$ & 3.494 & $0.1979 * * *$ & 4.451 & $0.0970^{*}$ & 1.827 \\
\hline Dividend Yield & $0.0409^{*}$ & 1.883 & $0.0609 * *$ & 2.320 & 0.0200 & 0.860 \\
\hline Investments/Assets & 0.0407 & 0.927 & 0.0602 & 1.152 & 0.0142 & 0.346 \\
\hline Net Stock Issuance & $0.0697^{*}$ & 1.712 & 0.0634 & 1.601 & 0.0573 & 1.303 \\
\hline Price & $0.0717^{*}$ & 1.940 & $0.1293^{* * *}$ & 3.067 & 0.0173 & 0.483 \\
\hline Momentum & 0.0454 & 0.670 & 0.0416 & 0.576 & 0.0445 & 0.714 \\
\hline Distress & 0.0382 & 1.044 & $0.1048^{* *}$ & 2.259 & -0.0165 & -0.480 \\
\hline
\end{tabular}


Table 7: Pooled panel regressions explaining individual stock returns

This table presents the results of regressing individual stock returns on prior one-month style-based earnings announcement returns (EAR) and a list of control variables. Controls include firm size, book-to-market, stock momentum, prior one-month returns (all measured as categorical variables ranging from one (lowest quintile) to five (highest quintile)), the most recent stock-specific earnings announcement return (EAR), the most recent standardized unexpected quarterly earnings (SUE), and average industry-based earnings surprises based on all firms that announced in the most recent month (Ind. EAR). SUE are winsorized at 99.9\%. Panel A shows the results when only the controls are used as explanatory variables. In panel B, style-based EAR are added to the baseline regression separately for each style. In panel C style-based EAR and prior one-month style-based returns are added to the baseline regression, again separately for each style. Finally, regression results in panel D are based on a specification that includes all style-based EAR simultaneously. Control variables are suppressed for brevity in panels B to D, but have qualitatively similar coefficients as in panel A. All specifications also include month dummies and the t-statistics (in parentheses) are based on standard errors clustered by month. Abbreviations are as follows: Book-to-market (BM), momentum (Mom), asset growth (AG), accruals (ACC), sales growth (SG), return on assets (ROA), dividend yield (DY), investment over assets (IA), and net stock issuance (NS). The sample period is from Q1:1972-Q4:2011. * indicates significance at the $10 \%$ level, ** indicates significance at the 5\% level and ${ }^{* * *}$ indicates significance at the $1 \%$ level.

\begin{tabular}{|c|c|c|c|c|c|c|c|c|c|c|c|c|c|c|}
\hline \multicolumn{15}{|c|}{ Panel A: Regression without style EAR } \\
\hline Size & BM & Mom & PR1M & EAR stock & SUE stock & Ind. EAR & & & & & & & & \\
\hline-0.0007 & $0.0017^{* * *}$ & $0.0014^{* *}$ & $-0.0036^{* * *}$ & $0.0387^{* * *}$ & $0.0012^{* * *}$ & $0.1065^{* * *}$ & & & & & & & & \\
\hline$(-1.012)$ & $(3.509)$ & $(2.132)$ & $(-6.694)$ & $(12.324)$ & $(6.393)$ & $(2.770)$ & & & & & & & & \\
\hline \multicolumn{15}{|c|}{ Panel B: Style-based EAR added as regressor - separate regression for each style } \\
\hline Size & Age & Beta & Res Vol & $\mathrm{AG}$ & $\mathrm{ACC}$ & SG & ROA & $\mathrm{BM}$ & DY & IA & NS & Price & Mom & Distress \\
\hline $0.304^{* * *}$ & $0.202^{* *}$ & 0.163 & $0.677^{* * *}$ & $0.343^{* * *}$ & $0.132^{* * *}$ & $0.288^{* * *}$ & $0.315^{* * *}$ & $0.318^{* * *}$ & $0.423^{* * *}$ & $0.136^{* * *}$ & $0.173^{* * *}$ & $0.630^{* * *}$ & 0.229 & $0.344^{* *}$ \\
\hline$(2.996)$ & $(2.403)$ & $(1.477)$ & $(4.143)$ & $(4.966)$ & $(3.558)$ & $(4.648)$ & $(3.413)$ & $(4.263)$ & $(2.840)$ & $(3.535)$ & $(2.792)$ & $(5.069)$ & $(1.376)$ & $(2.332)$ \\
\hline \multicolumn{15}{|c|}{ Panel C: Style-based EAR (results in the first two rows) and past-style returns (results in the second two rows) added as regressor - separate regression for each style } \\
\hline Size & Age & Beta & Res Vol & AG & ACC & SG & ROA & $\mathrm{BM}$ & DY & IA & $\mathrm{NS}$ & Price & Mom & Distress \\
\hline $0.305^{* * *}$ & $0.141^{*}$ & 0.062 & $0.516^{* * *}$ & $0.246^{* * *}$ & $0.111^{* * *}$ & $0.214^{* * *}$ & $0.231^{* * *}$ & $0.273^{* * *}$ & $0.240^{* *}$ & 0.063 & $0.117^{*}$ & $0.605^{* * *}$ & $0.203^{*}$ & $0.334^{* * *}$ \\
\hline$(3.417)$ & $(1.806)$ & $(0.626)$ & (3.693) & $(3.599)$ & $(2.630)$ & $(3.286)$ & $(2.883)$ & $(3.059)$ & $(2.019)$ & $(1.471)$ & (1.809) & $(4.251)$ & $(1.657)$ & $(2.803)$ \\
\hline-0.001 & 0.121 & 0.125 & 0.101 & $0.135^{*}$ & 0.073 & $0.135^{* *}$ & 0.111 & 0.074 & 0.143 & $0.180^{* * *}$ & 0.111 & 0.019 & 0.019 & 0.010 \\
\hline$(-0.008)$ & $(1.170)$ & $(1.537)$ & (0.949) & $(1.814)$ & (1.166) & $(2.150)$ & $(1.157)$ & $(0.885)$ & $(1.451)$ & $(4.442)$ & $(1.421)$ & $(0.206)$ & $(0.237)$ & $(0.094)$ \\
\hline \multicolumn{15}{|c|}{ Panel D: Style-based EAR simultaneously added as regressor } \\
\hline Size & Age & Beta & Res Vol & AG & $\mathrm{ACC}$ & SG & ROA & $\mathrm{BM}$ & DY & IA & NS & Price & Mom & Distress \\
\hline 0.023 & $0.132^{*}$ & 0.060 & $0.446^{* * *}$ & $0.158^{* * *}$ & $0.085^{* *}$ & $0.161^{* * *}$ & $0.177^{* *}$ & $0.159^{* *}$ & 0.141 & 0.034 & $0.108^{*}$ & $0.362^{* * *}$ & 0.083 & $0.224^{*}$ \\
\hline$(0.280)$ & $(1.823)$ & $(0.672)$ & $(3.754)$ & $(3.088)$ & $(2.402)$ & $(2.986)$ & $(2.248)$ & $(2.367)$ & (1.449) & $(0.863)$ & (1.926) & $(3.516)$ & $(0.588)$ & (1.690) \\
\hline
\end{tabular}


Table 8: Abnormal returns to a long-short SESM-based trading strategy

This table shows calendar time abnormal returns to a trading strategy that ranks stocks in ascending order of their style-based earnings surprise measure (SESM) at the beginning of every month and goes long in stocks with the highest SESM and short in stocks with the lowest SESM. Equal-weighted portfolio returns in panel A are based on quintiles (top quintile minus bottom quintile). The computation of value-weighted returns in panel B follows the procedure that Fama and French (1993) use for the construction of the $H M L$ factor. The value-weighted returns are also shown separately for small and big stocks in panel $\mathrm{C}$ and $\mathrm{D}$ using the NYSE median firm market capitalization as breakpoint. Reported alphas are the intercepts from a regression of long-short SESM-strategy returns on a set of explanatory variables. The three-factor regression includes the market excess return, and the Fama/French factors $H M L$ and $S M B$ as controls. Other factors (Fama/French momentum factor, Fama/French short-term reversal factor, and Pastor and Stambaugh (2003) liquidity factor) are sequentially added in the four-, five-, and six-factor regressions. The first (second) seven-factor regression adds the value-weighted return of a traditional PEAD-strategy based on earnings announcement returns (standardized unexpected quarterly earnings). The 20-factor alpha model includes the value-weighted returns of all 15 characteristic-based trading strategies (see table 2), plus the market excess return, the Fama/French short-term reversal factor, the Pastor and Stambaugh (2003) liquidity factor, and both PEAD-strategy returns. Regression coefficients for the explanatory variables can be found in the online appendix. The sample period is from Q1:1972-Q4:2010 for all models that include the Pastor and Stambaugh (2003) liquidity factor and otherwise from Q1:1972-Q4:2011. * indicates significance at the 10\% level, ** indicates significance at the $5 \%$ level and $* * *$ indicates significance at the $1 \%$ level. All t-statistics are based on West and Newey (1987) standard errors with a lag of four months.

\begin{tabular}{|c|c|c|c|c|c|c|c|c|}
\hline \multicolumn{9}{|c|}{ Panel A: Equal portfolio weights } \\
\hline $\begin{array}{l}\text { Excess } \\
\text { return }\end{array}$ & $\begin{array}{c}\text { CAPM } \\
\text { alpha }\end{array}$ & $\begin{array}{c}\text { 3-factor } \\
\text { alpha }\end{array}$ & $\begin{array}{c}\text { 4-factor } \\
\text { alpha }\end{array}$ & $\begin{array}{c}\text { 5-factor } \\
\text { alpha }\end{array}$ & $\begin{array}{c}\text { 6-factor } \\
\text { alpha }\end{array}$ & $\begin{array}{c}\text { 7-factor } \\
\text { alpha (1) }\end{array}$ & $\begin{array}{c}\text { 7-factor } \\
\text { alpha (2) }\end{array}$ & $\begin{array}{c}20 \text {-factor } \\
\text { alpha }\end{array}$ \\
\hline $\begin{array}{c}0.0184^{* * * *} \\
(7.464)\end{array}$ & $\begin{array}{c}0.0191^{* * *} \\
(7.647)\end{array}$ & $\begin{array}{c}0.0179^{* * *} \\
(6.834)\end{array}$ & $\begin{array}{c}0.0162^{* * *} \\
(5.321)\end{array}$ & $\begin{array}{c}0.0206^{* * *} \\
(7.387)\end{array}$ & $\begin{array}{c}0.0217^{* * *} \\
(7.665)\end{array}$ & $\begin{array}{c}0.0209^{* * *} \\
(7.015)\end{array}$ & $\begin{array}{c}0.0205^{* * *} \\
(5.570)\end{array}$ & $\begin{array}{c}0.0207^{* * *} \\
(6.105)\end{array}$ \\
\hline \multicolumn{9}{|c|}{ Panel B: Value-based portfolio weights } \\
\hline $\begin{array}{l}\text { Excess } \\
\text { return }\end{array}$ & $\begin{array}{l}\text { CAPM } \\
\text { alpha }\end{array}$ & $\begin{array}{c}\text { 3-factor } \\
\text { alpha }\end{array}$ & $\begin{array}{c}\text { 4-factor } \\
\text { alpha }\end{array}$ & $\begin{array}{c}\text { 5-factor } \\
\text { alpha }\end{array}$ & $\begin{array}{c}\text { 6-factor } \\
\text { alpha }\end{array}$ & $\begin{array}{c}\text { 7-factor } \\
\text { alpha (1) }\end{array}$ & $\begin{array}{c}\text { 7-factor } \\
\text { alpha (2) }\end{array}$ & $\begin{array}{c}20 \text {-factor } \\
\text { alpha }\end{array}$ \\
\hline $\begin{array}{c}0.0119 * * * \\
(5.992)\end{array}$ & $\begin{array}{c}0.0124^{* * *} \\
(6.403)\end{array}$ & $\begin{array}{c}0.0114^{* * *} \\
(5.453)\end{array}$ & $\begin{array}{c}0.0109 * * * \\
(5.379)\end{array}$ & $\begin{array}{c}0.0150^{* * *} \\
(6.551)\end{array}$ & $\begin{array}{c}0.0155^{* * *} \\
(6.605)\end{array}$ & $\begin{array}{c}0.0141^{* * *} \\
(5.753)\end{array}$ & $\begin{array}{c}0.0155^{* * *} \\
(5.090)\end{array}$ & $\begin{array}{c}0.0138^{* * *} \\
(5.538)\end{array}$ \\
\hline \multicolumn{9}{|c|}{ Panel C: Value-based portfolio weights, small firms } \\
\hline $\begin{array}{l}\text { Excess } \\
\text { return }\end{array}$ & $\begin{array}{c}\text { CAPM } \\
\text { alpha }\end{array}$ & $\begin{array}{c}\text { 3-factor } \\
\text { alpha }\end{array}$ & $\begin{array}{c}\text { 4-factor } \\
\text { alpha }\end{array}$ & $\begin{array}{c}\text { 5-factor } \\
\text { alpha }\end{array}$ & $\begin{array}{c}\text { 6-factor } \\
\text { alpha }\end{array}$ & $\begin{array}{c}\text { 7-factor } \\
\text { alpha (1) }\end{array}$ & $\begin{array}{c}\text { 7-factor } \\
\text { alpha (2) }\end{array}$ & $\begin{array}{c}20 \text {-factor } \\
\text { alpha }\end{array}$ \\
\hline $\begin{array}{c}0.0132^{* * *} \\
(6.569)\end{array}$ & $\begin{array}{c}0.0139^{* * *} \\
(6.960)\end{array}$ & $\begin{array}{c}0.0131^{* * *} \\
(5.982)\end{array}$ & $\begin{array}{c}0.0126^{* * *} \\
(6.116)\end{array}$ & $\begin{array}{c}0.0164^{* * *} \\
(7.046)\end{array}$ & $\begin{array}{c}0.0171^{* * *} \\
(7.213)\end{array}$ & $\begin{array}{c}0.0160^{* * *} \\
(6.527)\end{array}$ & $\begin{array}{c}0.0175^{* * *} \\
(5.600)\end{array}$ & $\begin{array}{c}0.0164^{* * *} \\
(6.072)\end{array}$ \\
\hline \multicolumn{9}{|c|}{ Panel C: Value-based portfolio weights, large firms } \\
\hline $\begin{array}{l}\text { Excess } \\
\text { return }\end{array}$ & $\begin{array}{c}\text { CAPM } \\
\text { alpha }\end{array}$ & $\begin{array}{c}\text { 3-factor } \\
\text { alpha }\end{array}$ & $\begin{array}{c}\text { 4-factor } \\
\text { alpha }\end{array}$ & $\begin{array}{c}\text { 5-factor } \\
\text { alpha }\end{array}$ & $\begin{array}{c}\text { 6-factor } \\
\text { alpha }\end{array}$ & $\begin{array}{c}7 \text {-factor } \\
\text { alpha (1) }\end{array}$ & $\begin{array}{c}7 \text {-factor } \\
\text { alpha (2) }\end{array}$ & $\begin{array}{c}\text { 20-factor } \\
\text { alpha }\end{array}$ \\
\hline $\begin{array}{c}0.0106^{* * *} \\
(4.682)\end{array}$ & $\begin{array}{c}0.0110^{* * *} \\
(4.973)\end{array}$ & $\begin{array}{c}0.0099^{* * *} \\
(4.289)\end{array}$ & $\begin{array}{c}0.0093^{* * *} \\
(3.995)\end{array}$ & $\begin{array}{c}0.0136^{* * *} \\
(5.249)\end{array}$ & $\begin{array}{c}0.0139 \text { *** } \\
(5.201)\end{array}$ & $\begin{array}{c}0.0123^{* * *} \\
(4.433)\end{array}$ & $\begin{array}{c}0.0137^{* * *} \\
(4.184)\end{array}$ & $\begin{array}{c}0.0112^{* * *} \\
(4.197)\end{array}$ \\
\hline
\end{tabular}


Table 9: Fama/MacBeth regressions: Profits to an SESM-strategy and relation to firm characteristics

This table reports the results of Fama/MacBeth regressions to forecast individual stocks returns. The independent variables of interest are the style-based earnings surprise measure (SESM) and number of interaction terms with this variable. All interaction terms are calculated by multiplying SESM with an indicator variable being 0 (1) if the value for the particular firm is below (above) the sample median in a given month. MktCap is the market capitalization of the firm at the end of June in every calendar year. $R E S-A C$ is residual analyst coverage, $R E S-I O$ is residual institutional ownership, $R E S-B A S$ is the residual bid-ask-spread estimator of Corwin and Schultz (2011), and RES-ILQ is the residual illiquidity measure of Amihud (2002) which is measured as the average daily absolute price change per dollar of daily trading volume in the recent month. I use the primary estimator of Corwin and Schultz (2011) where negative estimates are set to zero. Residuals are obtained by running separate monthly cross-sectional regressions on $\ln$ (firm size), and dummies for NYSE size deciles. Analyst coverage is set to $\ln (1+$ number of estimates $)$ in these regressions. Control variables (added to all regression models) include firm size, book-to-market, momentum, prior 1 month return, most recent earnings announcement return, most recent standardized unexpected quarterly earnings, and the most recent average earnings announcement return of same-industry stocks. The definition of industries follows the 48-industry classification system of Fama and French (1997). The $R 2$ is the average from the monthly cross-sectional regressions. The sample period is from from Q1:1972-Q4:2011, but data on analyst coverage and institutional ownership are available only from 1980 to $2011 .{ }^{*}$ indicates significance at the $10 \%$ level, ** indicates significance at the $5 \%$ level and $* * *$ indicates significance at the $1 \%$ level. All t-statistics (in parentheses) are based on the time-series mean and standard deviation for each coefficient, and adjusted for heteroskedasticity and autocorrelation using West and Newey (1987) with a lag of four months.

\begin{tabular}{|c|c|c|c|c|c|c|c|}
\hline Model & (1) & (2) & (3) & (4) & (5) & (6) & (7) \\
\hline SESM & $\begin{array}{c}1.885^{* * *} \\
(7.790)\end{array}$ & $\begin{array}{c}2.039 * * * \\
(8.041)\end{array}$ & $\begin{array}{c}1.922^{* * *} \\
(6.780)\end{array}$ & $\begin{array}{c}2.185^{* * *} \\
(6.794)\end{array}$ & $\begin{array}{c}1.897^{* * *} \\
(7.729)\end{array}$ & $\begin{array}{c}2.086^{* * *} \\
(8.343)\end{array}$ & $\begin{array}{c}1.873^{* * *} \\
(6.272)\end{array}$ \\
\hline $\begin{array}{l}\text { SESM* }^{*} \\
\text { MktCap>NYSE median }\end{array}$ & & $\begin{array}{c}-0.403^{* * *} \\
(-2.864)\end{array}$ & $\begin{array}{c}-0.428^{* * *} \\
(-2.992)\end{array}$ & $\begin{array}{c}-0.452^{* * *} \\
(-2.738)\end{array}$ & $\begin{array}{c}-0.371^{* * *} \\
(-2.597)\end{array}$ & $\begin{array}{c}-0.380^{* * *} \\
(-2.642)\end{array}$ & $\begin{array}{c}-0.374^{* *} \\
(-2.475)\end{array}$ \\
\hline $\begin{array}{l}\mathrm{SESM}^{*} \\
\text { Res-AC }>\text { median }\end{array}$ & & & $\begin{array}{l}-0.064 \\
(-0.570)\end{array}$ & & & & $\begin{array}{l}-0.035 \\
(-0.340)\end{array}$ \\
\hline $\begin{array}{l}\mathrm{SESM}^{*} \\
\text { Res-IO >median }\end{array}$ & & & & $\begin{array}{l}-0.207 \\
(-1.232)\end{array}$ & & & $\begin{array}{l}-0.196 \\
(-1.172)\end{array}$ \\
\hline $\begin{array}{l}\text { SESM* }^{*} \\
\text { Res-BAS >median }\end{array}$ & & & & & $\begin{array}{c}0.079 \\
(0.690)\end{array}$ & & $\begin{array}{c}0.143 \\
(0.980)\end{array}$ \\
\hline $\begin{array}{l}\text { SESM } * \\
\text { Res-ILQ }>\text { median }\end{array}$ & & & & & & $\begin{array}{l}-0.134 \\
(-1.228)\end{array}$ & $\begin{array}{l}-0.221^{*} \\
(-1.747)\end{array}$ \\
\hline Controls & YES & YES & YES & YES & YES & YES & YES \\
\hline Average R2 & 0.040 & 0.044 & 0.045 & 0.051 & 0.041 & 0.047 & 0.046 \\
\hline
\end{tabular}


Table 10: PEAD-SESM-strategy: Three-factor alphas of double sorted portfolios

This table presents three-factor alphas (expressed in \% per month) and associated t-statistics (in parentheses) of various stock portfolios which result from sequential double sorts. In panels A and B, stocks are first sorted into quintiles based on their most recent earnings announcement return (EAR), and then within each quintile further into five bins using the stocks' style-based earnings surprises measure (SESM). In panel C and D the sequential sorting starts based on the stocks' most recent standardized unexpected quarterly earnings (SUE). The portfolio rebalancing frequency is one month and six months, respectively. The returns from the six-month rebalancing strategy are based on overlapping portfolios as in Jegadeesh and Titman (1993). The "high-low" rows and columns show the abnormal returns of long-short portfolios, and for each panel the abnormal return of the ("high/high"- "low/low")-portfolio is highlighted in bolt. Three-factor alphas come from a time-series regression of portfolio returns (in excess of the risk-free rate if the portfolio is long-only) on the market excess return, and the Fama/French factors $H M L$ and $S M B$. The sample period is from Q1:1972-Q4:2011. * indicates significance at the $10 \%$ level, ** indicates significance at the $5 \%$ level and $* * *$ indicates significance at the $1 \%$ level. All t-statistics are based on West and Newey (1987) standard errors with a lag of five months.

\begin{tabular}{|c|c|c|c|c|c|c|}
\hline \multicolumn{7}{|c|}{ Panel A: EAR-SESM double sorts, one-month rebalancing } \\
\hline \multirow{2}{*}{$\begin{array}{l}\text { EAR } \\
\text { Quintile }\end{array}$} & \multicolumn{5}{|c|}{ SESM Quintile } & \multirow[b]{2}{*}{ high-low } \\
\hline & low & 2 & 3 & 4 & high & \\
\hline \multirow[t]{2}{*}{ low } & $-1.37^{* * *}$ & $-1.00^{* * *}$ & $-0.52^{* * *}$ & -0.13 & 0.24 & $1.62^{* * *}$ \\
\hline & $(-7.90)$ & $(-6.92)$ & $(-3.50)$ & $(-0.85)$ & $(1.45)$ & $(6.08)$ \\
\hline \multirow[t]{2}{*}{2} & $-0.93^{* * *}$ & $-0.46^{* * *}$ & -0.03 & $0.26^{* * *}$ & $0.62^{* * *}$ & $1.55^{* * *}$ \\
\hline & $(-6.73)$ & $(-4.90)$ & $(-0.40)$ & $(3.08)$ & $(4.64)$ & $(6.49)$ \\
\hline \multirow[t]{2}{*}{3} & $-0.74^{* * *}$ & $-0.24^{* * *}$ & $0.13^{*}$ & $0.42^{* * *}$ & $0.83^{* * *}$ & $1.57^{* * *}$ \\
\hline & $(-5.79)$ & $(-2.69)$ & $(1.85)$ & $(4.35)$ & $(5.92)$ & $(6.73)$ \\
\hline \multirow[t]{2}{*}{4} & $-0.58^{* * *}$ & -0.04 & $0.23^{* * *}$ & $0.53^{* * *}$ & $0.92^{* * *}$ & $1.50^{* * *}$ \\
\hline & $(-4.30)$ & $(-0.43)$ & $(2.69)$ & $(5.79)$ & $(6.78)$ & $(6.32)$ \\
\hline \multirow[t]{2}{*}{ high } & $-0.35^{* *}$ & $0.26^{* *}$ & $0.67^{* * *}$ & $0.99 * * *$ & $1.34^{* * *}$ & $1.68^{* * *}$ \\
\hline & $(-2.15)$ & $(2.25)$ & $(7.56)$ & $(7.07)$ & $(7.25)$ & $(5.89)$ \\
\hline \multirow[t]{2}{*}{ high-low } & $1.03^{* * *}$ & $1.26^{* * *}$ & $1.19^{* * *}$ & $1.12^{* * *}$ & $1.09 * * *$ & $2.71 * * *$ \\
\hline & $(9.56)$ & $(10.92)$ & $(9.24)$ & (9.73) & $(9.80)$ & $(9.31)$ \\
\hline \multicolumn{7}{|c|}{ Panel B: EAR-SESM double sorts, six-month rebalancing } \\
\hline \multirow{2}{*}{$\begin{array}{l}\text { EAR } \\
\text { Quintile }\end{array}$} & \multicolumn{5}{|c|}{ SESM Quintile } & \\
\hline & low & 2 & 3 & 4 & high & high-low \\
\hline \multirow[t]{2}{*}{ low } & $-0.61^{* * *}$ & $-0.52 * * *$ & $-0.26^{* *}$ & -0.15 & 0.00 & $0.61^{* * *}$ \\
\hline & $(-3.90)$ & $(-4.06)$ & $(-2.06)$ & $(-1.29)$ & $(0.04)$ & $(3.97)$ \\
\hline \multirow[t]{2}{*}{2} & $-0.25 * *$ & -0.12 & 0.01 & 0.10 & $0.23^{* * *}$ & $0.48^{* * *}$ \\
\hline & $(-2.36)$ & $(-1.54)$ & $(0.20)$ & $(1.63)$ & $(2.97)$ & $(3.83)$ \\
\hline \multirow[t]{2}{*}{3} & $-0.18^{*}$ & -0.03 & $0.12^{*}$ & $0.17^{* * *}$ & $0.33^{* * *}$ & $0.51^{* * *}$ \\
\hline & $(-1.76)$ & $(-0.50)$ & $(1.82)$ & $(2.66)$ & $(4.30)$ & $(4.27)$ \\
\hline \multirow[t]{2}{*}{4} & -0.10 & 0.09 & $0.16^{* *}$ & $0.23^{* * *}$ & $0.36^{* * *}$ & $0.47^{* * *}$ \\
\hline & $(-1.04)$ & $(1.21)$ & $(2.36)$ & $(3.82)$ & $(4.91)$ & $(3.88)$ \\
\hline \multirow[t]{2}{*}{ high } & -0.11 & $0.21^{* *}$ & $0.43^{* * *}$ & $0.49 * * *$ & $0.61^{* * *}$ & $0.72^{* * *}$ \\
\hline & $(-0.97)$ & $(2.43)$ & $(5.55)$ & $(6.20)$ & $(5.73)$ & $(4.98)$ \\
\hline \multirow[t]{2}{*}{ high-low } & $0.50^{* * *}$ & $0.73^{* * *}$ & $0.69^{* * *}$ & $0.64^{* * *}$ & $0.61^{* * *}$ & $1.22 * * *$ \\
\hline & $(6.42)$ & $(9.73)$ & $(7.91)$ & $(8.95)$ & $(9.47)$ & $(6.91)$ \\
\hline
\end{tabular}


Table 10: PEAD-SESM-strategy: Three-factor alphas of double sorted portfolios (continued)

\begin{tabular}{|c|c|c|c|c|c|c|}
\hline \multicolumn{7}{|c|}{ Panel C: SUE-SESM double sorts, one-month rebalancing } \\
\hline \multirow{2}{*}{$\begin{array}{l}\text { SUE } \\
\text { Quintile }\end{array}$} & \multicolumn{5}{|c|}{ SESM Quintile } & \multirow[b]{2}{*}{ high-low } \\
\hline & low & 2 & 3 & 4 & high & \\
\hline low & $\begin{array}{c}-1.62 * * * \\
(-9.92)\end{array}$ & $\begin{array}{c}-1.25^{* * *} \\
(-9.08)\end{array}$ & $\begin{array}{c}-0.80^{* * *} \\
(-6.83)\end{array}$ & $\begin{array}{c}-0.47^{* * *} \\
(-3.34)\end{array}$ & $\begin{array}{l}-0.05 \\
(-0.28)\end{array}$ & $\begin{array}{c}1.57^{* * *} \\
(5.48)\end{array}$ \\
\hline 2 & $\begin{array}{c}-1.06 * * * \\
(-6.69)\end{array}$ & $\begin{array}{c}-0.61 * * * \\
(-5.50)\end{array}$ & $\begin{array}{c}-0.23^{* *} \\
(-2.45)\end{array}$ & $\begin{array}{c}0.16 \\
(1.21)\end{array}$ & $\begin{array}{c}0.43^{* * *} \\
(2.69)\end{array}$ & $\begin{array}{c}1.49^{* * *} \\
(5.66)\end{array}$ \\
\hline 3 & $\begin{array}{c}-0.64^{* * *} \\
(-4.57)\end{array}$ & $\begin{array}{l}-0.08 \\
(-0.67)\end{array}$ & $\begin{array}{l}0.23^{* *} \\
(2.57)\end{array}$ & $\begin{array}{c}0.55^{* * *} \\
(5.51)\end{array}$ & $\begin{array}{c}0.98^{* * *} \\
(6.39)\end{array}$ & $\begin{array}{c}1.62^{* * *} \\
(6.46)\end{array}$ \\
\hline 4 & $\begin{array}{c}-0.44^{* * *} \\
(-3.16)\end{array}$ & $\begin{array}{c}0.13 \\
(1.33)\end{array}$ & $\begin{array}{c}0.56^{* * *} \\
(6.19)\end{array}$ & $\begin{array}{c}0.84^{* * *} \\
(7.84)\end{array}$ & $\begin{array}{c}1.36^{* * *} \\
(7.18)\end{array}$ & $\begin{array}{c}1.80^{* * *} \\
(6.23)\end{array}$ \\
\hline high & $\begin{array}{l}-0.10 \\
(-0.69)\end{array}$ & $\begin{array}{c}0.35^{* * *} \\
(3.10)\end{array}$ & $\begin{array}{c}0.82^{* * *} \\
(8.94)\end{array}$ & $\begin{array}{c}1.10^{* * *} \\
(10.11)\end{array}$ & $\begin{array}{l}1.59^{* * *} \\
(10.65)\end{array}$ & $\begin{array}{c}1.69 * * * \\
(6.76)\end{array}$ \\
\hline high-low & $\begin{array}{c}1.52^{* * *} \\
(10.25)\end{array}$ & $\begin{array}{c}1.61^{* * *} \\
(11.17)\end{array}$ & $\begin{array}{l}1.62^{* * *} \\
(11.72)\end{array}$ & $\begin{array}{l}1.57^{* * *} \\
(10.57)\end{array}$ & $\begin{array}{l}1.64^{* * *} \\
(11.16)\end{array}$ & $\begin{array}{c}3.21 * * * \\
(12.39)\end{array}$ \\
\hline & \multicolumn{6}{|c|}{ Panel D: SUE-SESM double sorts, six-month rebalancing } \\
\hline SUE & \multicolumn{5}{|c|}{ SESM Quintile } & \\
\hline Quintile & low & 2 & 3 & 4 & high & high-low \\
\hline low & $\begin{array}{c}-0.80^{* * *} \\
(-5.72)\end{array}$ & $\begin{array}{c}-0.67^{* * *} \\
(-6.00)\end{array}$ & $\begin{array}{c}-0.50^{* * *} \\
(-5.16)\end{array}$ & $\begin{array}{c}-0.46^{* * *} \\
(-5.06)\end{array}$ & $\begin{array}{c}-0.33^{* * *} \\
(-3.30)\end{array}$ & $\begin{array}{c}0.47^{* * *} \\
(3.09)\end{array}$ \\
\hline 2 & $\begin{array}{c}-0.34^{* * *} \\
(-2.68)\end{array}$ & $\begin{array}{c}-0.20^{* *} \\
(-2.00)\end{array}$ & $\begin{array}{c}-0.09 \\
(-1.03)\end{array}$ & $\begin{array}{c}0.04 \\
(0.51)\end{array}$ & $\begin{array}{c}0.11 \\
(1.23)\end{array}$ & $\begin{array}{c}0.45^{* * *} \\
(3.15)\end{array}$ \\
\hline 3 & $\begin{array}{c}-0.08 \\
(-0.72)\end{array}$ & $\begin{array}{c}0.11 \\
(1.29)\end{array}$ & $\begin{array}{c}0.25^{* * *} \\
(3.47)\end{array}$ & $\begin{array}{c}0.36^{* * *} \\
(4.99)\end{array}$ & $\begin{array}{c}0.50^{* * *} \\
(5.32)\end{array}$ & $\begin{array}{c}0.58^{* * *} \\
(4.27)\end{array}$ \\
\hline 4 & $\begin{array}{c}0.03 \\
(0.32)\end{array}$ & $\begin{array}{c}0.22^{* * *} \\
(2.90)\end{array}$ & $\begin{array}{c}0.35^{* * *} \\
(5.30)\end{array}$ & $\begin{array}{c}0.46^{* * *} \\
(6.67)\end{array}$ & $\begin{array}{c}0.68^{* * *} \\
(7.22)\end{array}$ & $\begin{array}{c}0.64^{* * *} \\
(4.87)\end{array}$ \\
\hline high & $\begin{array}{c}0.13 \\
(1.29)\end{array}$ & $\begin{array}{c}0.30^{* * *} \\
(3.68)\end{array}$ & $\begin{array}{c}0.42^{* * *} \\
(5.49)\end{array}$ & $\begin{array}{c}0.55^{* * *} \\
(7.76)\end{array}$ & $\begin{array}{c}0.66^{* * *} \\
(7.37)\end{array}$ & $\begin{array}{c}0.52^{* * *} \\
(4.45)\end{array}$ \\
\hline high-low & $\begin{array}{c}0.94^{* * *} \\
(7.85)\end{array}$ & $\begin{array}{c}0.97^{* * *} \\
(8.09)\end{array}$ & $\begin{array}{c}0.93^{* * *} \\
(7.75)\end{array}$ & $\begin{array}{c}1.02^{* * *} \\
(9.45)\end{array}$ & $\begin{array}{c}0.98^{* * *} \\
(9.29)\end{array}$ & $\begin{array}{c}1.46^{* * *} \\
(8.70)\end{array}$ \\
\hline
\end{tabular}


Table 11: Fama/MacBeth regressions: Forecasting EAR, SUE, analyst forecast errors, and revisions

This table reports the results of Fama/MacBeth regressions to forecast earnings announcement returns (EAR), standardized unexpected earnings (SUE), quarterly analyst forecast errors (FE), and revisions in forecasts of annual earnings estimates (FR). Independent variables include the style-based earnings surprise measure (SESM), firm size (SIZE), book-to-market ratio (BM), momentum (Mom; stock return over the last year excluding the most recent month), prior one-month return (PR1M), the most recent stock-specific earnings announcement return (Prev. EAR), the most recent standardized unexpected quarterly earnings (Prev. SUE), and average industry-based earnings surprises based on all firms that announced in the most recent month (Ind. EAR). The definition of industries follows the 48-industry classification system of Fama and French (1997). SUE, FE, and FR are winsorized at 99.9\%. Further information on the construction of the variables is given in the paper. The $R 2$ is the average from the monthly cross-sectional regressions. The sample period is from from Q1:1972-Q4:2011, but data on annual (quarterly) analyst earnings estimates is restricted to the period from 1980 (1984) onward. Regression coefficients are standardized. * indicates significance at the $10 \%$ level, ** indicates significance at the $5 \%$ level and $* * *$ indicates significance at the $1 \%$ level. All t-statistics (in parentheses) are based on the time-series mean and standard deviation for each coefficient, and adjusted for heteroskedasticity and autocorrelation using West and Newey (1987) with a lag of four months.

\begin{tabular}{lcccc}
\hline \hline Dependent variable & EAR & SUE & FE & FR \\
\hline Independent variables & & & & \\
SESM & $0.0564^{* * *}$ & $0.0308^{* * *}$ & $0.0739^{* *}$ & $0.0265^{* * *}$ \\
& $(5.507)$ & $(2.941)$ & $(2.330)$ & $(3.160)$ \\
Size & $-0.0052^{* *}$ & $0.0248^{* * *}$ & $0.0394^{* * *}$ & $0.0233^{* * *}$ \\
& $(-1.990)$ & $(5.757)$ & $(5.037)$ & $(4.726)$ \\
BM & $0.0264^{* * *}$ & $-0.0516^{* * *}$ & $-0.0332^{* * *}$ & $-0.0235^{* * *}$ \\
& $(8.494)$ & $(-11.402)$ & $(-4.756)$ & $(-11.405)$ \\
Mom & $0.0104^{* * *}$ & $0.1516^{* * *}$ & $0.1317^{* * *}$ & $0.0639^{* * *}$ \\
& $(3.679)$ & $(24.993)$ & $(19.263)$ & $(17.441)$ \\
PR1M & $-0.0137^{* * *}$ & $0.0659^{* * *}$ & $0.0860^{* * *}$ & $0.0285^{* * *}$ \\
& $(-5.787)$ & $(23.022)$ & $(16.074)$ & $(15.672)$ \\
Prev. EAR & $0.0304^{* * *}$ & $0.0304^{* * *}$ & $0.0493^{* * *}$ & $0.0103^{* * *}$ \\
& $(7.557)$ & $(8.491)$ & $(9.008)$ & $(8.042)$ \\
Prev. SUE & $0.0276^{* * *}$ & $0.2460^{* * *}$ & $0.0352^{* * *}$ & $0.0372^{* * *}$ \\
& $(3.910)$ & $(26.079)$ & $(5.746)$ & $(13.473)$ \\
Ind. EAR & $0.0083^{* * *}$ & $0.0063^{* *}$ & -0.0085 & $0.0076^{* * *}$ \\
& $(3.297)$ & $(2.069)$ & $(-1.012)$ & $(3.897)$ \\
Average R2 & 0.027 & 0.159 & 0.078 & 0.023 \\
\hline \hline
\end{tabular}




\title{
Appendix for "Style-Driven Earnings Momentum"
}

May 2013

\begin{abstract}
This appendix contains explanations and tables that supplement the analysis in the paper "StyleDriven Earnings Momentum". It starts with an overview of how characteristics (stock styles) are constructed. Figure 1 plots the distribution of the style-based earnings surprise measure (SESM) used as predictor of future stock returns in the paper. Table 1 summarizes the cross-section of characteristics by firm-year observations. Table 2 shows correlations between style-based return spreads and earnings announcement return (EAR) spreads. Table 3 extends the baseline forecasts of style-based return spreads by running further multivariate regressions. Table 4 reports forecasts of industry-adjusted return spreads for a number of alternative industry definitions. The results of the "placebo" tests which rely on prior one-month returns outside the earnings announcement windows as predictors are shown in table 5. Table 6 displays forecasts of style-based return spreads for different size buckets. Table 7 reports the loadings of the explanatory variables for the regressions shown in table 8, panel A and B of the paper. Table 8 provides the findings of the baseline forecasts for two subsamples (pre and post 1991). Finally, in table 9, three-factor alphas of triple sorted portfolios (based on the stocks' EAR, SUE, and SESM) are displayed.
\end{abstract}




\section{Appendix: Variable Definitions}

This section outlines how characteristics (stock styles) are constructed. Data sources are CRSP and annual and quarterly Compustat files. Consistent with Fama and French (1992) portfolio sorts take place once every year at the end of June. Market-based variables (like price, residual volatility, and beta) are measured as of the same date, while accounting variables are taken from financial statements of the last fiscal year ending in the previous calendar year. As exception from annual rebalancing, price momentum and financial distress portfolios are updated monthly.

Firm Size: Firm size is defined as number of shares outstanding (shrout) times price (prc).

Firm Age: Age is number of years since the firm's PERMCO first appeared in CRSP (starting year 1925).

Beta and Residual Volatility: Beta and residual volatility are obtained from a one factor regression (with mktrf from CRSP as excess market return) using up to previous 60 months of firm year returns. I require a firm to have at least 24 months of return data.

Accruals: Accruals (Acc) are defined as in Bergstresser and Philippon (2006):

$A c c_{t}=\frac{\left(\Delta C A_{t}-\Delta \operatorname{Cash}_{t}-\Delta C L_{t}+\Delta S T D_{t}+\Delta T P_{t}-D P_{t}\right)}{\left(A_{t}+A_{t-1}\right) / 2}$.

$C A$ is current assets (Compustat item act), $C L$ is current liabilities (lct), STD is short term debt (dlc), $T P$ is taxes payable $(t x p)$, and $D P$ is depreciation $(d p)$. Cash is Compustat item che.

Asset Growth: Asset growth is the increase in at compared to last year financial statements.

Sales Growth: Sales growth is the increase in sale compared to last year financial statements.

Return on Assets: Return on assets measures firm profitability and is defined as income before extraordinary items $(i b)$ divided by prior year total assets $(a t)$.

Book-to-Market: Book-to-Market is the book value of equity (ceq) divided by market value of equity from CRSP. Consistent with Fama and French (1992) market value of equity is measured at the end of the previous calendar year (which is also the year to which the book value data refers).

Dividend Yield: Dividend yield is calculated as dividends per share $\left(d v p s x_{-} f\right)$ over stock price as of fiscal year end. 
Investments over Assets: Investment over assets $(I A)$ are defined as in Chen et al. (2010):

$I A_{t}=\frac{P P E_{t}-P P E_{t-1}+I N V_{t}-I N V_{t-1}}{a t_{t-1}}$.

$P P E$ is property, plant and equipment from Compustat (item ppegt), and $I N V$ are inventories (invt).

Net Stock Issuance: Net stock issuance is defined as in Fama and French (2008) as the log increase in shares outstanding compared to last year financial statements. For each fiscal year, shares outstanding are first adjusted using the cumulative adjustment factor from Compustat $($ csho $\cdot$ adjex_c).

Price: Price is the nominal share price $(p r c)$ from CRSP.

Price Momentum: Price momentum is prior one year return from CRSP excluding the most recent month.

Distress: I use the failure probability from Campbell et al. (2008) as distress measure. More specifically, distress is calculated as:

Distress $_{t}=-9.164-20.264 \cdot N I M T A A V G_{t}+1.416 \cdot T L M T A_{t}-7.129 \cdot$ EXRETAVG $_{t}$

$+1.411 \cdot S I G M A_{t}-0.045 \cdot R S I Z E_{t}-2.132 \cdot C A S H M T A_{t}+0.075 \cdot M B_{t}-0.058 \cdot P R I C E_{t}$.

For further details about the variables used in the above equation I refer to Campbell et al. (2008) and Chen et al. (2010)). All accounting variables are based on Compustat quarterly files as in Campbell et al. (2008) with an appropriate lag to ensure that only historically available data is used (quarterly earnings announcement date +1 month). 
Figure 1: Distribution of the style-based earnings surprise measure (SESM)

This figure shows the historical distribution of the style-based earnings surprise measure (SESM) used as predictor of future stock returns in this paper. The sample period is from Q1:1972-Q4:2011.

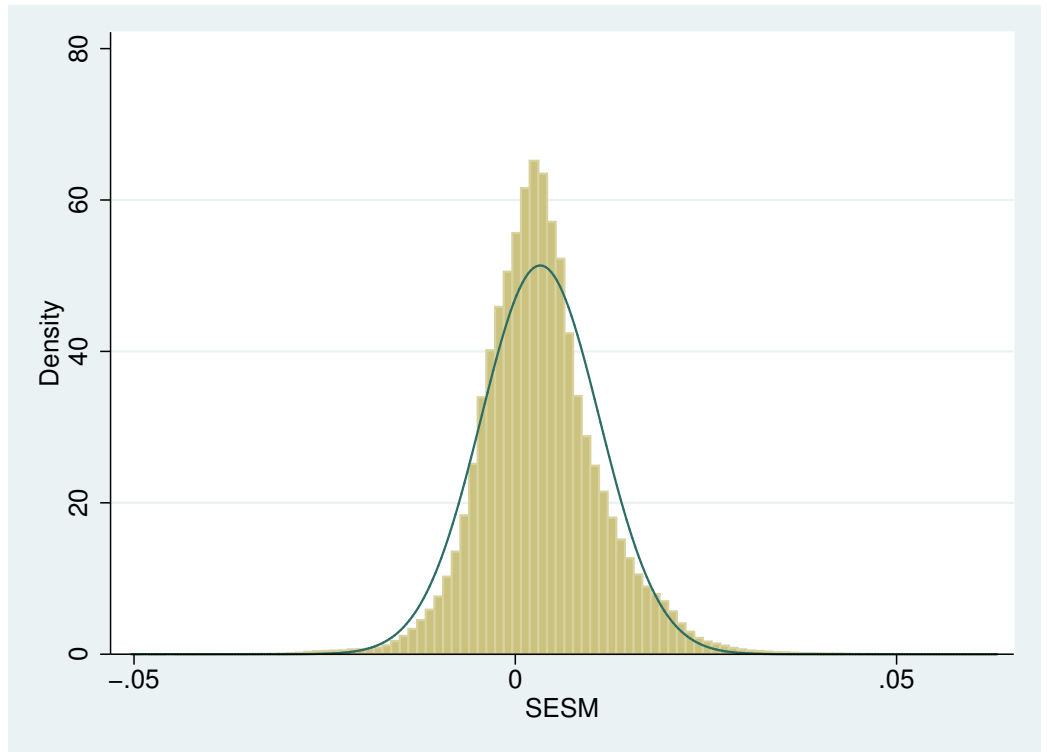


Table 1: Firm-year summary statistics

This table summarizes the cross-section of characteristics used to define stock styles by firm-year observations (number of observations (N), mean, median, standard deviation (SD), and extreme percentiles (P5 and P95)). The sample period is from 1972 to 2011 and includes all firm-years with a positive book value of equity in the fiscal year ending in calendar year $t-1$ and a CRSP market value of equity at the end of June of year $t$. Construction details for each characteristic are in the appendix.

\begin{tabular}{lcccccc}
\hline \hline Style Variable & $\mathrm{N}$ & Mean & Median & SD & P5 & P95 \\
\hline Firm Size (Mio. \$) & 179933 & 955.82 & 87.97 & 3098.78 & 3.67 & 4370.39 \\
Age [years] & 179933 & 14.19 & 9.58 & 14.02 & 1.42 & 46.33 \\
Beta & 156754 & 1.11 & 1.03 & 0.73 & 0.08 & 2.44 \\
Residual Vol (\%) & 156754 & 13.39 & 11.52 & 7.47 & 5.13 & 28.19 \\
Asset Growth (\%) & 163542 & 15.46 & 7.98 & 37.83 & -23.21 & 78.40 \\
Accruals (\%) & 136533 & -3.05 & -3.31 & 9.85 & -18.77 & 13.79 \\
Sales Growth (\%) & 161492 & 18.67 & 10.23 & 48.59 & -27.08 & 84.49 \\
Return on Assets (\%) & 163464 & 0.77 & 3.38 & 16.47 & -31.01 & 17.99 \\
Book-to-Market & 179933 & 0.89 & 0.65 & 0.83 & 0.12 & 2.49 \\
Dividend Yield (\%) & 178571 & 1.47 & 0.00 & 2.33 & 0.00 & 6.61 \\
Investments/Assets (\%) & 144615 & 8.99 & 5.51 & 17.86 & -11.39 & 40.59 \\
Net Stock Issuance & 163325 & 0.04 & 0.00 & 0.14 & -0.06 & 0.32 \\
Price & 179933 & 17.28 & 12.50 & 16.49 & 1.00 & 50.63 \\
Momentum (\%) & 173309 & 12.57 & 4.93 & 54.07 & -58.59 & 111.63 \\
Distress & 148347 & -7.51 & -7.72 & 1.11 & -8.84 & -5.31 \\
\hline \hline
\end{tabular}


Correlations between monthly equal-weighted style returns (earnings announcement returns (EAR)) are shown in Panel A (Panel B). Style returns and EAR spreads are long-short portfolio returns based on extreme characteristic portfolios. To calculate EAR spreads I use all firms having an earnings announcement in a particular month, except firms announcing at the last trading day of that month. For an individual firm, EAR is the cumulative stock return over the three-day window centered around the announcement date minus the cumulative CRSP value-weighted market return over the same period. Column "long-short PF" shows the direction of the characteristic sorting (upward or downward) to determine the long and short portfolio. Construction details for each characteristic are in the appendix.

\begin{tabular}{|c|c|c|c|c|c|c|c|c|c|c|c|c|c|c|c|c|}
\hline Style Variable & long-short PF & $(1)$ & $(2)$ & (3) & $(4)$ & $(5)$ & (6) & $(7)$ & (8) & (9) & $(10)$ & $(11)$ & $(12)$ & $(13)$ & $(14)$ & $(15)$ \\
\hline \multicolumn{17}{|c|}{ Panel A: Correlations between monthly style returns } \\
\hline Firm Size (1) & low-high & 1.00 & & & & & & & & & & & & & & \\
\hline Age $(2)$ & high-low & -0.79 & 1.00 & & & & & & & & & & & & & \\
\hline Beta (3) & high-low & 0.49 & -0.68 & 1.00 & & & & & & & & & & & & \\
\hline Residual Vol (4) & high-low & 0.78 & -0.88 & 0.86 & 1.00 & & & & & & & & & & & \\
\hline Asset Growth (5) & low-high & 0.53 & -0.32 & 0.04 & 0.31 & 1.00 & & & & & & & & & & \\
\hline Accruals (6) & low-high & 0.16 & -0.15 & 0.12 & 0.19 & 0.42 & 1.00 & & & & & & & & & \\
\hline Sales Growth (7) & low-high & 0.39 & -0.09 & -0.09 & 0.12 & 0.81 & 0.46 & 1.00 & & & & & & & & \\
\hline Return on Assets (8) & high-low & -0.73 & 0.66 & -0.37 & -0.63 & -0.79 & -0.43 & -0.62 & 1.00 & & & & & & & \\
\hline Book-to-Market (9) & high-low & 0.17 & 0.32 & -0.43 & -0.28 & 0.48 & 0.14 & 0.63 & -0.24 & 1.00 & & & & & & \\
\hline Dividend Yield (10) & high-low & -0.68 & 0.84 & -0.83 & -0.94 & -0.14 & -0.11 & 0.05 & 0.47 & 0.46 & 1.00 & & & & & \\
\hline Investments/Assets (11) & low-high & 0.45 & -0.28 & 0.00 & 0.23 & 0.81 & 0.40 & 0.75 & -0.66 & 0.41 & -0.10 & 1.00 & & & & \\
\hline Net Stock Issuance (12) & low-high & -0.37 & 0.74 & -0.71 & -0.73 & -0.04 & -0.16 & 0.20 & 0.43 & 0.62 & 0.73 & 0.02 & 1.00 & & & \\
\hline Nominal Price (13) & low-high & 0.95 & -0.76 & 0.55 & 0.79 & 0.57 & 0.22 & 0.42 & -0.81 & 0.19 & -0.66 & 0.44 & -0.43 & 1.00 & & \\
\hline Momentum (14) & high-low & -0.37 & 0.40 & -0.37 & -0.42 & -0.23 & -0.11 & -0.16 & 0.50 & -0.01 & 0.34 & -0.07 & 0.40 & -0.54 & 1.00 & \\
\hline Distress (15) & low-high & -0.70 & 0.66 & -0.60 & -0.72 & -0.40 & -0.24 & -0.32 & 0.75 & -0.08 & 0.60 & -0.29 & 0.49 & -0.80 & 0.81 & 1.00 \\
\hline \multicolumn{17}{|c|}{ Panel B: Correlations between monthly earnings announcement returns } \\
\hline Firm Size (1) & low-high & 1.00 & & & & & & & & & & & & & & \\
\hline Age $(2)$ & high-low & -0.28 & 1.00 & & & & & & & & & & & & & \\
\hline Beta $(3)$ & high-low & 0.23 & -0.13 & 1.00 & & & & & & & & & & & & \\
\hline Residual Vol (4) & high-low & 0.57 & -0.36 & 0.53 & 1.00 & & & & & & & & & & & \\
\hline Asset Growth (5) & low-high & 0.29 & -0.03 & 0.05 & 0.21 & 1.00 & & & & & & & & & & \\
\hline Accruals $(6)$ & low-high & -0.01 & 0.00 & 0.10 & 0.04 & 0.40 & 1.00 & & & & & & & & & \\
\hline Sales Growth (7) & low-high & 0.21 & 0.11 & 0.01 & 0.09 & 0.52 & 0.28 & 1.00 & & & & & & & & \\
\hline Return on Assets (8) & high-low & -0.36 & 0.06 & -0.16 & -0.32 & -0.57 & -0.36 & -0.44 & 1.00 & & & & & & & \\
\hline Book-to-Market (9) & high-low & 0.26 & 0.08 & -0.08 & 0.06 & 0.31 & 0.17 & 0.24 & -0.38 & 1.00 & & & & & & \\
\hline Dividend Yield (10) & high-low & -0.30 & 0.35 & -0.46 & -0.55 & -0.01 & -0.08 & 0.08 & 0.18 & 0.09 & 1.00 & & & & & \\
\hline Investments/Assets (11) & low-high & 0.20 & 0.00 & 0.07 & 0.07 & 0.64 & 0.30 & 0.53 & -0.44 & 0.20 & 0.03 & 1.00 & & & & \\
\hline Net Stock Issuance (12) & low-high & -0.15 & 0.12 & -0.15 & -0.20 & 0.17 & 0.07 & 0.17 & 0.08 & 0.23 & 0.21 & 0.05 & 1.00 & & & \\
\hline Nominal Price (13) & low-high & 0.76 & -0.24 & 0.22 & 0.49 & 0.31 & 0.05 & 0.29 & -0.45 & 0.29 & -0.24 & 0.32 & -0.11 & 1.00 & & \\
\hline Momentum (14) & high-low & -0.10 & 0.24 & -0.13 & -0.16 & -0.01 & -0.04 & 0.07 & 0.09 & -0.02 & 0.08 & -0.06 & 0.20 & -0.14 & 1.00 & \\
\hline Distress (15) & low-high & -0.32 & 0.08 & -0.17 & -0.27 & -0.22 & -0.07 & -0.05 & 0.42 & -0.29 & 0.15 & -0.17 & 0.11 & -0.38 & 0.46 & 1.00 \\
\hline
\end{tabular}


Table 3: Forecasting style-based return spreads: Further multi-factor models

This table presents the results of regressing equal-weighted characteristic-based long-short portfolio returns on prior one-month characteristic-based long-short earnings announcement returns (EAR). Panel A shows the results of a four-factor model which in addition to the market excess return, $H M L$ and $S M B$ also controls for the momentum factor $(U M D)$. Results in panel B are based on a five-factor model which additionally includes a short-term reversal factor. Panel C reports results for a six-factor model which is augmented with the Pastor and Stambaugh (2003) liquidity factor. Columns with heading "All" show results when portfolio returns are computed using all stocks in the extreme quintiles. Columns with heading "Announcers" ("Non-Announcers") show results when portfolio returns are computed using only the subset of stocks with (without) an earnings announcement in the previous month. The sample period is from Q1:1972-Q4:2011 for panels A and B, and from Q1:1972-Q4:2010 for panel C. Regression coefficients are standardized. * indicates significance at the $10 \%$ level, ${ }^{* *}$ indicates significance at the $5 \%$ level and $* * *$ indicates significance at the $1 \%$ level. All t-statistics are based on West and Newey (1987) standard errors with a lag of four months. See appendix for details about characteristics.

\begin{tabular}{|c|c|c|c|c|c|c|}
\hline \multirow[t]{3}{*}{ Style } & \multicolumn{6}{|c|}{ Panel A: Four-factor model } \\
\hline & \multicolumn{2}{|c|}{ All } & \multicolumn{2}{|c|}{ Announcers } & \multicolumn{2}{|c|}{ Non-Announcers } \\
\hline & $\mathrm{b}$ & t-stat & $\mathrm{b}$ & t-stat & $\mathrm{b}$ & t-stat \\
\hline Firm Size & $0.1285^{* * *}$ & 4.467 & $0.1060 * * *$ & 3.105 & $0.1167 * * *$ & 4.195 \\
\hline Age & $0.1074^{* * *}$ & 3.180 & 0.0611 & 1.429 & $0.1042^{* * *}$ & 2.943 \\
\hline Beta & 0.0274 & 0.925 & $0.0607^{*}$ & 1.727 & 0.0185 & 0.648 \\
\hline Residual Vol & $0.1358 * * *$ & 3.514 & $0.1141^{* * *}$ & 2.789 & $0.1345^{* * *}$ & 3.551 \\
\hline Asset Growth & $0.1569^{* *}$ & 2.328 & $0.1742^{* * *}$ & 2.939 & $0.1412^{* *}$ & 2.091 \\
\hline Accruals & 0.0675 & 1.346 & $0.1162^{* *}$ & 2.140 & 0.0320 & 0.676 \\
\hline Sales Growth & $0.1042^{* *}$ & 2.403 & 0.0785 & 1.552 & $0.0905^{* *}$ & 2.187 \\
\hline Return on Assets & $0.1595 * * *$ & 3.239 & $0.1322^{* *}$ & 2.509 & $0.1461^{* * *}$ & 3.081 \\
\hline Book-to-Market & $0.0623^{*}$ & 1.762 & $0.0677^{*}$ & 1.696 & $0.0629^{*}$ & 1.674 \\
\hline Dividend Yield & $0.1015^{* * *}$ & 3.224 & $0.1177^{* * *}$ & 3.400 & $0.0917^{* * *}$ & 2.933 \\
\hline Investments/Assets & 0.0627 & 1.016 & 0.0838 & 1.265 & 0.0311 & 0.524 \\
\hline Net Stock Issuance & $0.1068 * * *$ & 2.934 & 0.0592 & 1.291 & $0.1090^{* * * *}$ & 3.047 \\
\hline Price & $0.1365^{* * *}$ & 3.451 & $0.1020^{* *}$ & 2.095 & $0.1274^{* * *}$ & 3.371 \\
\hline Momentum & -0.0003 & -0.011 & -0.0219 & -0.662 & -0.0080 & -0.318 \\
\hline Distress & $0.1192^{* * *}$ & 3.143 & $0.1290 * * *$ & 3.072 & $0.1041^{* * *}$ & 2.743 \\
\hline
\end{tabular}


Table 3: Forecasting style-based return spreads: Further multi-factor models (continued)

\begin{tabular}{|c|c|c|c|c|c|c|}
\hline \multirow[t]{3}{*}{ Style } & \multicolumn{6}{|c|}{ Panel B: Five-factor model } \\
\hline & \multicolumn{2}{|c|}{ All } & \multicolumn{2}{|c|}{ Announcers } & \multicolumn{2}{|c|}{ Non-Announcers } \\
\hline & $\mathrm{b}$ & t-stat & $\mathrm{b}$ & t-stat & $\mathrm{b}$ & t-stat \\
\hline Firm Size & $0.1288^{* * *}$ & 4.489 & $0.1065^{* * *}$ & 3.186 & $0.1170^{* * *}$ & 4.194 \\
\hline Age & $0.1101^{* * *}$ & 3.324 & 0.0634 & 1.520 & $0.1065 * * *$ & 3.061 \\
\hline Beta & 0.0281 & 0.962 & $0.0602^{*}$ & 1.738 & 0.0196 & 0.692 \\
\hline Residual Vol & $0.1373^{* * *}$ & 3.600 & $0.1150 * * *$ & 2.844 & $0.1362^{* * *}$ & 3.646 \\
\hline Asset Growth & $0.1538^{* *}$ & 2.327 & $0.1740^{* * *}$ & 2.936 & $0.1374^{* *}$ & 2.081 \\
\hline Accruals & 0.0654 & 1.270 & $0.1148^{* *}$ & 2.111 & 0.0298 & 0.611 \\
\hline Sales Growth & $0.1049^{* *}$ & 2.425 & 0.0783 & 1.551 & $0.0915^{* *}$ & 2.216 \\
\hline Return on Assets & $0.1593^{* * *}$ & 3.273 & $0.1320^{* *}$ & 2.534 & $0.1460 * * *$ & 3.104 \\
\hline Book-to-Market & $0.0645^{*}$ & 1.861 & $0.0667^{*}$ & 1.665 & $0.0660^{*}$ & 1.819 \\
\hline Dividend Yield & $0.1025^{* * *}$ & 3.224 & $0.1185^{* * *}$ & 3.419 & $0.0931^{* * *}$ & 2.952 \\
\hline Investments/Assets & 0.0626 & 1.015 & 0.0820 & 1.246 & 0.0315 & 0.529 \\
\hline Net Stock Issuance & $0.1092^{* * *}$ & 3.020 & 0.0625 & 1.413 & $0.1114^{* * *}$ & 3.108 \\
\hline Price & $0.1361 * * *$ & 3.528 & $0.1017^{* *}$ & 2.113 & $0.1270 * * *$ & 3.443 \\
\hline Momentum & 0.0015 & 0.055 & -0.0201 & -0.607 & -0.0063 & -0.260 \\
\hline Distress & $0.1135 * * *$ & 3.171 & $0.1185^{* * *}$ & 3.074 & $0.1013^{* * *}$ & 2.725 \\
\hline \multirow[t]{3}{*}{ Style } & \multicolumn{6}{|c|}{ Panel C: Six-factor model } \\
\hline & \multicolumn{2}{|c|}{ All } & \multicolumn{2}{|c|}{ Announcers } & \multicolumn{2}{|c|}{ Non-Announcers } \\
\hline & $\mathrm{b}$ & t-stat & $\mathrm{b}$ & t-stat & $\mathrm{b}$ & t-stat \\
\hline Firm Size & $0.1353^{* * *}$ & 4.796 & $0.1148^{* * *}$ & 3.590 & $0.1246^{* * *}$ & 4.512 \\
\hline Age & $0.1060^{* * *}$ & 3.114 & $0.0833^{* *}$ & 2.039 & $0.0997^{* * *}$ & 2.792 \\
\hline Beta & 0.0284 & 0.958 & $0.0616^{*}$ & 1.763 & 0.0203 & 0.706 \\
\hline Residual Vol & $0.1434^{* * *}$ & 3.780 & $0.1190^{* * *}$ & 2.924 & $0.1439 * * *$ & 3.897 \\
\hline Asset Growth & $0.1562^{* *}$ & 2.248 & $0.1868 * * *$ & 3.096 & $0.1375^{* *}$ & 1.974 \\
\hline Accruals & 0.0669 & 1.292 & $0.1269^{* *}$ & 2.346 & 0.0322 & 0.658 \\
\hline Sales Growth & $0.1097^{* *}$ & 2.390 & 0.0857 & 1.628 & $0.0933^{* *}$ & 2.115 \\
\hline Return on Assets & $0.1639 * * *$ & 3.314 & $0.1360^{* *}$ & 2.572 & $0.1492^{* * *}$ & 3.104 \\
\hline Book-to-Market & $0.0603^{*}$ & 1.727 & 0.0632 & 1.609 & $0.0618^{*}$ & 1.687 \\
\hline Dividend Yield & $0.1033^{* * *}$ & 3.229 & $0.1152^{* * *}$ & 3.312 & $0.0958 * * *$ & 3.031 \\
\hline Investments/Assets & 0.0527 & 0.829 & 0.0853 & 1.258 & 0.0203 & 0.327 \\
\hline Net Stock Issuance & $0.1100 * * *$ & 2.926 & 0.0661 & 1.464 & $0.1145^{* * *}$ & 3.094 \\
\hline Price & $0.1446^{* * *}$ & 3.805 & $0.1166^{* * *}$ & 2.626 & $0.1352^{* * *}$ & 3.679 \\
\hline Momentum & 0.0023 & 0.088 & -0.0208 & -0.620 & -0.0052 & -0.212 \\
\hline Distress & $0.1146^{* * *}$ & 3.142 & $0.1160^{* * *}$ & 2.996 & $0.1038^{* * *}$ & 2.725 \\
\hline
\end{tabular}


Table 4: Forecasting industry-adjusted return spreads: Alternative industry definitions

This table presents the results of univariate regressions of characteristic-based long-short portfolio returns on prior one-month characteristic-based long-short earnings announcement returns (EAR). Portfolio returns are based on industry-adjusted stock returns and a variety of different industry definitions is used. Panel A uses value-weighted industry returns for the adjustment (as opposed to equal-weighted returns used in the paper). Panel B classifies firms according to their first digit SIC code, the classification in panel $\mathrm{C}$ relies on the 2-digit SIC code, and the classification in panel D on the 3-digit SIC code. SIC codes are from CRSP. In addition, panels $\mathrm{E}$ and $\mathrm{F}$ use the Hoberg and Phillips (2010) text-based fixed industry classifications ("FIC") and network industry classifications ("TNIC") which are based on similarity scores from 10K product descriptions. The sample period is from Q1:1972-Q4:2011 for panels A to D and from Q3:1997-Q2:2010 for panels D and E. Multivariate regression results are not reported but provide qualitatively similar results (available upon request). Regression coefficients are standardized. * indicates significance at the $10 \%$ level, ** indicates significance at the $5 \%$ level and $* * *$ indicates significance at the $1 \%$ level. All t-statistics are based on West and Newey (1987) standard errors with a lag of four months. See appendix for details about characteristics.

\begin{tabular}{|c|c|c|c|c|c|c|}
\hline \multirow[t]{3}{*}{ Style } & \multicolumn{6}{|c|}{ Panel A: Adjustment using value-weighted industry returns } \\
\hline & \multicolumn{2}{|c|}{ All } & \multicolumn{2}{|c|}{ Announcers } & \multicolumn{2}{|c|}{ Non-Announcers } \\
\hline & $\mathrm{b}$ & t-stat & $\mathrm{b}$ & t-stat & $\mathrm{b}$ & t-stat \\
\hline Firm Size & $0.1531^{* * *}$ & 3.337 & $0.1445^{* * *}$ & 2.840 & $0.1369 * * *$ & 3.026 \\
\hline Age & $0.1920^{* * *}$ & 3.906 & $0.1595^{* * *}$ & 2.850 & $0.1775^{* * *}$ & 3.582 \\
\hline Beta & $0.1722^{* *}$ & 2.562 & $0.1802^{* *}$ & 2.558 & $0.1618^{* * *}$ & 2.632 \\
\hline Residual Vol & $0.3071^{* * *}$ & 4.765 & $0.2613^{* * *}$ & 3.792 & $0.3023^{* * *}$ & 4.787 \\
\hline Asset Growth & $0.1830^{* * *}$ & 2.617 & $0.2023^{* * *}$ & 3.215 & $0.1634^{* *}$ & 2.360 \\
\hline Accruals & 0.0620 & 1.250 & $0.1069^{*}$ & 1.953 & 0.0242 & 0.515 \\
\hline Sales Growth & $0.1977^{* * *}$ & 3.575 & $0.1327^{* *}$ & 2.481 & $0.1819^{* * *}$ & 3.386 \\
\hline Return on Assets & $0.1684^{* * *}$ & 3.691 & $0.1487^{* * *}$ & 2.937 & $0.1537^{* * *}$ & 3.462 \\
\hline Book-to-Market & $0.2313^{* * *}$ & 4.037 & $0.1910^{* * *}$ & 3.700 & $0.2201^{* * *}$ & 3.735 \\
\hline Dividend Yield & $0.2076^{* * *}$ & 3.811 & $0.1839^{* * *}$ & 3.515 & $0.1944^{* * *}$ & 3.639 \\
\hline Investments/Assets & 0.0838 & 1.370 & 0.0811 & 1.303 & 0.0561 & 0.942 \\
\hline Net Stock Issuance & $0.1297^{* * *}$ & 2.832 & 0.0752 & 1.433 & $0.1271^{* * *}$ & 2.903 \\
\hline Price & $0.2022^{* * *}$ & 3.425 & $0.1582^{* *}$ & 2.253 & $0.1928^{* * *}$ & 3.401 \\
\hline Momentum & 0.0704 & 0.839 & 0.0504 & 0.637 & 0.0560 & 0.689 \\
\hline Distress & $0.1735^{* * *}$ & 3.075 & $0.1712^{* * *}$ & 3.292 & $0.1550^{* * *}$ & 2.679 \\
\hline \multirow[t]{3}{*}{ Style } & \multicolumn{6}{|c|}{ Panel B: Industry defined by first digit SIC code } \\
\hline & \multicolumn{2}{|c|}{ All } & \multicolumn{2}{|c|}{ Announcers } & \multicolumn{2}{|c|}{ Non-Announcers } \\
\hline & $\mathrm{b}$ & t-stat & $\mathrm{b}$ & t-stat & $\mathrm{b}$ & t-stat \\
\hline Firm Size & $0.1573^{* * *}$ & 3.534 & $0.1631^{* * *}$ & 3.473 & $0.1422^{* * *}$ & 3.214 \\
\hline Age & $0.1828^{* * *}$ & 4.093 & $0.1434^{* * *}$ & 2.698 & $0.1746^{* * *}$ & 3.809 \\
\hline Beta & $0.1532^{* *}$ & 2.450 & $0.1738^{* * *}$ & 2.737 & $0.1425^{* *}$ & 2.402 \\
\hline Residual Vol & $0.2816^{* * *}$ & 4.686 & $0.2568^{* * *}$ & 4.119 & $0.2783^{* * *}$ & 4.699 \\
\hline Asset Growth & $0.1884^{* * *}$ & 2.711 & $0.2050^{* * *}$ & 3.256 & $0.1682^{* *}$ & 2.428 \\
\hline Accruals & 0.0594 & 1.222 & $0.1250^{* *}$ & 2.199 & 0.0152 & 0.329 \\
\hline Sales Growth & $0.1761^{* * *}$ & 3.063 & $0.1247^{* *}$ & 2.253 & $0.1601^{* * *}$ & 2.828 \\
\hline Return on Assets & $0.1800^{* * *}$ & 4.037 & $0.1468^{* * *}$ & 2.990 & $0.1723^{* * *}$ & 3.969 \\
\hline Book-to-Market & $0.2128^{* * *}$ & 3.423 & $0.1792^{* * *}$ & 3.314 & $0.2090^{* * *}$ & 3.277 \\
\hline Dividend Yield & $0.1727^{* * *}$ & 3.160 & $0.1738^{* * *}$ & 3.131 & $0.1598^{* * *}$ & 3.015 \\
\hline Investments/Assets & 0.0846 & 1.424 & 0.0929 & 1.421 & 0.0527 & 0.928 \\
\hline Net Stock Issuance & $0.1301^{* * *}$ & 2.592 & 0.0738 & 1.275 & $0.1310^{* * *}$ & 2.804 \\
\hline Price & $0.1838^{* * *}$ & 3.058 & $0.1639^{* *}$ & 2.449 & $0.1730^{* * *}$ & 2.980 \\
\hline Momentum & 0.0564 & $0.656 \mathrm{q}$ & 0.0250 & 0.309 & 0.0495 & 0.593 \\
\hline Distress & $0.1545^{* * *}$ & $2.915^{9}$ & $0.1566^{* * *}$ & 2.968 & $0.1419^{* * *}$ & 2.712 \\
\hline
\end{tabular}


Table 4: Forecasting industry-adjusted return spreads:

Alternative industry definitions (continued)

\begin{tabular}{|c|c|c|c|c|c|c|}
\hline \multirow[t]{3}{*}{ Style } & \multicolumn{6}{|c|}{ Panel C: Industry defined by 2-digit SIC code } \\
\hline & \multicolumn{2}{|c|}{ All } & \multicolumn{2}{|c|}{ Announcers } & \multicolumn{2}{|c|}{ Non-Announcers } \\
\hline & $\mathrm{b}$ & t-stat & $\mathrm{b}$ & t-stat & b & t-stat \\
\hline Firm Size & $0.1418^{* * *}$ & 3.104 & $0.1386 * * *$ & 3.036 & $0.1264^{* * *}$ & 2.785 \\
\hline Age & $0.1782^{* * *}$ & 3.850 & $0.1320^{* *}$ & 2.332 & $0.1721^{* * *}$ & 3.635 \\
\hline Beta & $0.1479^{* *}$ & 2.308 & $0.1584^{* *}$ & 2.305 & $0.1369^{* *}$ & 2.332 \\
\hline Residual Vol & $0.2722^{* * *}$ & 4.434 & $0.2112^{* * *}$ & 3.259 & $0.2697^{* * *}$ & 4.510 \\
\hline Asset Growth & $0.1754^{* *}$ & 2.569 & $0.2001^{* * *}$ & 3.251 & $0.1553^{* *}$ & 2.282 \\
\hline Accruals & 0.0314 & 0.628 & $0.0947^{*}$ & 1.660 & -0.0077 & -0.164 \\
\hline Sales Growth & $0.1679^{* * *}$ & 3.092 & $0.1206^{* *}$ & 2.399 & $0.1489^{* * *}$ & 2.751 \\
\hline Return on Assets & $0.1814^{* * *}$ & 3.981 & $0.1447 * * *$ & 2.871 & $0.1762^{* * *}$ & 3.984 \\
\hline Book-to-Market & $0.1939^{* * *}$ & 3.238 & $0.1720^{* * *}$ & 3.283 & $0.1823^{* * *}$ & 2.895 \\
\hline Dividend Yield & $0.1704^{* * *}$ & 3.230 & $0.1474^{* * *}$ & 2.830 & $0.1531^{* * *}$ & 2.976 \\
\hline Investments/Assets & 0.0753 & 1.289 & 0.0825 & 1.315 & 0.0443 & 0.812 \\
\hline Net Stock Issuance & $0.1239^{* *}$ & 2.528 & 0.0769 & 1.491 & $0.1190^{* *}$ & 2.580 \\
\hline Price & $0.1863^{* * *}$ & 3.120 & $0.1612^{* *}$ & 2.473 & $0.1733^{* * *}$ & 3.026 \\
\hline Momentum & 0.0597 & 0.682 & 0.0331 & 0.401 & 0.0509 & 0.605 \\
\hline Distress & $0.1637^{* * *}$ & 2.993 & $0.1642^{* * *}$ & 3.125 & $0.1509^{* * *}$ & 2.748 \\
\hline \multirow[t]{3}{*}{ Style } & \multicolumn{6}{|c|}{ Panel D: Industry defined by 3 -digit SIC code } \\
\hline & \multicolumn{2}{|c|}{ All } & \multicolumn{2}{|c|}{ Announcers } & \multicolumn{2}{|c|}{ Non-Announcers } \\
\hline & $\mathrm{b}$ & t-stat & $\mathrm{b}$ & t-stat & $\mathrm{b}$ & t-stat \\
\hline Firm Size & $0.1337^{* * *}$ & 2.875 & $0.1496^{* * *}$ & 3.172 & $0.1155^{* *}$ & 2.510 \\
\hline Age & $0.1579^{* * *}$ & 3.363 & $0.1039 *$ & 1.789 & $0.1421^{* * *}$ & 2.949 \\
\hline Beta & $0.1369^{* *}$ & 2.277 & $0.1400^{* *}$ & 2.181 & $0.1203^{* *}$ & 2.191 \\
\hline Residual Vol & $0.2719^{* * *}$ & 4.227 & $0.1860^{* * *}$ & 2.842 & $0.2672^{* * *}$ & 4.279 \\
\hline Asset Growth & $0.1510^{* *}$ & 2.132 & $0.1680^{* * *}$ & 2.731 & $0.1317^{*}$ & 1.850 \\
\hline Accruals & 0.0195 & 0.380 & $0.0889 *$ & 1.683 & -0.0132 & -0.275 \\
\hline Sales Growth & $0.1669^{* * *}$ & 3.000 & 0.0825 & 1.518 & $0.1495^{* * *}$ & 2.724 \\
\hline Return on Assets & $0.1730^{* * *}$ & 3.736 & $0.1339 * * *$ & 2.649 & $0.1667^{* * *}$ & 3.733 \\
\hline Book-to-Market & $0.1787^{* * *}$ & 3.006 & $0.1516^{* * *}$ & 2.850 & $0.1655^{* * *}$ & 2.637 \\
\hline Dividend Yield & $0.1560^{* * *}$ & 3.041 & 0.1481 & 1.517 & $0.1302^{* * *}$ & 2.633 \\
\hline Investments/Assets & 0.0430 & 0.685 & 0.0366 & 0.573 & 0.0194 & 0.329 \\
\hline Net Stock Issuance & $0.1320^{* * *}$ & 2.787 & $0.0924^{*}$ & 1.921 & $0.1207^{* * *}$ & 2.778 \\
\hline Price & $0.1837^{* * *}$ & 3.048 & $0.1632^{* *}$ & 2.523 & $0.1649^{* * *}$ & 2.870 \\
\hline Momentum & 0.0592 & 0.699 & 0.0227 & 0.282 & 0.0504 & 0.626 \\
\hline Distress & $0.1697^{* * *}$ & 2.917 & $0.1640 * * *$ & 3.022 & $0.1554^{* * *}$ & 2.626 \\
\hline
\end{tabular}


Table 4: Forecasting industry-adjusted return spreads:

Alternative industry definitions (continued)

\begin{tabular}{|c|c|c|c|c|c|c|}
\hline \multirow[t]{3}{*}{ Style } & \multicolumn{6}{|c|}{$\begin{array}{l}\text { Panel E: Industry defined by Hoberg and Phillips (2011) } \\
\text { fixed industry classifications (FIC) }\end{array}$} \\
\hline & \multicolumn{2}{|c|}{ All } & \multicolumn{2}{|c|}{ Announcers } & \multicolumn{2}{|c|}{ Non-Announcers } \\
\hline & $\mathrm{b}$ & t-stat & $\mathrm{b}$ & t-stat & $\mathrm{b}$ & t-stat \\
\hline Firm Size & 0.0886 & 1.383 & 0.0835 & 1.226 & 0.0646 & 1.000 \\
\hline Age & 0.1274 & 1.618 & -0.0150 & -0.171 & 0.1266 & 1.528 \\
\hline Beta & $0.2552^{* *}$ & 2.374 & $0.3302^{* * *}$ & 3.793 & $0.2191^{* *}$ & 2.164 \\
\hline Residual Vol & $0.2855^{* * *}$ & 3.654 & $0.2567^{* * *}$ & 2.766 & $0.2609^{* * *}$ & 3.469 \\
\hline Asset Growth & $0.3092^{* * *}$ & 3.369 & $0.3314^{* * *}$ & 3.365 & $0.2654^{* * *}$ & 2.926 \\
\hline Accruals & 0.1225 & 1.440 & $0.2941^{* * *}$ & 2.880 & 0.0343 & 0.471 \\
\hline Sales Growth & $0.1986^{* *}$ & 2.131 & $0.1527^{*}$ & 1.930 & 0.1430 & 1.500 \\
\hline Return on Assets & $0.2859 * * *$ & 3.169 & $0.2534^{* *}$ & 2.550 & $0.2684^{* * *}$ & 3.029 \\
\hline Book-to-Market & $0.1960^{*}$ & 1.903 & $0.2154^{* *}$ & 2.431 & 0.1584 & 1.437 \\
\hline Dividend Yield & $0.2151^{* *}$ & 2.471 & $0.1530^{*}$ & 1.916 & $0.1514^{* *}$ & 2.057 \\
\hline Investments/Assets & $0.1617^{* *}$ & 2.136 & $0.1936^{* *}$ & 2.284 & 0.1089 & 1.565 \\
\hline Net Stock Issuance & $0.1848^{* * *}$ & 2.905 & $0.1436^{* *}$ & 2.005 & $0.1779^{* * *}$ & 2.932 \\
\hline Price & $0.2310^{* *}$ & 2.495 & $0.1964^{*}$ & 1.715 & $0.2135^{* *}$ & 2.457 \\
\hline Momentum & 0.1603 & 1.247 & 0.1018 & 0.791 & 0.1447 & 1.183 \\
\hline Distress & $0.2664^{* * *}$ & 3.940 & $0.2724^{* * *}$ & 3.876 & $0.2425^{* * *}$ & 3.649 \\
\hline \multirow[t]{4}{*}{ Style } & \multirow{2}{*}{\multicolumn{6}{|c|}{$\begin{array}{l}\text { Panel F: Industry defined by Hoberg and Phillips (2011) } \\
\text { network industry classifications (TNIC) }\end{array}$}} \\
\hline & & & & & & \\
\hline & \multicolumn{2}{|c|}{ All } & \multicolumn{2}{|c|}{ Announcers } & \multicolumn{2}{|c|}{ Non-Announcers } \\
\hline & $\mathrm{b}$ & t-stat & $\mathrm{b}$ & t-stat & $\mathrm{b}$ & t-stat \\
\hline Firm Size & 0.0907 & 1.303 & 0.1092 & 1.549 & 0.0659 & 0.947 \\
\hline Age & 0.1217 & 1.432 & 0.0047 & 0.049 & 0.0910 & 1.090 \\
\hline Beta & $0.2319^{*}$ & 1.692 & $0.2782^{* *}$ & 2.212 & 0.1961 & 1.576 \\
\hline Residual Vol & $0.3256^{* * *}$ & 4.382 & $0.2521^{* * *}$ & 3.149 & $0.2840^{* * *}$ & 4.029 \\
\hline Asset Growth & $0.2995^{* * *}$ & 3.280 & $0.2856^{* * *}$ & 2.887 & $0.2640^{* * *}$ & 2.873 \\
\hline Accruals & 0.0758 & 0.955 & $0.2178^{*}$ & 1.836 & -0.0020 & -0.029 \\
\hline Sales Growth & $0.2452^{* *}$ & 2.460 & $0.1840^{*}$ & 1.856 & $0.1840^{*}$ & 1.758 \\
\hline Return on Assets & $0.2851^{* * *}$ & 3.224 & $0.2107^{* *}$ & 1.997 & $0.2703^{* * *}$ & 3.131 \\
\hline Book-to-Market & 0.0507 & 0.444 & 0.1282 & 1.179 & 0.0138 & 0.116 \\
\hline Dividend Yield & 0.1535 & 1.547 & 0.0028 & 0.044 & 0.0801 & 0.968 \\
\hline Investments/Assets & 0.1519 & 1.561 & 0.1205 & 1.521 & 0.1003 & 1.099 \\
\hline Net Stock Issuance & $0.1832^{* * *}$ & 2.723 & $0.1445^{* *}$ & 2.057 & $0.1747 * *$ & 2.489 \\
\hline Price & $0.2251^{* *}$ & 2.318 & $0.2313^{* *}$ & 2.046 & $0.2005^{* *}$ & 2.222 \\
\hline Momentum & 0.1752 & 1.392 & 0.1288 & 1.068 & 0.1549 & 1.291 \\
\hline Distress & $0.2650^{* * *}$ & 4.346 & $0.2837^{* * *}$ & 4.094 & $0.2329^{* * *}$ & 3.807 \\
\hline
\end{tabular}


Table 5: Placebo test for forecasting style return spreads

This table presents the results of regressing equal-weighted characteristic-based long-short portfolio returns on prior one-month characteristic-based long-short "placebo" earnings announcement returns (EAR). To construct the placebo EAR, I randomly select a three-day period return (in excess of the market return) from the previous month that does not fall in the earnings announcement window. The long-short style-based EAR spread is then constructed as before. Panel A (B) shows results from univariate (multivariate) regressions; in the multivariate design the market excess return, and the Fama/French factors $H M L$ and $S M B$ are added as controls. Columns with heading "All" show results when portfolio returns are computed using all stocks in the extreme quintiles. Columns with heading "Announcers" ("Non-Announcers") show results when portfolio returns are computed using only the subset of stocks with (without) an earnings announcement in the previous month. The sample period is from Q1:1972-Q4:2011. Regression coefficients are standardized. * indicates significance at the $10 \%$ level, $* *$ indicates significance at the $5 \%$ level and $* * *$ indicates significance at the $1 \%$ level. All t-statistics are based on West and Newey (1987) standard errors with a lag of four months. See appendix for details about characteristics.

\begin{tabular}{|c|c|c|c|c|c|c|}
\hline \multirow[t]{3}{*}{ Style } & \multicolumn{6}{|c|}{ Panel A: Univariate Regression Results } \\
\hline & \multicolumn{2}{|c|}{ All } & \multicolumn{2}{|c|}{ Announcers } & \multicolumn{2}{|c|}{ Non-Announcers } \\
\hline & b & t-stat & $\mathrm{b}$ & t-stat & $\mathrm{b}$ & t-stat \\
\hline Firm Size & 0.0330 & 0.464 & 0.0104 & 0.163 & 0.0272 & 0.382 \\
\hline Age & 0.0074 & 0.141 & 0.0567 & 1.062 & -0.0021 & -0.039 \\
\hline Beta & $0.1066^{* *}$ & 2.310 & $0.1160^{* *}$ & 2.344 & $0.0943^{* *}$ & 2.098 \\
\hline Residual Vol & $0.1541^{* *}$ & 2.029 & $0.1419^{*}$ & 1.904 & $0.1491^{* *}$ & 1.967 \\
\hline Asset Growth & -0.0018 & -0.033 & -0.0318 & -0.580 & 0.0045 & 0.082 \\
\hline Accruals & -0.0718 & -1.346 & -0.0226 & -0.375 & -0.0719 & -1.434 \\
\hline Sales Growth & 0.0274 & 0.475 & 0.0208 & 0.354 & 0.0144 & 0.247 \\
\hline Return on Assets & 0.0445 & 0.779 & 0.0658 & 1.200 & 0.0340 & 0.587 \\
\hline Book-to-Market & 0.0553 & 0.997 & 0.1079 & 1.638 & 0.0497 & 0.946 \\
\hline Dividend Yield & $0.1219^{*}$ & 1.698 & $0.1121^{*}$ & 1.685 & 0.1176 & 1.634 \\
\hline Investments/Assets & 0.0495 & 0.775 & 0.0169 & 0.298 & 0.0434 & 0.692 \\
\hline Net Stock Issuance & 0.0268 & 0.445 & 0.0060 & 0.101 & 0.0200 & 0.333 \\
\hline Price & 0.0713 & 1.371 & 0.0418 & 0.756 & 0.0759 & 1.473 \\
\hline Momentum & 0.0025 & 0.024 & -0.0189 & -0.191 & -0.0030 & -0.030 \\
\hline Distress & 0.0262 & 0.324 & 0.0166 & 0.216 & 0.0235 & 0.288 \\
\hline \multirow[t]{3}{*}{ Style } & \multicolumn{6}{|c|}{ Panel B: Multivariate Regression Results } \\
\hline & \multicolumn{2}{|c|}{ All } & \multicolumn{2}{|c|}{ Announcers } & \multicolumn{2}{|c|}{ Non-Announcers } \\
\hline & $\mathrm{b}$ & t-stat & $\mathrm{b}$ & t-stat & $\mathrm{b}$ & t-stat \\
\hline Firm Size & 0.0023 & 0.048 & -0.0081 & -0.202 & -0.0044 & -0.089 \\
\hline Age & 0.0512 & 1.475 & $0.0943^{* *}$ & 2.344 & 0.0400 & 1.150 \\
\hline Beta & 0.0436 & 1.633 & $0.0581^{*}$ & 1.836 & 0.0322 & 1.203 \\
\hline Residual Vol & $0.0932^{* *}$ & 2.022 & $0.0806^{*}$ & 1.739 & $0.0887^{*}$ & 1.923 \\
\hline Asset Growth & -0.0484 & -1.039 & -0.0634 & -1.289 & -0.0413 & -0.875 \\
\hline Accruals & -0.0806 & -1.595 & -0.0229 & -0.388 & $-0.0793^{*}$ & -1.671 \\
\hline Sales Growth & -0.0028 & -0.062 & 0.0054 & 0.096 & -0.0162 & -0.350 \\
\hline Return on Assets & -0.0215 & -0.462 & 0.0018 & 0.037 & -0.0298 & -0.634 \\
\hline Book-to-Market & 0.0419 & 1.333 & $0.0965^{* *}$ & 2.014 & 0.0362 & 1.203 \\
\hline Dividend Yield & $0.0870^{* *}$ & 2.100 & $0.0777^{*}$ & 1.841 & $0.0842^{* *}$ & 2.037 \\
\hline Investments/Assets & 0.0181 & 0.320 & 0.0009 & 0.017 & 0.0132 & 0.239 \\
\hline Net Stock Issuance & 0.0383 & 0.960 & 0.0146 & 0.334 & 0.0300 & 0.730 \\
\hline Price & 0.0142 & 0.389 & -0.0142 & -0.337 & 0.0196 & 0.529 \\
\hline Momentum & 0.0110 & 0.109 & -0.0086 & -0.088 & 0.0054 & 0.055 \\
\hline Distress & -0.0310 & -0.450 & -0.0311 & -0.505 & -0.0353 & -0.500 \\
\hline
\end{tabular}


Table 6: Forecasting equal-weighted return spreads for different size buckets

This table presents of regressing equal-weighted characteristic-based long-short portfolio returns on prior onemonth characteristic-based long-short earnings announcement returns (EAR). Stocks are classified as tiny stocks, small stocks or big stocks based on the 20th and 50th percentile of end-of-June market capitalization for NYSE stocks (see Fama and French (2008)). Characteristic-based return spreads (the dependent variable) are then calculated separately for each size group. Size is excluded as characteristic in this table because it is also used to sort stocks into the three different groups. Panel A (B) shows results from univariate (multivariate) regressions; in the multivariate design the market excess return, and the Fama/French factors $H M L$ and $S M B$ are added as controls. The sample period is from Q1:1972-Q4:2011. Regression coefficients are standardized. * indicates significance at the $10 \%$ level, ${ }^{* *}$ indicates significance at the $5 \%$ level and ${ }^{* * *}$ indicates significance at the $1 \%$ level. All t-statistics are based on West and Newey (1987) standard errors with a lag of four months. See appendix for details about characteristics.

\begin{tabular}{|c|c|c|c|c|c|c|}
\hline \multirow[t]{3}{*}{ Style } & \multicolumn{6}{|c|}{ Panel A: Univariate regression results } \\
\hline & \multicolumn{2}{|c|}{ Tiny } & \multicolumn{2}{|c|}{ Small } & \multicolumn{2}{|c|}{ Large } \\
\hline & $\mathrm{b}$ & t-stat & $\mathrm{b}$ & t-stat & $\mathrm{b}$ & t-stat \\
\hline Age & $0.1250^{* * *}$ & 2.903 & 0.0559 & 1.497 & $0.0716^{*}$ & 1.712 \\
\hline Beta & $0.1478^{* * *}$ & 2.612 & $0.1607^{* * *}$ & 3.251 & $0.1236^{* * *}$ & 2.590 \\
\hline Residual Vol & $0.2243^{* * *}$ & 3.323 & $0.1651^{* * *}$ & 2.956 & $0.1647^{* * *}$ & 3.253 \\
\hline Asset Growth & $0.1547^{* *}$ & 2.191 & $0.1650^{* *}$ & 2.451 & 0.0681 & 1.131 \\
\hline Accruals & 0.0434 & 0.816 & $0.0776^{*}$ & 1.781 & 0.0339 & 0.729 \\
\hline Sales Growth & $0.1161^{* *}$ & 2.326 & 0.1009 & 1.569 & 0.0643 & 0.945 \\
\hline Return on Assets & $0.1319^{* * *}$ & 2.645 & $0.1120^{* *}$ & 2.069 & $0.1022^{* *}$ & 2.181 \\
\hline Book-to-Market & $0.2162^{* * *}$ & 2.861 & $0.2437^{* * *}$ & 3.241 & $0.1990^{* * *}$ & 2.939 \\
\hline Dividend Yield & $0.1839 * * *$ & 3.196 & $0.1140 * *$ & 2.204 & $0.0817^{*}$ & 1.678 \\
\hline Investments/Assets & 0.0749 & 1.284 & $0.0978^{*}$ & 1.865 & 0.0391 & 0.734 \\
\hline Net Stock Issuance & $0.1247^{* *}$ & 2.360 & 0.0861 & 1.428 & 0.0775 & 1.415 \\
\hline Price & $0.1779 * * *$ & 3.311 & $0.1473^{* *}$ & 2.430 & 0.0838 & 1.398 \\
\hline Momentum & 0.0253 & 0.360 & 0.0533 & 0.631 & 0.0280 & 0.339 \\
\hline Distress & $0.1528^{* * *}$ & 3.504 & $0.0924^{*}$ & 1.693 & 0.0225 & 0.400 \\
\hline \multirow[t]{3}{*}{ Style } & \multicolumn{6}{|c|}{ Panel B: Multivariate regression results } \\
\hline & \multicolumn{2}{|c|}{ Tiny } & \multicolumn{2}{|c|}{ Small } & \multicolumn{2}{|c|}{ Large } \\
\hline & $\mathrm{b}$ & t-stat & $\mathrm{b}$ & t-stat & $\mathrm{b}$ & t-stat \\
\hline Age & $0.1107^{* * *}$ & 3.141 & 0.0309 & 1.129 & 0.0221 & 0.695 \\
\hline Beta & 0.0373 & 1.023 & $0.0562^{*}$ & 1.831 & 0.0214 & 0.699 \\
\hline Residual Vol & $0.1417^{* * *}$ & 2.765 & $0.0697^{* *}$ & 2.257 & $0.0657^{* *}$ & 2.094 \\
\hline Asset Growth & $0.1616^{* *}$ & 2.258 & $0.1122^{* *}$ & 2.054 & 0.0052 & 0.117 \\
\hline Accruals & 0.0424 & 0.831 & 0.0588 & 1.278 & 0.0193 & 0.411 \\
\hline Sales Growth & $0.0976^{* *}$ & 2.219 & 0.0440 & 1.028 & 0.0026 & 0.052 \\
\hline Return on Assets & $0.1479 * * *$ & 2.962 & $0.1031^{*}$ & 1.707 & 0.0295 & 0.677 \\
\hline Book-to-Market & $0.0860^{*}$ & 1.744 & $0.0807^{* *}$ & 2.075 & 0.0231 & 0.821 \\
\hline Dividend Yield & $0.1287^{* * *}$ & 3.093 & $0.0537^{*}$ & 1.918 & 0.0182 & 0.839 \\
\hline Investments/Assets & 0.0833 & 1.410 & 0.0696 & 1.352 & -0.0044 & -0.104 \\
\hline Net Stock Issuance & $0.1028^{* * *}$ & 2.589 & 0.0621 & 1.335 & 0.0615 & 1.321 \\
\hline Price & $0.1523^{* * *}$ & 3.222 & $0.1075^{* *}$ & 2.207 & 0.0374 & 0.796 \\
\hline Momentum & 0.0057 & 0.089 & 0.0284 & 0.377 & 0.0072 & 0.097 \\
\hline Distress & $0.1438^{* * *}$ & 3.190 & $0.0862^{*}$ & 1.747 & 0.0170 & 0.325 \\
\hline
\end{tabular}


Table 7: Long-short SESM-based trading strategy: Factor loadings

This table reports the loadings of the explanatory variables for the regressions shown in table 7, panel A and B of the paper. $M K T R F$ is the excess market return, $H M L, S M B, U M D$, and $S T-R E V$ are the value, size, momentum, and short-term reversal factors obtained from Kenneth French's homepage. LIQ is the Pastor and Stambaugh (2003) liquidity factor. PEAD-EAR (PEAD-SUE) is the value-weighted return of a traditional PEAD-strategy based on earnings announcement returns (standardized unexpected quarterly earnings). All remaining variables are the value-weighted returns of the characteristic-based long-short strategies outlined in table 1 of the paper. The sample period is from Q1:1972-Q4:2010 for all models that include the Pastor and Stambaugh (2003) liquidity factor and otherwise from Q1:1972-Q4:2011. * indicates significance at the 10\% level, ** indicates significance at the $5 \%$ level and *** indicates significance at the $1 \%$ level. All t-statistics are based on West and Newey (1987) standard errors with a lag of four months.

\begin{tabular}{|c|c|c|c|c|c|c|c|c|}
\hline \multicolumn{9}{|c|}{ Panel A: Equal portfolio weights } \\
\hline Model & $(1)$ & $(2)$ & $(3)$ & $(4)$ & $(5)$ & (6) & $(7)$ & $(8)$ \\
\hline Variables & & & & & & & & \\
\hline MKTRF & $-0.1544^{* *}$ & $-0.1520^{*}$ & -0.1169 & 0.0346 & 0.0224 & 0.0227 & 0.0175 & 0.0043 \\
\hline SMB & & 0.2181 & 0.2179 & $0.3208^{* * *}$ & $0.3135^{* * *}$ & $0.3180^{* * *}$ & $0.3606^{* * *}$ & $0.3635^{* * *}$ \\
\hline HML & & 0.2113 & 0.2692 & $0.3140^{* *}$ & $0.3107^{* *}$ & $0.3158^{* *}$ & $0.3418^{* *}$ & -0.0034 \\
\hline UMD & & & 0.1732 & 0.0085 & 0.0018 & -0.0159 & -0.0454 & $-0.2567^{* *}$ \\
\hline ST-REV & & & & $-0.8657^{* * *}$ & $-0.8789 * * *$ & $-0.8616^{* * *}$ & $-0.8807^{* * *}$ & $-0.7771^{* * *}$ \\
\hline LIQ & & & & & $-0.1242^{* *}$ & $-0.1284^{* *}$ & $-0.1220^{* *}$ & $-0.1163^{* *}$ \\
\hline PEAD-EAR & & & & & & 0.1669 & & -0.1237 \\
\hline PEAD-SUE & & & & & & & 0.1768 & $0.2774 *$ \\
\hline AGE & & & & & & & & $0.4197^{*}$ \\
\hline BETA & & & & & & & & $0.3248^{*}$ \\
\hline RES VOL & & & & & & & & 0.1061 \\
\hline $\mathrm{AG}$ & & & & & & & & 0.5197 \\
\hline ACCRUALS & & & & & & & & $-0.4041^{*}$ \\
\hline SG & & & & & & & & $0.3780^{*}$ \\
\hline ROA & & & & & & & & $-0.7595^{* * *}$ \\
\hline DY & & & & & & & & 0.0438 \\
\hline IA & & & & & & & & -0.3485 \\
\hline NS & & & & & & & & 0.1369 \\
\hline PRICE & & & & & & & & -0.2085 \\
\hline FAILURE & & & & & & & & $0.4877^{* *}$ \\
\hline $\mathrm{R} 2$ & & & & & & & & \\
\hline
\end{tabular}


Table 7: Long-short SESM-based trading strategy: Factor loadings (continued)

\begin{tabular}{|c|c|c|c|c|c|c|c|c|}
\hline Mod & & & & (1) & $(-)$ & & (7) & \\
\hline \multicolumn{9}{|l|}{ Variables } \\
\hline MKTRF & $-0.1083^{* *}$ & $-0.1302^{*}$ & $-0.1194^{* *}$ & 0.0199 & 0.0125 & 0.0146 & 0.0126 & -0.0904 \\
\hline SMB & & 0.2538 & 0.2537 & $0.3485^{* *}$ & $0.3445^{* *}$ & $0.3518^{* *}$ & $0.3431^{* * *}$ & 0.1548 \\
\hline HML & & 0.1264 & 0.1441 & $0.1843^{* *}$ & $0.1805^{* *}$ & $0.1880^{* *}$ & 0.1796 & 0.0757 \\
\hline UMD & & & 0.0535 & -0.0982 & -0.0998 & $-0.1328^{*}$ & -0.0984 & $-0.2321^{* *}$ \\
\hline ST-REV & & & & $-0.7976 * * *$ & $-0.8027 * * *$ & $-0.7694^{* * *}$ & $-0.8026^{* * *}$ & $-0.6952^{* * *}$ \\
\hline LIQ & & & & & -0.0468 & -0.0544 & -0.0469 & -0.0574 \\
\hline PEAD-EAR & & & & & & $0.3164^{* *}$ & & 0.1618 \\
\hline PEAD-SUE & & & & & & & -0.0052 & 0.1343 \\
\hline AGE & & & & & & & & 0.0359 \\
\hline BETA & & & & & & & & $0.2629^{*}$ \\
\hline RES VOL & & & & & & & & 0.0550 \\
\hline $\mathrm{AG}$ & & & & & & & & $0.4289^{*}$ \\
\hline ACCRUALS & & & & & & & & -0.0743 \\
\hline SG & & & & & & & & 0.2260 \\
\hline ROA & & & & & & & & $-0.4790 * *$ \\
\hline DY & & & & & & & & -0.0548 \\
\hline IA & & & & & & & & -0.2101 \\
\hline NS & & & & & & & & 0.0727 \\
\hline PRICE & & & & & & & & -0.0213 \\
\hline FAILURE & & & & & & & & 0.2771 \\
\hline R2 & & & & & & & & \\
\hline
\end{tabular}


Table 8: Forecasting style-based return spreads: Sub-sample results

This table presents the results of regressing equal-weighted characteristic-based long-short portfolio returns on prior one-month characteristic-based long-short earnings announcement returns (EAR). Characteristic-based return spreads are calculated only for the "All" firms sample. Panel A shows univariate and multivariate regression results for the period before January 1992, panel B shows results for the same regression models for the period from January 1992 onwards. In the multivariate design the market excess return, and the Fama/French factors $H M L$ and $S M B$ are added as controls. Regression coefficients are standardized. * indicates significance at the $10 \%$ level, ** indicates significance at the $5 \%$ level and *** indicates significance at the $1 \%$ level. All t-statistics are based on West and Newey (1987) standard errors with a lag of four months. See appendix for details about characteristics.

\begin{tabular}{|c|c|c|c|c|}
\hline \multirow[t]{3}{*}{ Style } & \multicolumn{4}{|c|}{ Panel A: Q1:1972 - Q4:1991 } \\
\hline & \multicolumn{2}{|c|}{ Univariate regressions } & \multicolumn{2}{|c|}{ Multivariate regressions } \\
\hline & $\mathrm{b}$ & t-stat & $\mathrm{b}$ & t-stat \\
\hline Firm Size & $0.2027^{* * *}$ & 2.707 & $0.1206^{* * *}$ & 3.354 \\
\hline Age & $0.1852^{* *}$ & 2.232 & 0.0567 & 0.886 \\
\hline Beta & 0.0929 & 0.981 & 0.0060 & 0.182 \\
\hline Residual Vol & $0.2443^{* * *}$ & 2.648 & $0.1306^{* * *}$ & 3.479 \\
\hline Asset Growth & $0.1492^{* * *}$ & 2.738 & $0.1134^{* *}$ & 2.365 \\
\hline Accruals & 0.1037 & 1.459 & 0.0563 & 0.911 \\
\hline Sales Growth & $0.2285^{* * *}$ & 3.264 & $0.1328^{* * *}$ & 2.861 \\
\hline Return on Assets & $0.2007 * * *$ & 3.655 & $0.1473^{* * *}$ & 2.962 \\
\hline Book-to-Market & 0.0988 & 1.247 & 0.0238 & 0.527 \\
\hline Dividend Yield & $0.2046^{* * *}$ & 2.717 & $0.1348^{* * *}$ & 3.031 \\
\hline Investments/Assets & 0.0595 & 1.024 & 0.0624 & 0.846 \\
\hline Net Stock Issuance & 0.0403 & 0.439 & 0.0317 & 0.389 \\
\hline Price & 0.1136 & 1.120 & $0.1336^{* * *}$ & 3.063 \\
\hline Momentum & -0.0804 & -0.928 & -0.0644 & -0.828 \\
\hline Distress & 0.0112 & 0.154 & 0.0415 & 0.961 \\
\hline \multirow[t]{3}{*}{ Style } & \multicolumn{4}{|c|}{ Panel B: Q1:1992 - Q4:2011 } \\
\hline & \multicolumn{2}{|c|}{ Univariate regressions } & \multicolumn{2}{|c|}{ Multivariate regressions } \\
\hline & $\mathrm{b}$ & t-stat & $\mathrm{b}$ & t-stat \\
\hline Firm Size & $0.1644^{* * *}$ & 2.914 & $0.1369^{* * *}$ & 3.306 \\
\hline Age & $0.2017^{* * *}$ & 3.476 & $0.1583^{* * *}$ & 3.778 \\
\hline Beta & $0.1992^{* * *}$ & 2.801 & 0.0560 & 1.226 \\
\hline Residual Vol & $0.2990^{* * *}$ & 3.985 & $0.1696^{* * *}$ & 3.443 \\
\hline Asset Growth & $0.2061^{* *}$ & 2.039 & $0.1697^{*}$ & 1.794 \\
\hline Accruals & 0.0680 & 0.952 & 0.0199 & 0.311 \\
\hline Sales Growth & 0.0976 & 1.293 & 0.0859 & 1.353 \\
\hline Return on Assets & $0.2006^{* * *}$ & 3.232 & $0.1620^{* *}$ & 2.336 \\
\hline Book-to-Market & $0.3198^{* * *}$ & 3.320 & $0.1117^{* *}$ & 2.053 \\
\hline Dividend Yield & $0.1432^{*}$ & 1.897 & $0.0833^{* *}$ & 1.999 \\
\hline Investments/Assets & 0.0814 & 0.991 & 0.0697 & 0.846 \\
\hline Net Stock Issuance & $0.1717^{* * *}$ & 2.738 & $0.1156^{* * *}$ & 2.923 \\
\hline Price & $0.2607^{* * *}$ & 3.571 & $0.1919 * * *$ & 2.956 \\
\hline Momentum & 0.1116 & 1.097 & 0.0838 & 1.024 \\
\hline Distress & $0.2136^{* * *}$ & 3.771 & $0.1956^{* * *}$ & 3.607 \\
\hline
\end{tabular}


Table 9: EAR-SUE-SESM-strategy: Three-factor alphas of triple sorted portfolios

This table presents three-factor alphas (expressed in \% per month) of various stock portfolios which result from a sequential triple sorting. Stocks are first sorted into quintiles based on their most recent earnings announcement return (EAR), then into quintiles based on their most recent standardized unexpected quarterly earnings (SUE), and finally into quintiles according to their style-based earnings surprises measure (SESM). The portfolio rebalancing frequency is monthly. The "high-low" rows and columns show the abnormal returns of long-short portfolios, and the abnormal return of the ("high/high/high"- "low/low/low")-portfolio is highlighted in bolt. Three-factor alphas come from a time-series regression of portfolio returns (in excess of the risk-free rate if the portfolio is long-only) on the market excess return, and the Fama/French factors $H M L$ and $S M B$. The sample period is from Q1:1972-Q4:2011. * indicates significance at the $10 \%$ level, ** indicates significance at the $5 \%$ level and ${ }^{* * *}$ indicates significance at the $1 \%$ level. All t-statistics are based on West and Newey (1987) standard errors with a lag of five months. For brevity, asterisks and t-statistics are reported for the "high-low" rows and columns only.

\begin{tabular}{|c|c|c|c|c|c|c|c|c|}
\hline \multirow{2}{*}{$\begin{array}{l}\text { EAR } \\
\text { Quintile }\end{array}$} & \multirow{2}{*}{$\begin{array}{l}\text { SUE } \\
\text { Quintile }\end{array}$} & \multicolumn{5}{|c|}{ SESM Quintile } & \multirow[b]{2}{*}{ high-low } & \multirow[b]{2}{*}{ t-stat high-low } \\
\hline & & low & 2 & 3 & 4 & high & & \\
\hline 1 & 1 & -2.04 & -1.72 & -1.19 & -0.93 & -0.54 & $1.49 * * *$ & $(4.14)$ \\
\hline 2 & 1 & -1.67 & -1.26 & -0.71 & -0.62 & -0.36 & $1.31^{* * *}$ & $(4.41$ \\
\hline 3 & 1 & -1.10 & -1.08 & -0.57 & -0.01 & 0.28 & $1.37^{* * *}$ & $(3.77)$ \\
\hline 4 & 1 & -0.90 & -0.71 & -0.25 & 0.47 & 0.91 & $1.80^{* * *}$ & $(5.42)$ \\
\hline 5 & 1 & -0.62 & -0.30 & 0.43 & 0.55 & 1.04 & $1.65^{* * *}$ & $(4.57)$ \\
\hline 1 & 2 & -1.48 & -1.13 & -0.60 & -0.51 & 0.06 & $1.54 * * *$ & $(5.84)$ \\
\hline 2 & 2 & -1.21 & -0.58 & -0.36 & 0.13 & 0.25 & $1.46^{* * *}$ & $(5.11)$ \\
\hline 3 & 2 & -0.79 & -0.12 & 0.08 & 0.46 & 0.78 & $1.57^{* * *}$ & $(4.68)$ \\
\hline 4 & 2 & -0.47 & -0.07 & 0.14 & 0.48 & 0.93 & $1.40 * * *$ & $(5.07)$ \\
\hline 5 & 2 & -0.37 & 0.10 & 0.51 & 0.71 & 1.21 & $1.58^{* * *}$ & $(6.26)$ \\
\hline 1 & 3 & -1.38 & -1.01 & -0.45 & -0.31 & 0.13 & $1.50 * * *$ & $(4.96)$ \\
\hline 2 & 3 & -0.78 & -0.40 & -0.01 & 0.13 & 0.58 & $1.36^{* * *}$ & $(4.74)$ \\
\hline 3 & 3 & -0.65 & -0.29 & 0.35 & 0.37 & 0.92 & $1.57^{* * *}$ & $(6.59)$ \\
\hline 4 & 3 & -0.51 & 0.03 & 0.50 & 0.65 & 1.25 & $1.76^{* * *}$ & $(5.71)$ \\
\hline 5 & 3 & -0.06 & 0.21 & 0.76 & 0.92 & 1.38 & $1.44^{* * *}$ & $(5.59)$ \\
\hline 1 & 4 & -1.17 & -0.98 & -0.58 & -0.33 & 0.46 & $1.63^{* * *}$ & $(5.31)$ \\
\hline 2 & 4 & -0.69 & -0.05 & 0.14 & 0.30 & 0.48 & $1.18^{* * *}$ & $(4.34)$ \\
\hline 3 & 4 & -0.35 & 0.08 & 0.43 & 0.66 & 0.89 & $1.25^{* * *}$ & $(5.25)$ \\
\hline 4 & 4 & -0.15 & 0.18 & 0.44 & 0.86 & 1.45 & $1.60 * * *$ & $(5.49)$ \\
\hline 5 & 4 & 0.10 & 0.42 & 0.75 & 0.99 & 1.45 & $1.35^{* * *}$ & $(4.94)$ \\
\hline 1 & 5 & -1.36 & -0.91 & -0.44 & -0.39 & 0.42 & $1.78^{* * *}$ & $(4.84)$ \\
\hline 2 & 5 & -0.51 & 0.24 & 0.65 & 0.62 & 1.05 & $1.56^{* * *}$ & $(4.60)$ \\
\hline 3 & 5 & 0.06 & 0.52 & 0.94 & 1.19 & 1.60 & $1.54^{* * *}$ & $(4.94)$ \\
\hline 4 & 5 & 0.39 & 0.67 & 0.97 & 1.51 & 1.75 & $1.36^{* * *}$ & $(4.24)$ \\
\hline 5 & 5 & 0.41 & 0.96 & 1.47 & 1.81 & 1.97 & $1.57^{* * *}$ & $(4.53)$ \\
\hline \multicolumn{2}{|c|}{ high-low } & $2.45^{* * *}$ & $2.68^{* * *}$ & $2.67^{* * *}$ & $2.74 * * *$ & $2.52^{* * *}$ & $4.01 * * *$ & \\
\hline \multicolumn{2}{|c|}{ t-stat high-low } & $(9.81)$ & $(9.73)$ & $(9.23)$ & $(9.10)$ & $(9.37)$ & $(11.21)$ & \\
\hline
\end{tabular}




\section{References}

Bergstresser, D., and T. Philippon, 2006, "CEO incentives and earnings management," Journal of Financial Economics, 80, 511-529.

Campbell, J. Y., J. Hilscher, and J. Szilagyi, 2008, "In search of distress risk," Journal of Finance, 63, 2899-2939.

Chen, L., R. Novy-Marx, and L. Zhang, 2010, "An alternative three-factor model," Working Paper.

Fama, E. F., and K. R. French, 1992, "The cross-section of expected stock returns," Journal of Finance, $47,427-465$.

_ 2008, "Dissecting anomalies," Journal of Finance, 63, 1653-1678.

Pastor, L., and R. F. Stambaugh, 2003, "Liquidity risk and expected stock returns," Journal of Political Economy, 111, 642-685.

West, K. D., and W. K. Newey, 1987, "A simple, positive semi-definite, heteroskedasticity and autocorrelation consistent covariance matrix," Econometrica, 55, 703-708. 